\title{
Hong Kong High DensCity: merging urban scale with human scale
}

by

Marion Caroline Romane Roux

A thesis submitted to the Faculty of Graduate and Postdoctoral Affairs in partial fulfillment of the requirements for the degree of

Master of Architecture

in

M.Architecture - 8.0 credits

Carleton University

Ottawa, Ontario

(C) 2016, Marion Caroline Romane Roux 


\section{Abstract}

Urbanization and civilization go hand in hand. Human beings have, over time, largely transitioned from a nomadic to more sedentary, urban way of life. Cities however tend to generate and incite their own forms of movement, both horizontal and vertical.

Cities are living organisms. In order to function and grow they require air, light, water: they must breathe, accommodate continuous flow, sustain incessant renewal. While cities throughout time have struggled with high densities and overpopulation, these challenges are also proof of their attractiveness. Liveliness, diversity and spontaneous encounters ensure the city's appeal.

The high-densities of mega cities make it both necessary and possible to pursue extraordinary infrastructures (sometimes "over the top"?) to address congestion; there will always be people to occupy the space. The crowd/mass dictates both the evolution of the built environment and the nature and extent of urban circulation systems.

On the onehand, cities must adapt to the modes and routes along which its residents wish to travel; on the other hand, they must manage them. In extreme cases cities must also deal with challenging topography as, for example, those that occupy narrow bands of land trapped between 
mountains and the sea. Space constraints not only push buildings together but upward, further increasing the density. The more people occupy a city, the more challenging it is to manage the movement of people. The combination of high densities and robust topography is what produced the network of elevated walkways in the central business district of Hong Kong Island. This thesis researches an as-yet-unrealized but inevitable fourth generation $(4 \mathrm{G})$ circulation system for Hong Kong's downtown core. While primarily for pedestrians, this new circulation layer will be physically and functionally distinguishable from the city's current network of elevated walkways. While the latter only brushes past towers' façades, this proposal has the audacity of merging with the architecture, refurbishing in consequence its interior layout. 


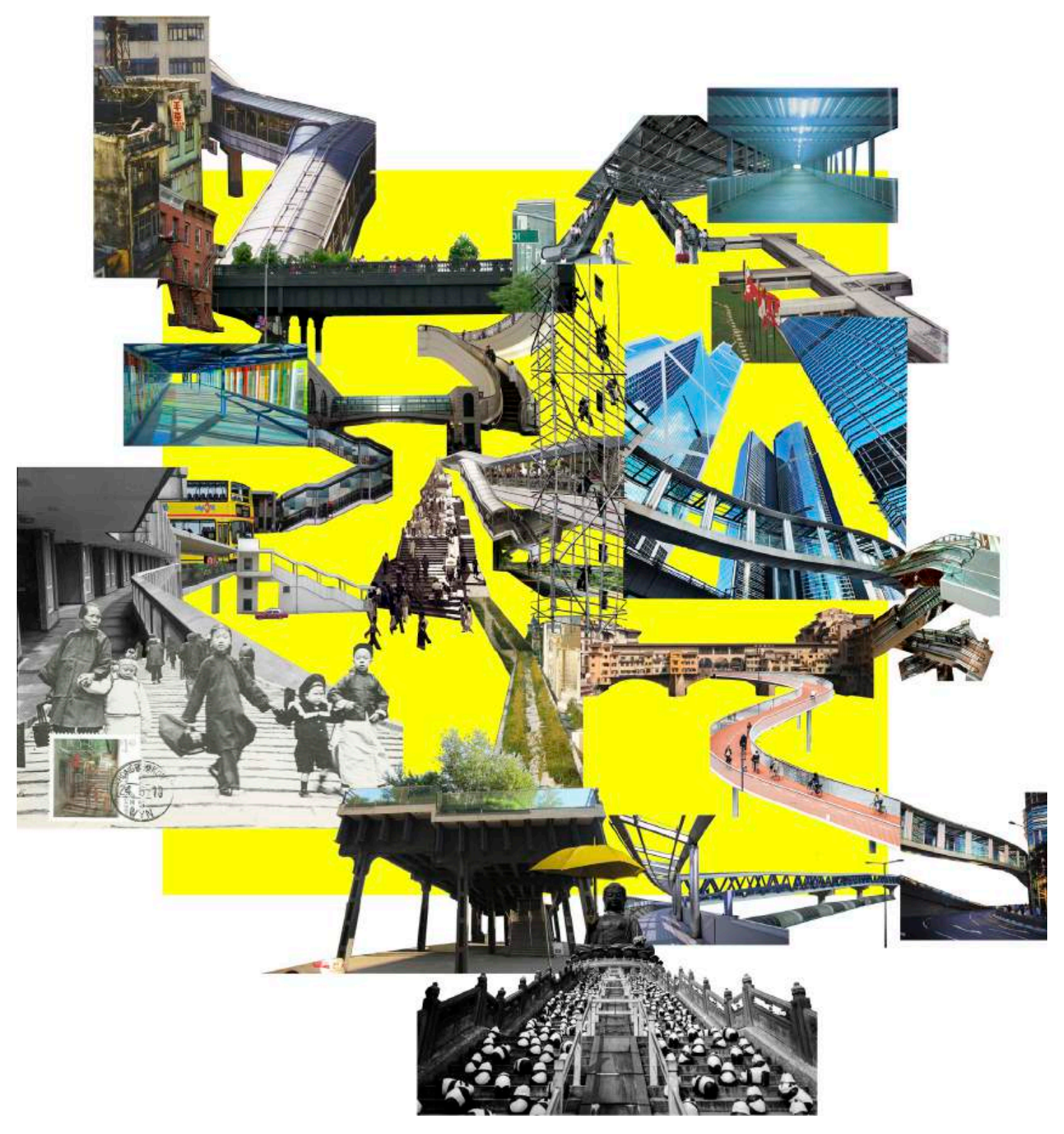




\section{Acknowledgements}

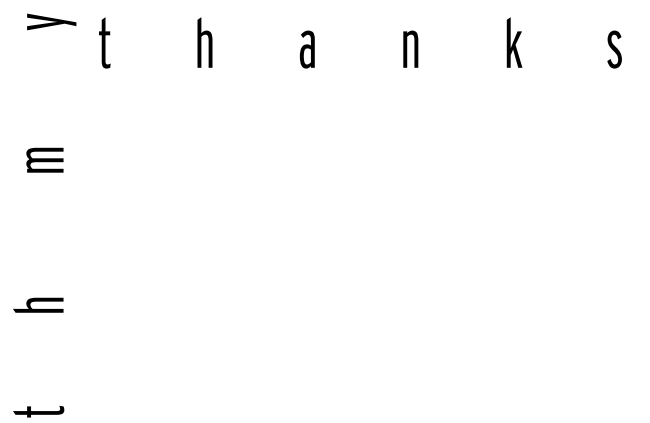

to

Professor Benjamin Gianni, my advisor

Professor Pascal Quintard-Hofstein, who triggered my architecture intuition

Xavier Roux, my father, without whom I would never have experienced Hong Kong

Caroline Lacheray, my mother, for reviewing the written composition of this thesis

Friends, you know who you are, for their support and encouragement throughout my architecture studies. 


\section{Table of Contents}
Abstract
ii-iv
Acknowledgements
V
Table of Contents
$\mathrm{xi}$
List of Figures
xii-Xviii
1 Introduction
pp1-3
2 Elevating the Street since the 1900s
pp4-9
3 Modernist Visions of Segregating Modes of Transportation
pp10-20
4 Elevated Walkways in Hong Kong: from defying topography to defying authority pp21-37

5 Reviving the City's Façade with the Authentic Hong Kong

pp38-48

6 One Bridge, Two Identities: a dual experience through the urban jungle

pp49-51

7 Hong Kong Population: a proposal for all

pp52-85

8 Experiencing Hong Kong's Topography

pp86-97

9 Merging Urban Scale with Human Scale: tower and man

pp98-102

11 Conclusion

p103

12 Set of Drawings

pp104-120

13 Bibliography

p121

14 Exhibitions

p122

15 Films

p122 


\section{List of Figures}

\section{figure 1: collage of main references and existing elevated walkways in Hong}

Kong (piv)

<http://greatmuseums.org/images/proj_gallery_full/HLN_APT_01_Large_Gallery.jpg >

<https://www.behance.net/gallery/6078179/The-Escalator-A-Liquid-Journey>

$<$ http://julianneyang.com/page/9>

$<$ https://municipaldreams.files.wordpress.com/2013/12/p14305-robin-hood-gardens-

1972-300dpi.jpg>

$<$ https://bravecolin.files.wordpress.com/2011/07/wyn.jpg>

<http://farm3.staticflickr.com/2541/4172217394_f1ded8a9af_b.jpg>

$<$ http://www.domusweb.it/content/dam/domusweb/en/news/2010/08/04/urban-green-eu-

ropean-landscape-architecture-for-the-21st-century/1192.jpg>

<https://georgefattell.files.wordpress.com/2011/08/high-line-start-point.jpg>

$<$ http://www.thehindu.com/multimedia/dynamic/01943/11_ISBS_HONG_

KO_11_1943401f.jpg>

$<$ http://www.firenzelodging.it/wp-content/uploads/2013/10/Ponte-Vecchio-a-Firenze.

jpg>

$<$ http://hongkongthrumyeyes.com/wp-content/uploads/2013/06/steel-pedestrian-walkway-bridge-over-a-road-between-to-buildings-of-glass-and-steel-in-central-hongk.jpg> $<$ http://images.worldarchitecture.org/bv.jpg >

$<$ http://www.threesixfivecity.com/wp-content/uploads/elevated-walkway-hong-kong-central.jpg>

$<$ http://www.fosterandpartners.com/media/1706211/img5.jpg>

$<$ http://www.boredpanda.com/hong-kong-street-photography-memoir-fan-ho/> 
figure 2: on site sketching from Kowloon looking towards Victoria Harbour,

Hong Kong Island (pxviii) image by the author

red dragon stencil: «Chinese Dragon Paper Cut.» DeviantArt. Accessed January 8, 2016. [Online] Available from: http://gamerchick56.deviantart.com/art/Chinese-DragonPaper-Cut-18513799.

figure 3: People cross a street in the Mong Kok district of Hong Kong. Photo: REUTERS (p3)

«World Population to Reach 9.7 Billion by 2050 New Study Predicts.» The Telegraph. October 2, 2013. Accessed January 8, 2016. [Online] Available from: http://www.telegraph. co.uk/news/earth/10348822/World-population-to-reach-9.7-billion-by-2050-new-studypredicts.html.

figure 4: Waker Drive, Chicago (p5)

«WATER STREET MARKET.» WTTW. Accessed January 8, 2016. [Online] Available from: http://interactive.wttw.com/timemachine/water-street-market.

figure 5: Unité d'H Labitation sketch by Le Corbusier (p5)

«Comparaison Entre 5 Villes Méditerranéennes.» MED ECO-QUARTIERS. Accessed January 8, 2016. [Online] Available from: http://www.dicat.unige.it/la_citta_sostenibile/ med-ECO-QUARTIER/WEB/INDEX4FC6.HTM.

\section{figure 6: Robin Hood Gardens (p5)}

«Robin Hood Gardens, Poplar: 'presence, Dignity and a Bit Grim'» Municipal Dreams. February 11, 2014. Accessed January 8, 2016. [Online] Available from: https://municipaldreams.wordpress.com/2014/02/11/robin-hood-gardens-poplar-presence-dignity-anda-bit-grim/. 
figure 7: +15 Calgary (p7)

«15.» Wikipedia. Accessed January 8, 2016. [Online] Available from: https://en.wikipedia. org/wiki/+15.

\section{figure 8: Promenade Plantée, Paris, France (p7)}

«Paris: It's More than Just the Eiffel Tower | The Times.» The Times. October 24, 2013. Accessed January 8, 2016. [Online] Available from: http://www.thetimes.co.uk/tto/public/ finest/article3903455.ece.

\section{figure 9: HafenCity, Hamburg, Germany (p7)}

Pingallery. «On Sandtorkai - Hamburg.» DeviantArt. Accessed January 8, 2016. [Online] Available from: http://pingallery.deviantart.com/art/On-Sandtorkai-Hamburg-205254231.

\section{figure 10: High Line, New York City, USA (p7)}

«The High Line.» NYC Parks. Accessed January 8, 2016. [Online] Available from: http:// www.nycgovparks.org/parks/the-high-line/photos.

\section{figure 11: LuJiaZui bridge, Shanghai, China (p7)}

«Lujiazui Circular Pedestrian Bridge in Shanghai, China.» When On Earth For People Who Love Travel Lujiazui Circular Pedestrian Bridge in Shanghai China Comments. January 17, 2014. Accessed January 8, 2016. [Online] Available from: http://whenonearth. net/lujiazui-circular-pedestrian-bridge-shanghai-china/.

\section{figure 12: Hovenring, the Netherlands (p7)}

Acott, Ken. «Dutch Lead the Way in Bike Infrastructure.» The West Australian. March 19, 2015. Accessed January 8, 2016. [Online] Available from: https://au.news.yahoo.com/ thewest/wa/a/26724268/dutch-lead-the-way-in-bike-infrastructure/. 


\section{figure 13: Bicycle Snake Bridge, Copenhagen, Danemark (p7)}

«The Bicycle Snake - Danish Architecture Centre.» DAC\&Life. Accessed January 8, 2016. [Online] Available from: http://www.dac.dk/en/dac-life/copenhagen-X-gallery/cases/ the-bicycle-snake/.

\section{figure 14: SkyCycle, London, United Kingdom (p9)}

«Foster Promotes «cycling Utopia» Named SkyCycle above London Railways.» Dezeen. January 2, 2014. Accessed January 8, 2016. [Online] Available from: http://www.dezeen. com/2014/01/02/foster-promotes-cycling-utopia-above-londons-railways/.

\section{figure 15: Hudson Yards, New York City, USA (p9)}

«Hudson Yards Masterplan by Steven Holl.» Dezeen. November 26, 2007. Accessed January 8, 2016. [Online] Available from: http://www.dezeen.com/2007/11/26/hudson-yardsmasterplan-by-steven-holl/.

\section{figure 16: SkyWay-scraper (p9)}

FREELAND, Ryan. «SkyWAY-scraper.» Ryan FREELAND. 2012. Accessed January 8, 2016. [Online] Available from: http://ryanfreeland.weebly.com/skyway-scraper.html.

figure 17: EugèneHénard"s proposal for the streets of Paris, early 20th Century (p11)

Reps, John W. «Cities of the Future.» Urban Planning, 1794-1918: An International Anthology of Articles, Conference Papers, and Reports. Accessed January 8, 2016. [Online] Available from: http://urbanplanning.library.cornell.edu/DOCS/henard.htm.

\section{figure 18: New York proposals for street expansions (p15)}

Hilberseimer, Ludwig, and Richard Anderson. Metropolisarchitecture and Selected Essays. 
figure 19: "Distant Natures", Manuel Alvarez Diestro (p20)

«Anything Photography.» Anything Photography. Accessed January 8, 2016. [Online] Available from: http://anythingphotography.tumblr.com/.

\section{figure 20: merging hilly landscape + urban planning (p22)}

Lee, Nicolas M.J. «Naturally Artificial: When Grid Meets Topography in Hong Kong.» NICLEEDESIGN. Accessed January 8, 2016. [Online] Available from: http://www.nicleedesign.com/Naturally-Artificial-Hong-Kong-HKSAR.

figure 21: Hong Kong's topography, mountain vs. sea, collage (physical model+photography) (p23)

image by the author, 2016.

\section{figure 22: site situation (p24)}

image by the author, 2016 .

\section{figure 23: evolution of Hong Kong Ilsands' shores (land fills from 1841 to pre-} sent) (p25)

land fills outlines: «Hong Kong Costaline Map. Accessed January 8, 2016. [Online] Available from: http://www.oldhkphoto.com/coast/Map.html.

old Hong Kong map: «Edward Belcher.» Wikipedia. Accessed January 8, 2016. [Online] Available from: https://en.wikipedia.org/wiki/Edward_Belcher.

\section{figure 24: Proba image of Victoria Harbor in Hong Kong, ESA, 2006 (p27)}

«Proba Image of Victoria Harbour in Hong Kong.» European Space Agency. January 10, 2006. Accessed January 8, 2016. [Online] Available from: http://www.esa.int/spaceinimages/Images/2005/12/Proba_image_of_Victoria_Harbour_in_Hong_Kong. 
figure 25: site massing (p29) image by the author, 2016.

figure 26: street network in Central, Hong Kong Island (p30)

image by the author, 2016 .

figure 27: network of existing elevated walkways in Central, Hong Kong Island (p31)

Frampton, Adam, Wong, Clara, and Solomon, Jonathan D. Cities without Ground: A Hong Kong Guidebook. 2012

\section{figure 28: the Umbrella Revolution, logo (p33)}

Bosin, Jodi. «The Design of the Umbrella Revolution.» Alfalfastudio. October 9, 2014. Accessed January 8, 2016. [Online] Available from: http://alfalfastudio.com/the-design-of-the-umbrella-revolution/.

figure 29: "We will be back", occupy Central, photo by Pedro Ugarte, 2014 (p35)

Sim, David. «Hong Kong: Defiant Protesters Give Hunger Games’ Three-fingered Salute as Police Clear Camp.» International Business Times RSS. December 11, 2014. Accessed January 8, 2016. [Online] Available from: http://www.ibtimes.co.uk/hong-kong-defiantprotesters-give-hunger-games-three-fingered-salute-police-clear-camp-1479120.

figure 30: Office workers walk through streets closed by protesters in the business district of Central in Hong Kong, China, on Monday, Sept. 29, 2014 (p36)

Barber, Elizabeth. «Hong Kong Businesses Bearing Up.» Time. October 4, 2014. Accessed January 8, 2016. [Online] Available from: http://time.com/3465269/occupy-hong-kong-central-business-community/. 
figure 31: mapping the Umbrella Revolution sites in the district of Central in Hong Kong, SAR China, 2014 (p37)

image by Parallel Lab, «Why Mapping Our Cities Can Help Us Plan the Future : Introducing the Atlas of Social Maps.» FUTURE CAPE TOWN. November 25, 2015. Accessed January 8, 2016. [Online] Available from: http://futurecapetown.com/2015/11/futurecape-town-why-mapping-our-cities-can-help-us-plan-the-future-introducing-the-atlasof-social-maps/\#.VndgOPnhCHs.

figure 32: side alley in Happy Valley, Hong Kong Island, photograph by Zielecki, Chris, 2016 (p41)

Zielecki, Chris. «Side Alley.» Flickr. April 28, 2013. Accessed March 13, 2016. [Online] Available from: https://www.flickr.com/photos/11821713@N00/10389626085.

figures 33 (p43), 34 (p44), 35 (p45) and 36 (p46): diagrams by the author, 2016. vintage Hong Kong image: «Pedestrians \& Vendors On Pottinger Street, A Stepped Street, Central District, Hong Kong Island [c1946] Hedda Morrison [RESTORED].» Flickr. Accessed March 13, 2016. [Online] Available from: https://www.flickr.com/photos/ ralphrepo_photolog/4172217394.

buildings façades image: «Hong Kong Business District.» Dreamstime. Accessed March 13, 2016. [Online] Available from: http://www.dreamstime.com/stock-photo-hongkong-business-district-various-office-buildings-central-image57850476.

figure 37: mapping of ladder streets in Sheung Wan and Central, Hong Kong Island (p48)

modified image from DeWolf, Christopher. «Mapped: Hong Kong.» URBANPHOTO: Cities / People / Place. October 6, 2013. Accessed March 2, 2016. [Online] Available from: http://www.urbanphoto.net/blog/2013/10/06/mapped-hong-kongs-public-steps/. 
figure 38: "searching for void in Central, Hong Kong» (p50)

«Chinese Architecture, Old and New.» Accessed January 8, 2016. [Online] Available from: http://photo.sf.co.ua/id75?lang=ru.

figure 39: exploded axonometric of the Long Line (structure) (p51)

image by the author, 2016 .

figure 40: «à vous de juger», a fourth tier for Central, Hong Kong («uncles» playing mah-jong photography) (p53)

Stokes, Gary. «Old Hong Kong.» Gary Stokes Photography. April 9, 2011. Accessed January 8, 2016. [Online] Available from: http://www.garystokesphotography.com/blog/?p=774.

figure 41: 1600 Pandas World Tour in Hong Kong, Paulo Grangeon (WWF, PMW, ARR) (p56)

«1600 Pandas World Tour Coming to Hong Kong.» Urdesign Magazine. May 6, 2014. Accessed January 8, 2016. [Online] Available from: http://www.urdesign.it/index. php/2014/05/06/1600-pandas-world-tour-coming-to-hong-kong/.

figure 42: main functions at ground level in Central, Hong Kong, 2015 (p57) image by the author, 2016 .

figure 43: Elevated walkway in Central, Hong Kong, 2015 (p58) photography by the author, August, 2015.

figure 44: Elevated walkway in Central, Hong Kong, 2015 + Ponte Vecchio, Florence, Italy, 14th century (p59) ponte Vecchio image: «Ponte Vecchio.» Wikipedia. Accessed January 8, 2016. 
[Online] Available from: https://en.wikipedia.org/wiki/Ponte_Vecchio.

figure 45: sketching a proposal for the back lanes of Central district, Hong Kong Island (p60)

image by the author, 2016 .

figure 46: sketching a proposal for the streets of Central district, Hong Kong Island (p61)

image by the author, 2016 .

figure 47: on site sketching, Pottinger street (ladder street) in Central, Hong Kong (p62)

image by the author, 2015 .

figure 48: sketch for proposal (red) through the urban jungle (existing context) in Central, Hong Kong (p63)

background image: «Chinese Architecture, Old and New.» Accessed January 8, 2016. [Online] Available from: http://photo.sf.co.ua/id75?lang=ru.

figure 49: «up the ladder», sketch for proposal (red) over Pottinger street (ladder street) in Central, Hong Kong (p65)

image by the author, 2015 .

figure 50: long section (p67)

image by the author, 2016.

figure 51: master plan (p69)

image by the author, 2016 . 
figures 52 (p71), 53 (p72), 54 (p73) and 55 (p74): Nodes LL+XX plans (above $50 \mathrm{~m}$ cut)

images by the author, 2016 .

figures 56 (p75), 57 (p76), 58 (p77), 59 (p78) and 60 (p79) Nodes LL+XX sections images by the author, 2016 .

figures 61 (p80), 62 (p81), 63 (p82) and 64 (p83): functional sections images by the author, 2016 .

figure 65: «a different point of view», Queensway Road from an elevated walkway in Admiralty, Hong Kong Island, 2015 (p85)

photography by the author, August, 2015.

figures 66 (p87) and 67 (p88): Central district topography and massing images by the author, 2015 .

figure 68 (p89): personal sketch over image from:

Gutierrez, Laurent, and Portefaix, Valérie. Mapping Hong Kong. Hong Kong: Map Book, 2000.

figure 69 (p90): simplified site mapping

image by the author, 2015.

figures 70 (p91), 71 (p92), 72 (p93) and 73 (p94): axonometric view of Central district, Hong Kong Island

diagrams by the author, 2016 . 
figures 74 (p95)and 75 (p96): simplified mapping of site and proposed Long Line

images by the author, 2016 .

figure 76: long sections and cross section through Central, Hong Kong and +50m above sea marker (p97)

image by the author, 2015 .

figures 77 (p101) and 78 (p102): axonometric and axonometric section drawing of type Node5: LL+RES

images by the author, 2016 .

figures 79 (p104), 80 (p105), 81 (p106), 82 (p107), 83 (p108), 84 (p109), 85 (p110), 86 (p111) and 87 (p112): perspectives

images by the author, 2016 .

figures 88 (p113), 89 (p114), 90 (p115), 91 (p116), 92 (p117), 93 (p118), 94 (p119) and 95 (p120): physical model (1/2000)

model and images by the author, 2016 . 


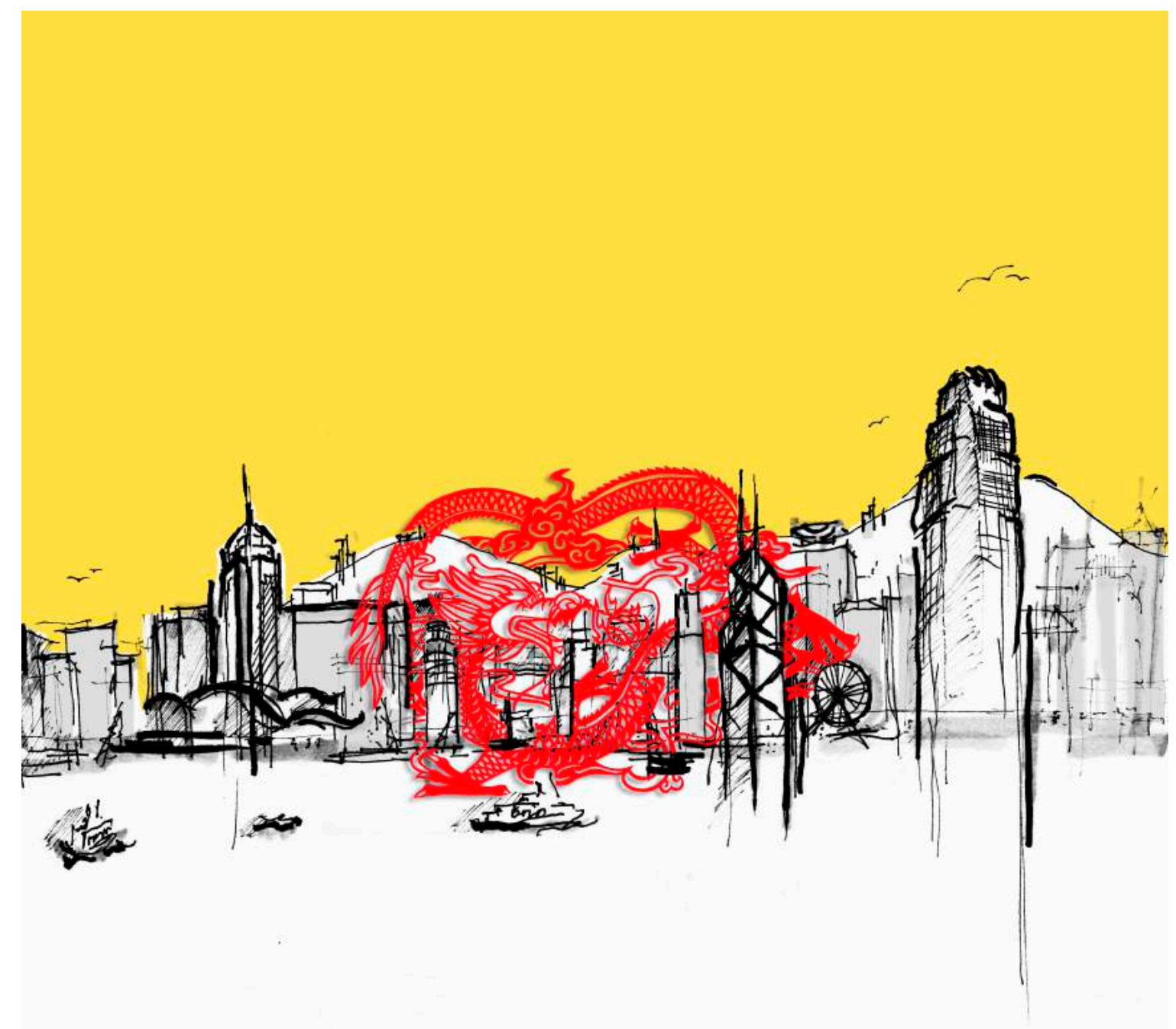

HWNG KONG ISANA. 10. Of. 2015 


\section{Introduction}

Hong Kong is a Special Administrative Region -special in the sense that the city has a peculiar governance system: autonomous but under the sovereignty of the People's Republic of China. Hong Kong's status as a SAR, however, is not the only characteristic that makes it unique. A combination of factors makes this "almost city-state" memorable, including its intricate and detailed urban layout comprised of overlapping grids that connect in various ways and at numerous points to create something that transcends confusion.

Hong Kong Island, and more specifically its Central District, is the core of an archipelago projecting into the South China Sea. Because it is the business center of the metropolis, «Central» acts as the heart(h) of the city. Everything initiates from, ends at, or goes through this area. Movement is constant. For this city to function, circulation must be rapid and fluid.

In a way, the speed and quality of movement in the megacity reflects on both the economic health of the city and the vitality of international business generally -since Hong Kong is a gateway to Asia.

Particularly for Hong Kong, movement is multi-directional -horizontal, through the city's many paths, streets and transportation arteries, and vertical, through its stairs, escalators, elevators and funiculars.

Despite our having «evolved» from a nomadic to a sedentary way of life, megacities such as Hong Kong awaken an urge to travel. They "promote" movement, continuous flow, circulation. Hong Kong proves this by its surfeit of transportation networks, -one atop the other. They begin underground with the Mass Transit Railway (MTR) over which is laid a web of streets for cars, buses and trams, above which run both highways and the city's extensive system of elevated pedestrian walkways, used to «hop» from one tower to another. 
Hong Kong's two main vertical forces are its vigorous topography and its landscape of human-built towers. Horizontal flow, along streets, sidewalks and passageways, is complemented by the city's elevated walkways. The latter perform two roles in this global city: facilitating the flow of people and resources and, conversely, hampering it by assisting protest.

Together the topography and population density of Hong Kong enable it to support an extensive transportation infrastructure, which is sometimes used for other functions. Redundant circulation systems work because there is more than enough demand to support them.

In large part this seemingly insatiable demand for space in which to move inspired the idea of adding a new circulation system -a fourth tier- to complement the existing systems. This innovative path will function both at the scale of the city and at the more human scale of individual buildings, which it passes by or through.

The proposed circulation system is not about finding an alternative to existing systems or better strategies for dealing with density. Rather, the proposal aims to complement and build on existing systems, forging a next generation of public space and a new genre of connections, between circulation networks and the private realm of buildings. If continuity is what the city needs to function then the transition between public and private must be a smooth one. The border where both urban and human scales merge must be non-identifiable; it must pertain to the public realm as much as it does to the private area.

This fourth tier route through the city, what we will refer to as the «Long Line», will be suspended in the air. As envisioned, it has two complementary functions: 1 . to forge more fluid connections between key nodes within Central and, 2. to recapture some of the «original» Hong Kong by providing elbow room for a demographic that has lost ground to the «shiny façades» of Hong Kong's office towers. The Long Line will offer a new experience of Hong Kong's topography, a new way to experience and interact with the city. 


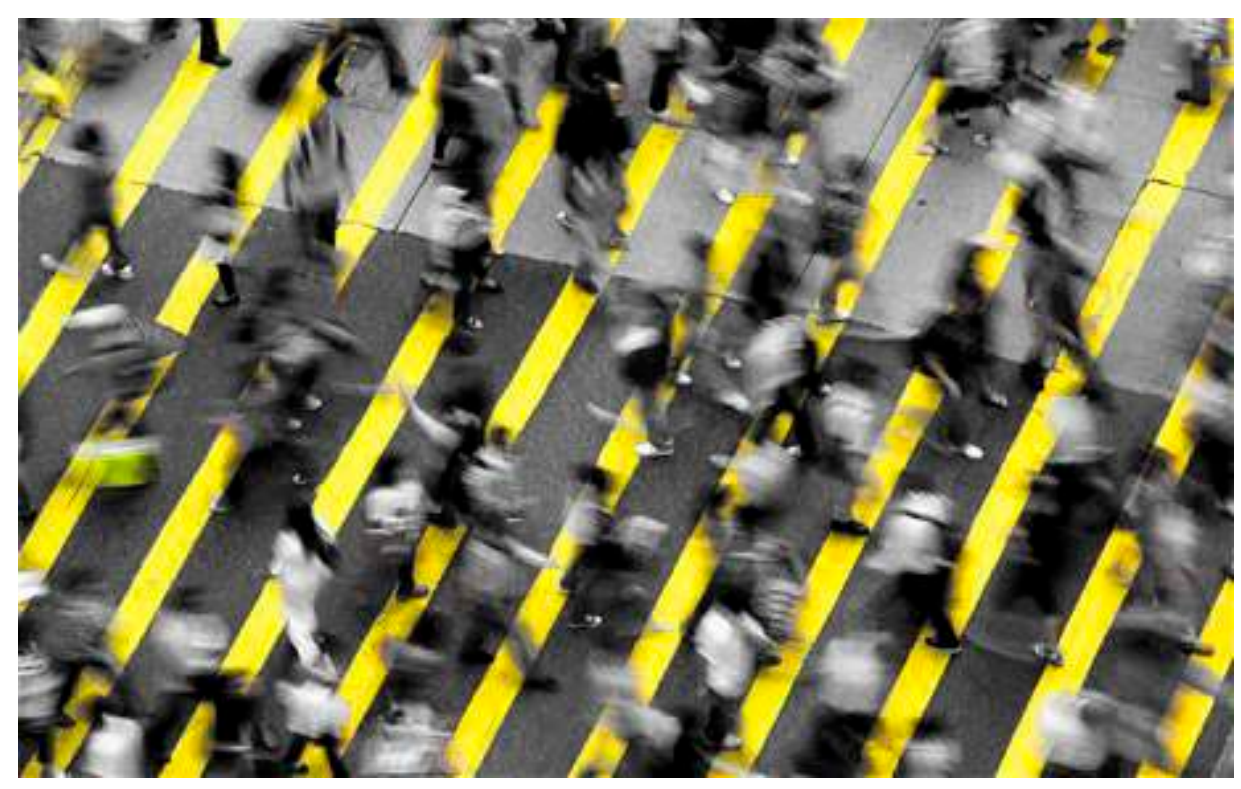




\section{Elevating the Street since the $1900 \mathrm{~s}$}

Elevating pedestrians over the regular street is not a modern concept for (usually high-dense) cities. Whether it is for recreational use, to protect from winter weather or to cross over water, urbanization has handled the street for pedestrians in various ways. From Wacker Drive, Chicago, built in 1926; to unrealized projects such as the SkyCycle, bike path envisioned by Foster+Partners for the city of London, these following examples are precedents for this proposal of the Long Line. Has this concept already been introduced, to what extent and can it be transposed from one city to another regardless of its urban layout?

Wacker Drive is one of many examples of streets in Chicago that were transformed by town planners and architects such as Daniel Burnham and Edward H. Bennett, into multi-level streets ("double-decked roadway"). The primary intention being to filter different purpose vehicles (pleasure versus commercial). figure 4 (p5)

The Unité d'Habitation by Le Corbusier in Marseilles, France, was one of the first attempts to integrate a commercial street into a residential building. Located on the $11^{\text {th }}$ floor, this main artery not only provides for basic needs of residents but also offers services such as schools and medical care. figure 5 (p5)

Robin Hood Gardens was designed by Alison and Peter Smithson in London. Like Le Corbusier's Unité d'Habitation, this social housing complex deploys a skip-stop circulation system with corridors on every third level to increase the frequency of interaction between residents. These corridors are envisioned as «streets in the sky.» figure 6 (p5) 

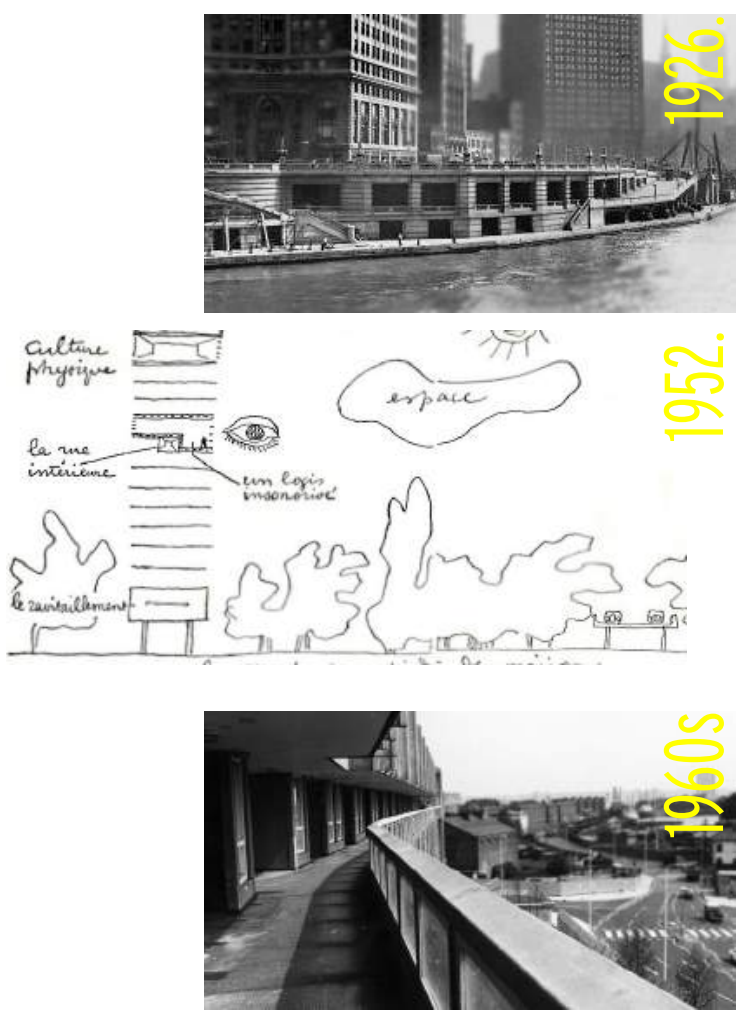
Plus 15 Calgary is a climate-controlled network of 59 bridges (total of 16km walkable paths) initiated by Harold Hanen mainly to protect from the rough winter weather. It connects office towers with retail centers and parking lots within a 50- block area. The network is interrupted at some points after hours. figure $7(\mathrm{p} 7)$

The Promenade Plantée/ Coulée Verte in Paris, France, is built on a former railway line connecting the Bois de Vincennes with the Place de la Bastille. Along the way, it shifts from the ground level to an elevated grid. This recreational path manages to block out the bustling city. figure $8(\mathrm{p} 7)$

The district of HafenCity in Hamburg planned by the Hamburg Urban Development and Environment Ministry as well as Kees Christiaanse, with ASTOC, displays an elevated main ground floor and bridges to avoid flooding.

figure 9 (p7)

The High Line, New York City, USA designed by James Corner Field Operations (landscape architecture firm) and Diller Scofidio + Renfro and Piet Oudolf (planting designer) is a purely recreational project and allows pedestrians to discover the city from another angle, away from car traffic.

LuJiaZui pedestrian bridge in the Pudong New Area of Shanghai, China, allows people (mostly business men and women) to avoid the noise and traffic of the city. Because it is elevated at almost 20 feet over the ground it also provides unique views of the metropolis. figure $11(\mathrm{p} 14)$ 

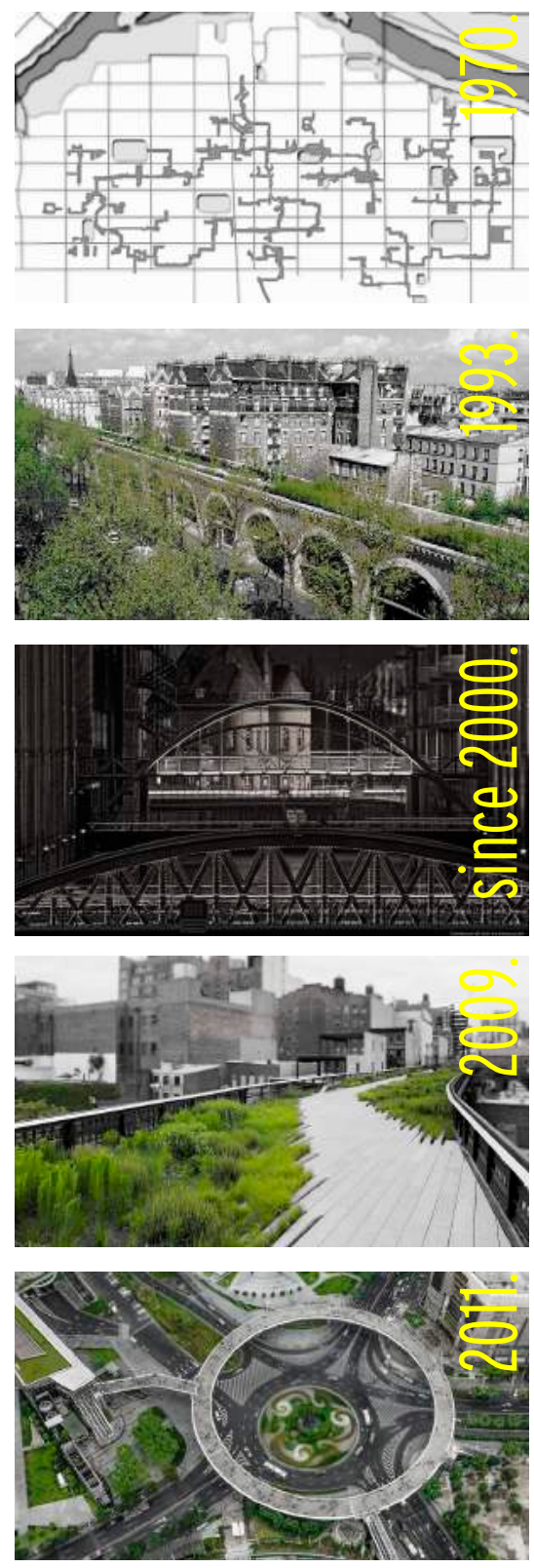
Hovenring, suspended roundabout bike path, by IPV Delft is situated between Eindhoven, Veldhoven and Meerhoven in the Netherlands. It was built mainly to cope with growing traffic figure 12 (p9)

The Bicycle Snake Bridge in Copenhagen, Danemark by Dissing+Weitling ensures safety and reduces travel time for cyclists. The bridge acts as a shortcut through the city. The everyday obstacles such as traffic, pedestrians and stairs are avoided by suspension of the infrastructure. figure $13(\mathrm{p} 9)$

SkyCycle is an elevated bike path proposal by Foster+Partners for the city of London, United Kingdom, to offer an alternative option to transportation. If built, this would be a first vertical layer added to the city in more than a century. figure 14 (p9)

Hudson Yards. In New York City, Steven Holl Architects designed a master plan mixeduse complexe on a deck over an extensive system or rail yards leading to New York's Penn Station. Described as a "high mixed-use density of 12 million square feet," this ensemble integrates the city's High Line, which currently travels around the site.

SkyWAY-scraper by Ryan Freeland and Jeffrey Pauling. The architects evoke the idea of the horizontal skyscraper to guide a proposal for Minneapolis. "The new horizontal skyscraper is conceived as an elevated street scene that will connect with the existing skyscraper infrastructure to create a new public realm working in synthesis to activate not only the buildings it touches, but also within itself.' figure 16 (p9) 

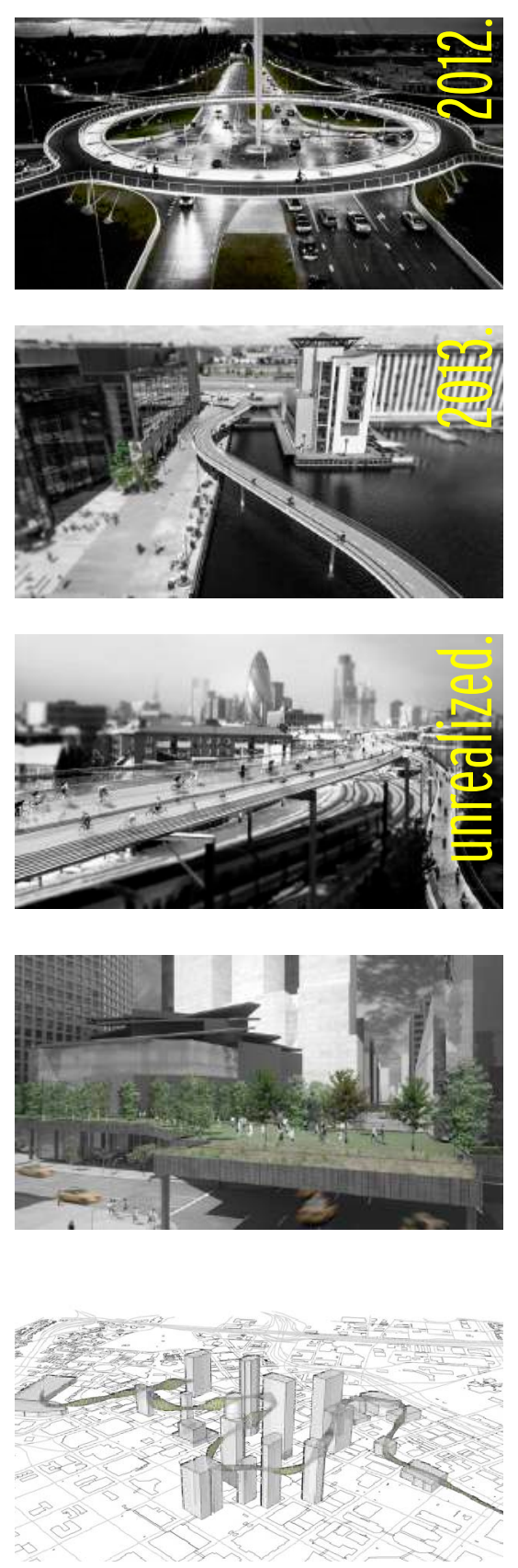


\section{Modernist Visions of Segregating Modes of Transportation}

The previous examples were not void of theoretical reasoning. In regards to segregating modes of transportation, revolutionary ideas were brought forward long before the start of the $20^{\text {th }}$ century. To which model of segregation of different modes of transportation can Hong Kong be associated to? And towards which one should it aspire?

Urban growth increased exponentially in Europe in the 19th century. Due to a number of factors, large numbers of unskilled workers began flocking to cities in the early part of the century. In addition to overcrowding, this rapid influx of people put huge strains on the city's sanitary infrastructure. Water supplies and sewers were not extensive or robust enough to handle the every-increasing load being placed on them.

Among the many examples of large-scale public works projects to transform the 19th century city are Haussmann's upgrades to Paris. Under the rubric of «Paris embellie, Paris agrandie, Paris assainie» («Paris embellished, Paris extended, Paris cleansed»), Haussmann cut out boulevards through the medieval center of Paris, established new parks and suburban districts, undertook a massive campaign of street lighting, tree planting and sidewalks, and implemented an extensive network of sewers. Haussmann brought light, air and a higher level of sanitation to the older districts of Paris as well as laying the groundwork for the orderly expansion of the periphery.

Despite significant investments in infrastructure, overcrowding and poor sanitation continued to plague many European cities into the early 20th century. With the advent of street rail and (after 1900) the automobile, cities experienced an increasing amount of congestion in the core. A new generation of reformers began to formulate strategies to decongest the city and further increase the amount of light and air. Among these was Eugène Hénard (1849-1923). 


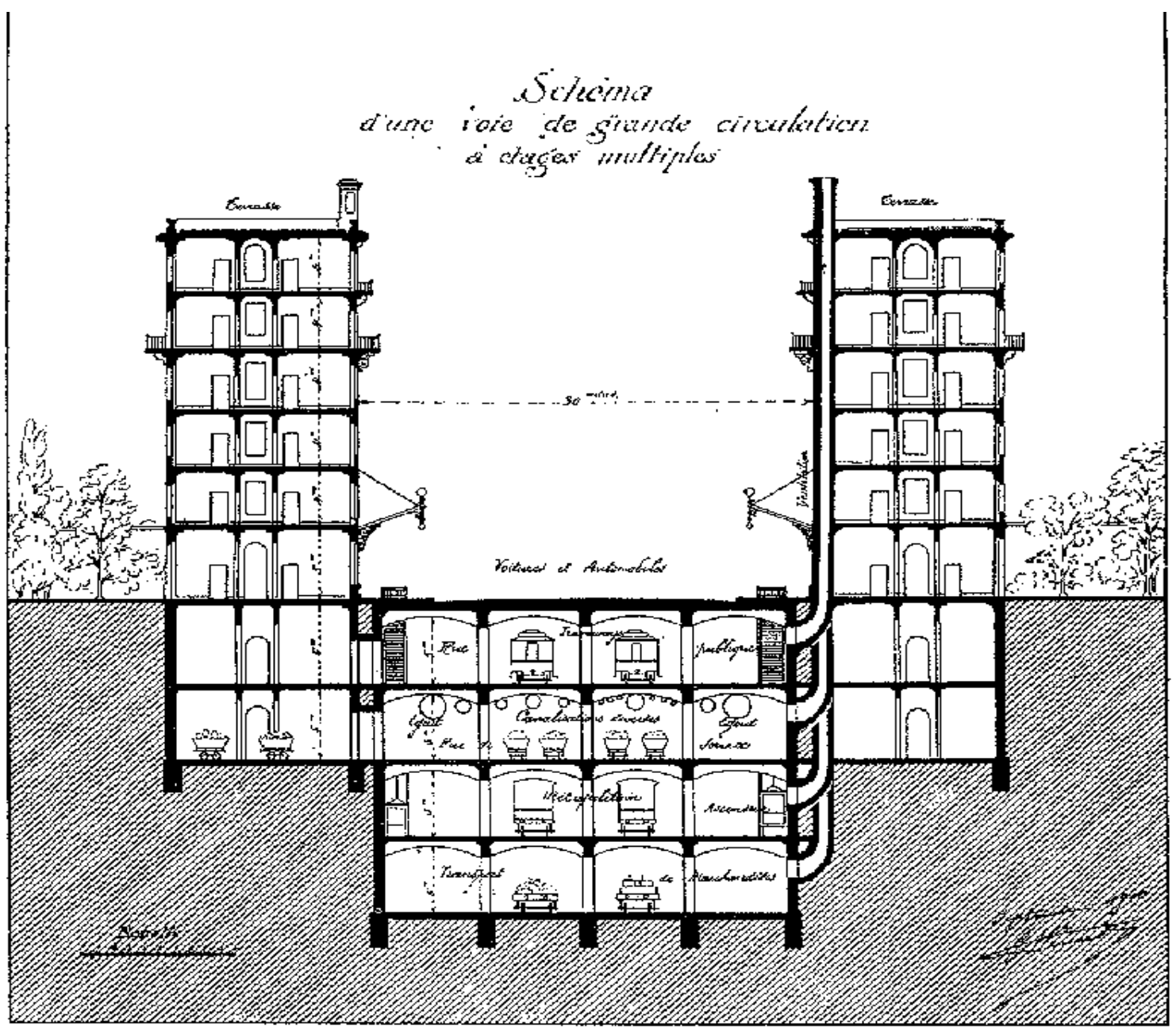


An architect and town planner, Hénard's work includes contributions to the Paris exhibitions of 1889 and 1900 and the introduction of the traffic roundabout. Hénard spent a good deal of time formulating solutions to congestion in Paris.

\section{«l shall make a special effort to describe the considerations which must determine the form of both our houses and of our streets, as these constitute the primary elements out of which a city is built up.»}

What he aimed for was "underground settlement", adding layers/grids from the ground down (as seen in figure 17), each layer pertaining to a specific type of locomotion.

«The city as a whole will be traversed by wide roads radiating from the centre, and partly occupied by elevated platforms kept continually in motion, so that by this means rapid intercommunication between the several zones will be assured. These platforms will be terminated by revolving turn-tables, erected over the point of intersection of the principal streets.》

In the first quarter of the $20^{\text {th }}$ century architects Le Corbusier and Ludwig Hilberseimer also formulated plans for cities of the future. Hilberseimer picked up where Hénard left off, especially with respect to the relationship between buildings and streets. In 1910 Hénard recommended that: "the normal height of buildings would be exactly equal to the width of the street." ${ }^{\prime 1}$ Hilberseimer wrote in Metropolisarchitecture in 1927:

«The provision of light and air demands at minimum a distance between buildings that is equal to their height: street width equals building height.»

${ }^{1}$ from Eugène Hénard's paper, "The Cities of the Future" presented to the Royal Institute of British Architects' Town Planning Conference in London in 1910. 
Hilberseimer took a rational approach to the city which he described as an organism.

«The definition of the means of transportation -train and canal routes, main streets, elevated and underground trains- is of primary importance. These are the arteries of the entire organism.» (p91)

He depicts two urban types: the city that develops organically over time and the artificial, geometric city.

Whatever the urban pattern, traffic management poses challenges.

«Both residential and traffic problems are closely connected, because the traffic of the metropolis is, of course, not an end unto itself but a means in the hands of the inhabitant of the metropolis.» (p97)

This observation is all the more valid in Hong Kong's central business district where high-density residential buildings have given way to even higher density office towers. While employees may be allocated their own spaces inside these towers, congestion is a major challenge when these buildings empty out toward the end of the day. The city's narrow streets are not equipped to handle the volume of traffic they are asked to accommodate.

«The impossibility of these conditions naturally increases with the height of the building. Thus Raymond Unwin makes the following observation on the 55-storey Woolworth Building. If an employee is allotted five square meters of workspace, this building can contain 14,000 people. If a standing employee is allotted 60 square centimeters of ground, then, if all of these employees were gathered in front of the building at the same time on a sidewalk six meters wide, a sidewalk 855 meters long would be required to accommodate these 14,000 people. But if one begins to calculate the figures for these people in motion, then, with a necessary surface for a walking person of 60 by 150 centimeters, a sidewalk of the same width would have to be 2,100 meters long. [...] how circulation is even possible given New York's narrow streets.» (p107) 
In support of this observation, Hilberseimer refers to a 1924 proposal by Harvey Wiley Corbett for a system of superimposed traffic networks for lower Manhattan. Corbett recommended the vertical segregation of modes of transportation to provide more space for each system of movement. Vehicular traffic remained on the street where additional lanes replaced sidewalks while pedestrians were re-directed to elevated walkways on either side of the road. Over the course of time, the upper, pedestrian level became the primarily commercial level of the street while ground floor storefronts were carved out to accommodate parking, deliveries, and servicing. In the final iteration the elevated walkways were incorporated into the design of buildings as arcades.

While proposed almost a century ago, Hilberseimer's approach still resonates today. Rather than arguing against density and building height, he accepts and attempts to accommodate it. As Jason Y. Ng observed in No City for Slow Men: "Hong Kong is charming when it is bustling." (p38) While posing significant challenges, high densities are also confirmation of a city's vitality. Like Hénard, Hilberseimer suggests that this density be addressed through higher buildings and the segregation of modes of transportation. Movement would be stratified as follows: 1. underground tunnels would be used for faster, longer distance transportation, 2. local vehicular transportation would occur at grade and, 3. pedestrian circulation would be elevated. 

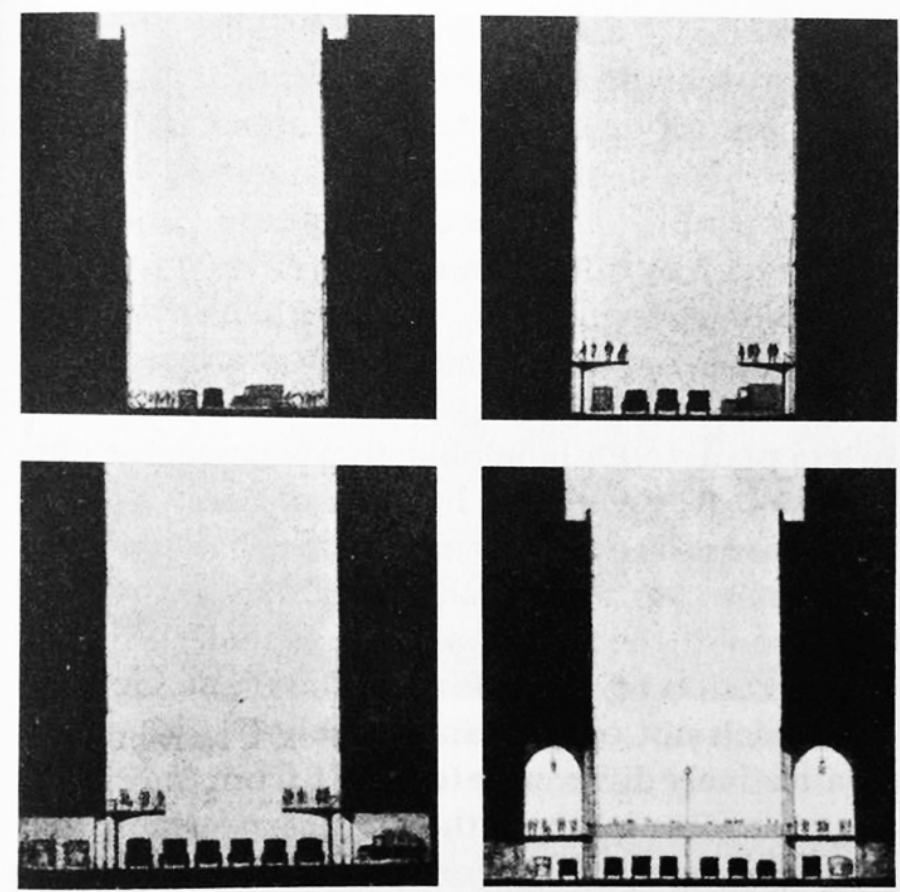

New York, Proposals for street expansions to accommodate traffic: (Top Left) Current condition; (Top Right) Elevation of sidewalks; (Bottom) Elevation of sidewalks, the use of the ground floor space of buildings for transportation, and the enclosure of streets for pedestrian traffic 
While the rigid partitioning of buildings and streets may be too drastic, the segregation of different modes of transportation -and especially elevated pedestrian walkways- is appealing and innovative where density can support it.

In his 1925 book, Urbanisme, Le Corbusier laid out his plan for a contemporary city for three million inhabitants. In it the author advocates rationally planned and "artificial, geometric city," -whose plan is largely dictated by circulation networks:

\section{«the street defines the structure of the urban plan» (p117)}

Le Corbusier rejected the traditional relationship between buildings and streets, dismissing the narrow, lightless routes through most cities as «corridors». Consequently the high-rise buildings comprising his new city are separated by open spaces whose dimensions are commensurate with the heights of the buildings. Le Corbusier also believed that, to be successful, cities must foster speed. Therefore the tramway for example is a transportation mode that Le Corbusier eliminates; something too valuable, «precious» to the city of Hong Kong to be removed. Streets and other communication arteries must not cross paths. However the latter becomes possible with a multiplicity of elevated (or buried) networks. Furthermore the second can be carried out on the grounds that high density nourishes this project.

Ten years later, architect Frank Lloyd Wright released his plan for «Broadacre City: A New Community Plan» (Architectural Record 77, April 1935, pp. 243-54). Driven by the notion of radical decentralization made possible by the car and communication technologies such as the telephone, Wright's proposal was the exact antithesis of Le Corbusier's City for Three Million Inhabitants. That said, the fluid movement of automobiles played a significant role in both proposals.

On the other hand, Edmund Bacon in the 1960s favored the pedestrian over the automobile. This transpires in his recommendations for the city of Philadelphia as he proposed pedestrian-only streets. 
In the early 1960s the critic Jane Jacobs weighed in on the idea of segregating modes of circulation. Describing the city as a ballet to be choreographed rather than a scientific problem to be solved, she rejected modernist "tower-in-the-park" planning principles and argued for the return to street-oriented buildings and for the integration of uses and forms of movement. Jacobs promoted dynamic and active streets linked to an integrated and continuous network in which pedestrians co-exist with vehicles, over which they have priority. Arguing that streets must be diverse and conducive to a range of interactions between an array of users over the course of a day, she articulated the following four principles:

«1. The district, and indeed as many of its internal parts as possible, must serve more than one primary function; preferably more than two. These must insure the presence of people who go outdoors on different schedules and are in the place for different purposes, but who are able to use many facilities in common.

2. Most blocks must be short; that is, streets and opportunities to turn corners must be frequent.

3. The district must mingle buildings that vary in age and condition, including a good proportion of old ones so that they vary in the economic yield they must produce. This mingling must be fairly close-grained.

4. There must be a sufficient dense concentration of people, for whatever purposes they may be there. This includes dense concentration in the case of people who are there because of residence.» (Jacobs, 2006, p.151)

Hong Kong does not pertain to any one of these proposals mainly because topography is what drives its urban sprawl growth. However it draws elements from each, and more, to create unique layout and ramifications. For example, on one hand the segregated modes of transportation in Hong Kong seem to adhere to Bacon's modernist planning principle (pedestrians walk over automobiles). On the other hand, even though Jacobs refuses to segregate at the expense of the street, her idea of mixing functions to ensure a continuous interweaving of the population occupying the space at different times and for different reasons is an aspect I wish to apply to my proposal. 
The area in and around Hong Kong's business district supports three levels of circulation: the underground subway network, the network of streets, sidewalks and tramways at grade, and the elevated pedestrian walkways. Inasmuch as the same individuals use all three networks in concert with each other, segregation of uses and modes of transportation is far from radical in Hong Kong. Also, given the frequent changes in topography, elevated modes of circulation often connect seamlessly with at-grade pathways, funiculars and other modes of vertical transport. Similarly automobiles find themselves alongside high-speed trains in underground tunnels (Airport Express) and streets are shared by pedestrians, cars, busses and trams.

What happens naturally, however, is a classification of the walking population through these elevated walkways. This crowd consists of the local/working citizens, the ones that know the city and do not need to think twice before taking an escalator down or up to another passage to get to their destination. The fourth tier, or Long Line, I am proposing above the existing networks will facilitate a "dérive" for the «flâneur», the solitary urban walker (or wandering tourist) as Guy Debord, from the Situationist International group, describes it. Over the bustling city core, this level is simultaneously a promenade, a destination, a short-cut. Its function adapts to the environment, the user and the time of day/week. On one hand office workers may use it on weekdays to access the ferry while, on the other hand, Filipino workers may use it to access World Wide House on Pedder Street -which is a center/micro mall containing employment agencies, groceries, cell phone and money-wiring services. On weekends the project would provide much needed recreational space for domestic workers on their only day off. 


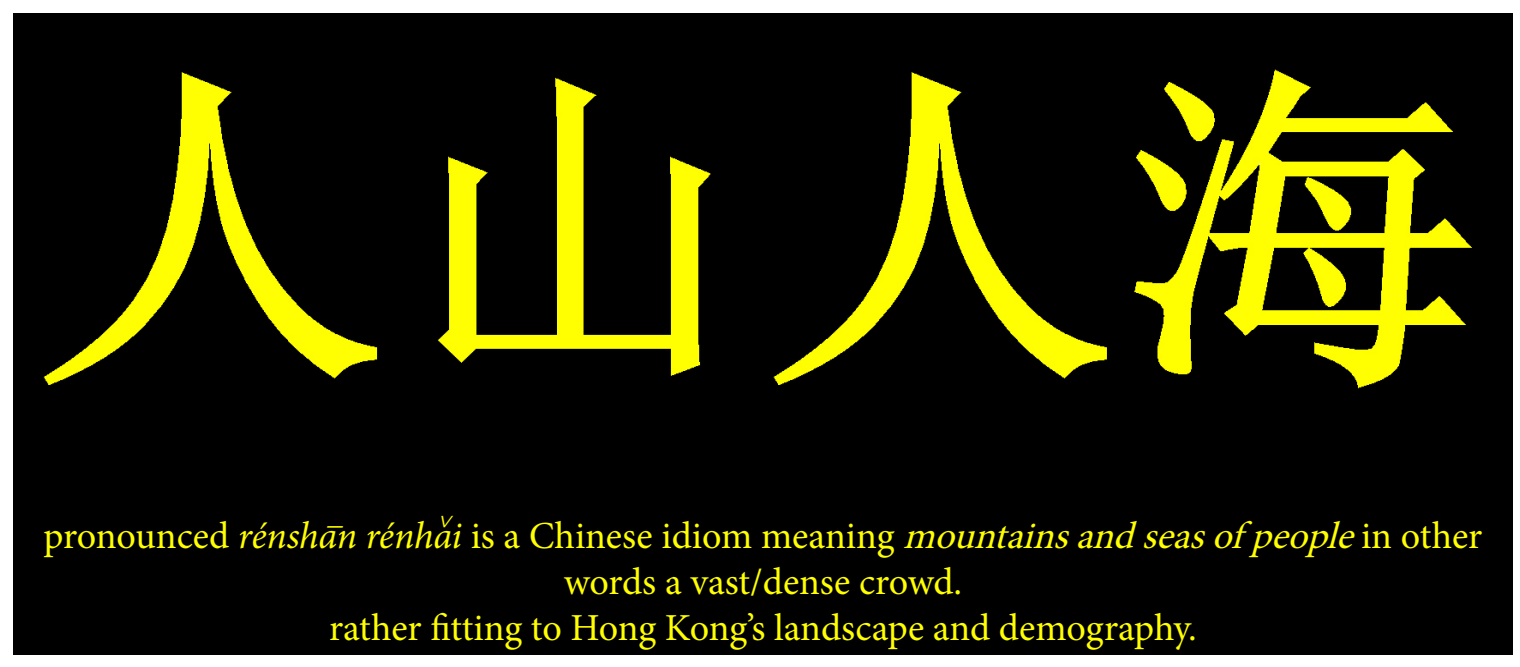




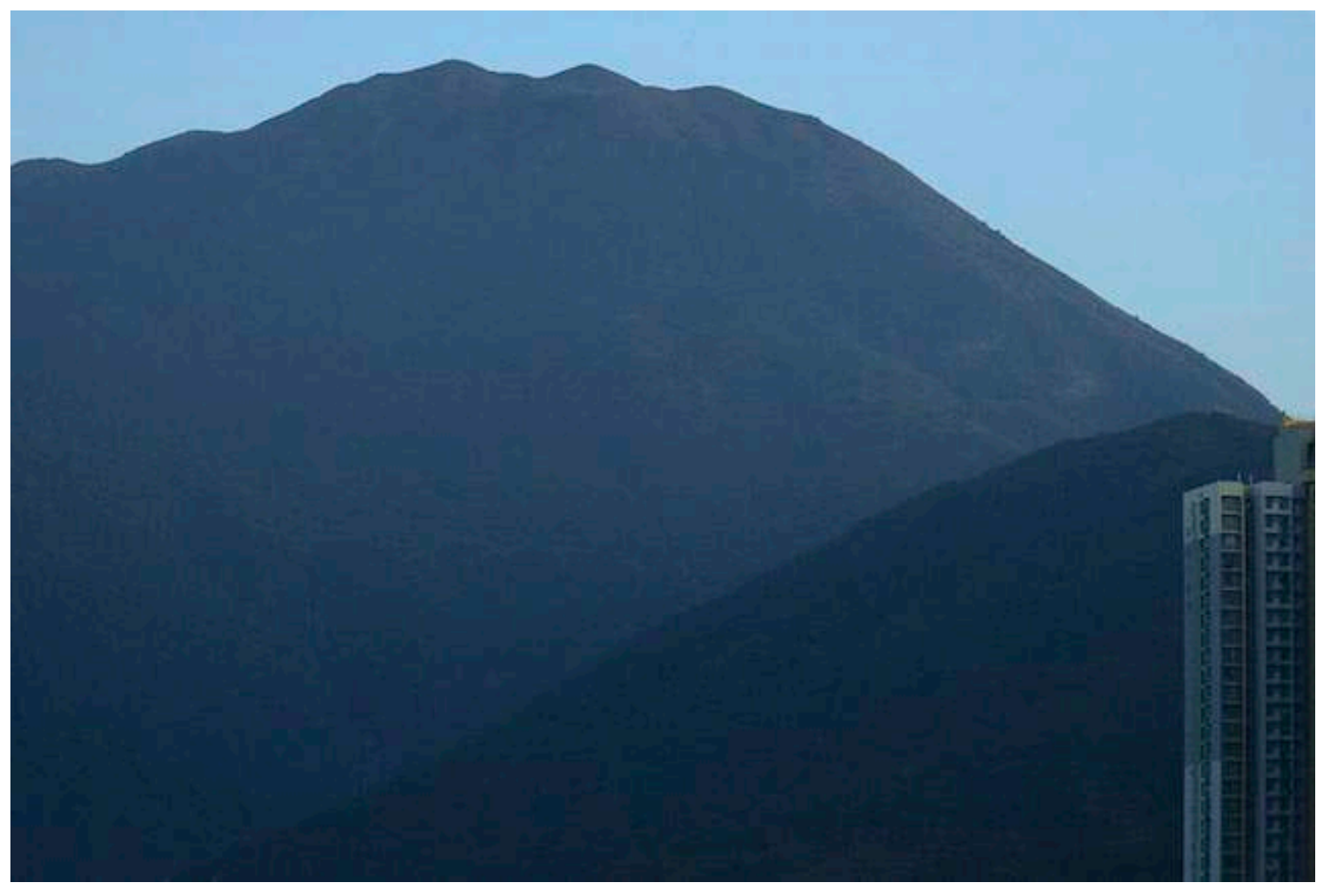




\section{Elevated Walkways in Hong Kong: from defying topography to defying authority}

The network of elevated walkways is a start to segregating modes of transportation in Hong Kong. Its first objective, without function, is to ensure continuous movement for pedestrians through Central and facilitate circulation through the topography lines. However, because of its elevation away from the commotion of the street at grade, it has gradually become appropriated by various activities.

Defining Hong Kong by its surface becomes irrelevant once we learn that only $17 \%$ of the land on the island has been built out and much of it was once water. Extremely high densities in tandem with $83 \%$ open space has produced a city of high-rises, most of which sit on reclaimed land at the waterfront.

The territory is spread across an archipelago of over 200 islands and mainland territories; the main ones include Kowloon, New Territories and Hong Kong Island where the central business district stretches along the north coast. The majority of Hong Kong's residential areas are located on the opposite (south) side of the island. Wherever they are located, however, buildings are constrained to narrow strips of land along the waterfront, if not on landfill. Steep slopes force settlements to the waterfront where they are constrained by the sea. Less than two kilometers separate mountain and sea in the central business district. After Midtown Manhattan, Hong Kong's CBD has one of the highest rates of employment per square kilometer. 


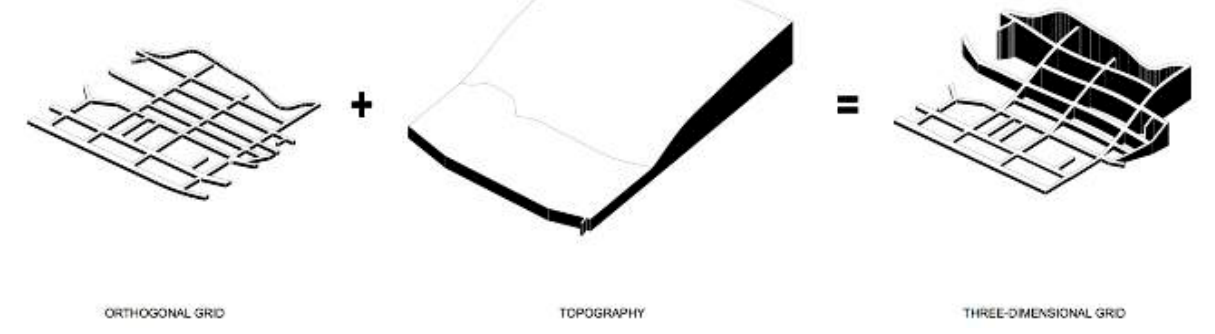




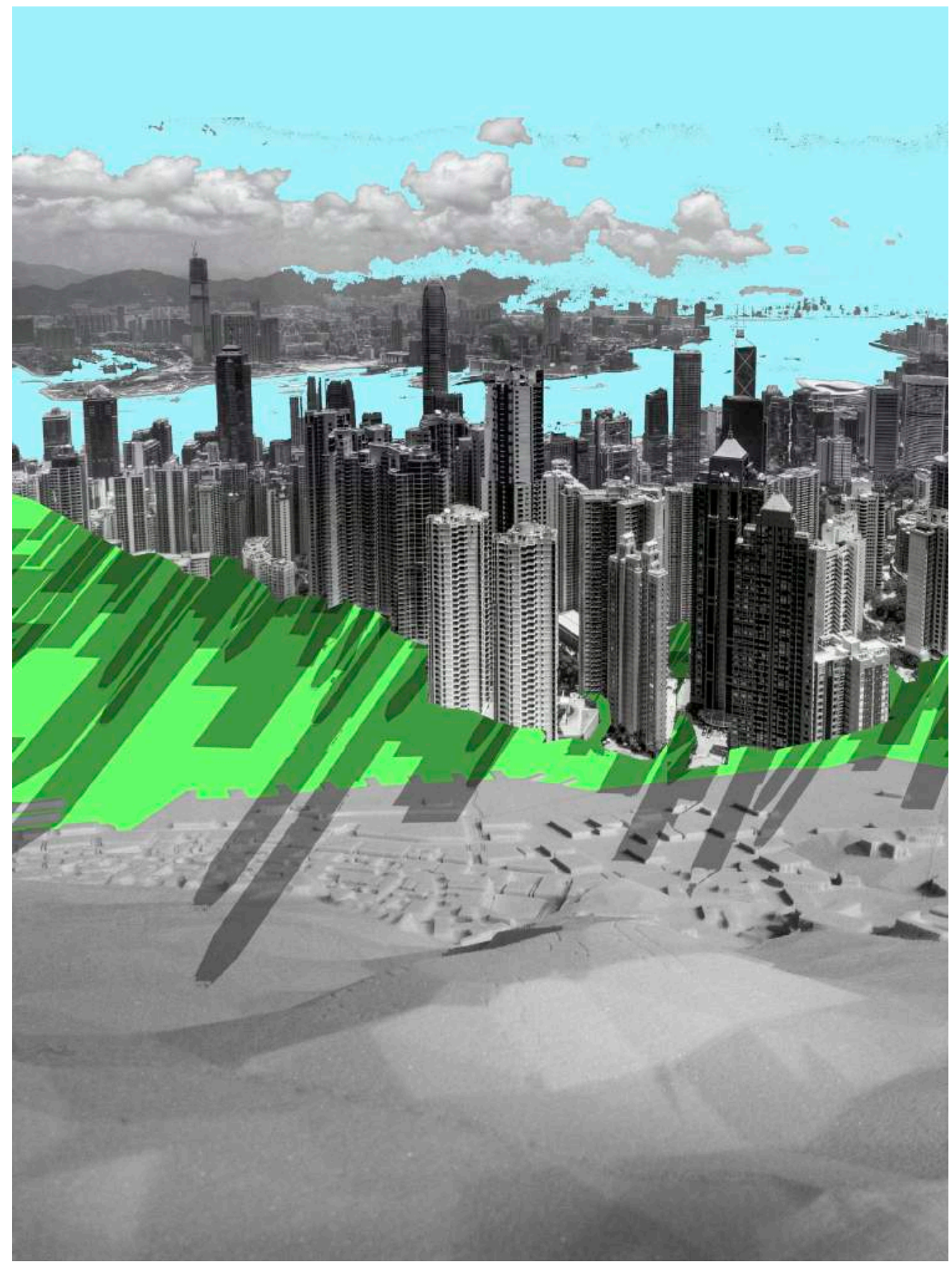




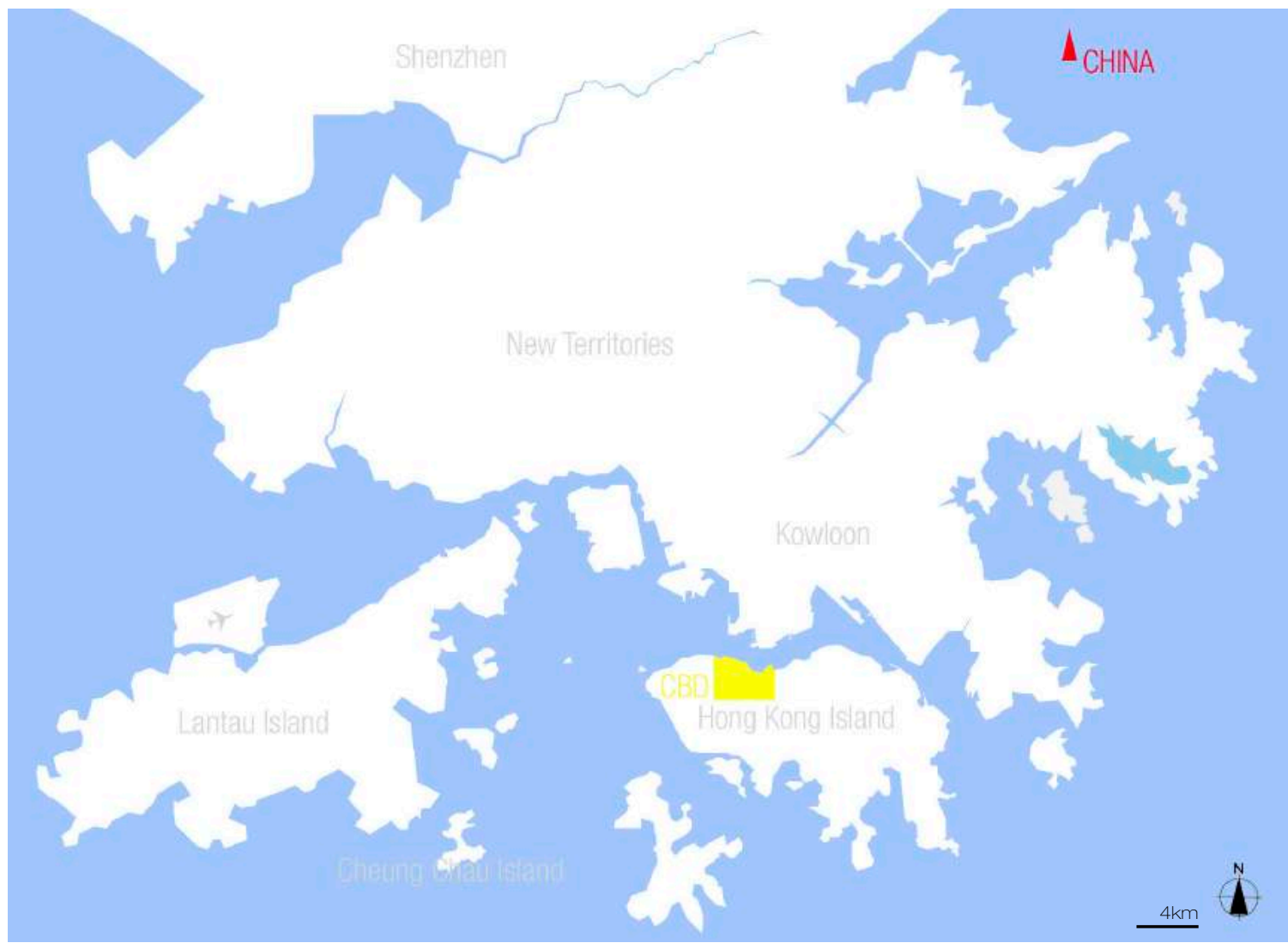




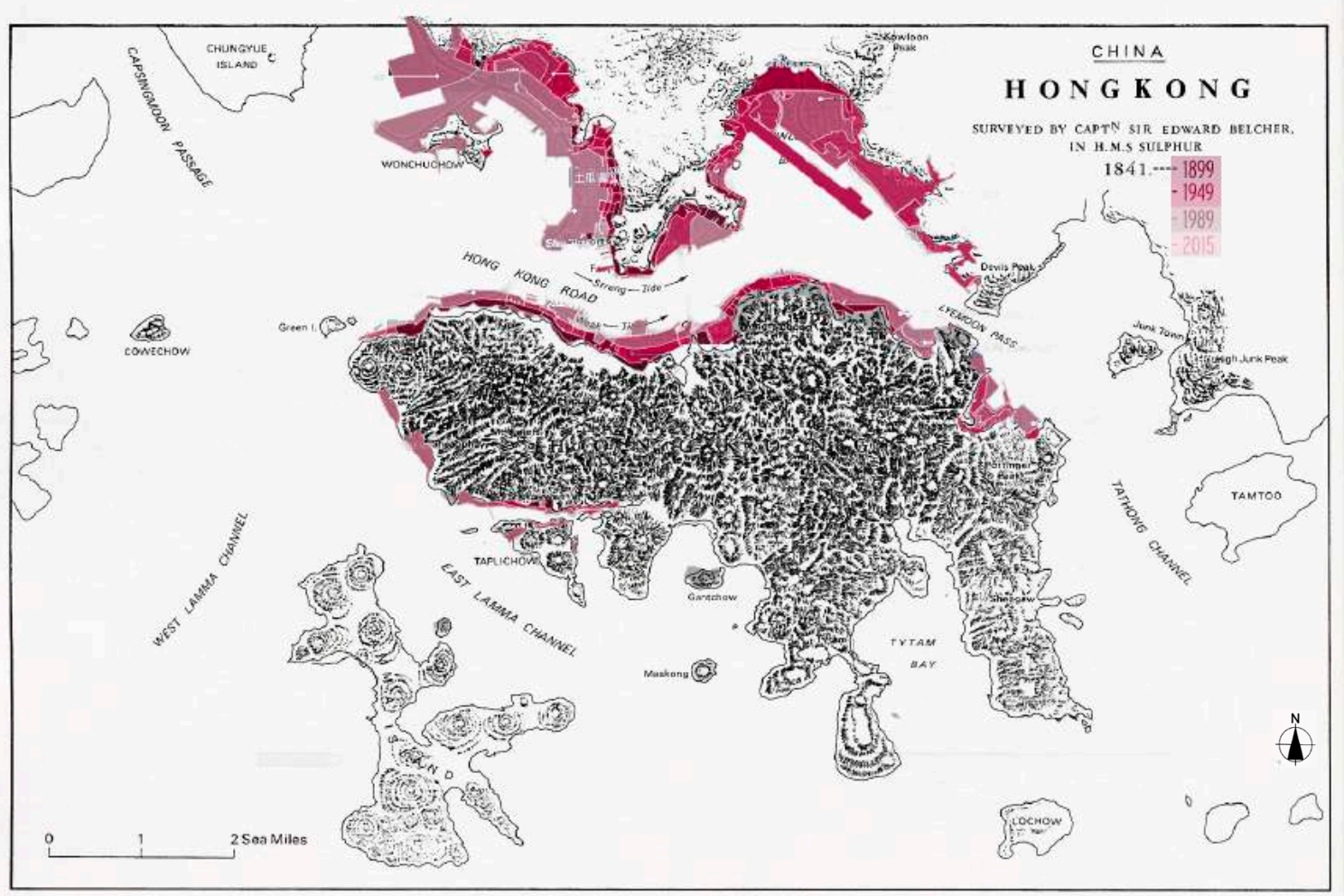


While the first obvious responses to the lack of useable land are to build higher and to produce additional land through reclamation, this is only part of the solution to the problem of density. As both Ludwig Hilberseimer or Le Corbusier observed, the higher the buildings the more likely it is that the streets around will become crowded and constricted. If tall buildings are constructed too close together, there will not be enough room at grade to accommodate those who use them. Le Corbusier argued for fewer, taller buildings.

Hong Kong has responded to this challenge by gradually spawning an elevated pedestrian circulation network, to augment movement between towers and different tiers -from underground to ground and from ground to over ground- since it is not uncommon for Hong Kongers to take various modes of transportation to get from A to B.

\section{«Urbanism in Hong Kong is a result of combination of top-down planning and bottom-up solutions, a unique collaboration between pragmatic thinking and comprehensive master- planning, played out in three dimensional space.» -Adam Frampton, Jonathan D Solomon, Clara Wong in Cities Without Ground: A Hong Kong Guidebook (p6)}

Because the ground is interrupted by highways, tramway tracks, tunnel entrances and incessant traffic, Hong Kong provides connectivity at the higher level. Activity in the streets of Hong Kong is relentless. But what constitutes the street in contemporary Hong Kong? «Uncles» use elevated walkways to play Mah-jong while white-collar workers take their lunch breaks in corporate lobbies. Malls have become stages for flash mobs and performance art. Domestic workers frequently spend their days off on sheltered skywalks since most of them live with the families for whom they work and they have no spaces of their own. 


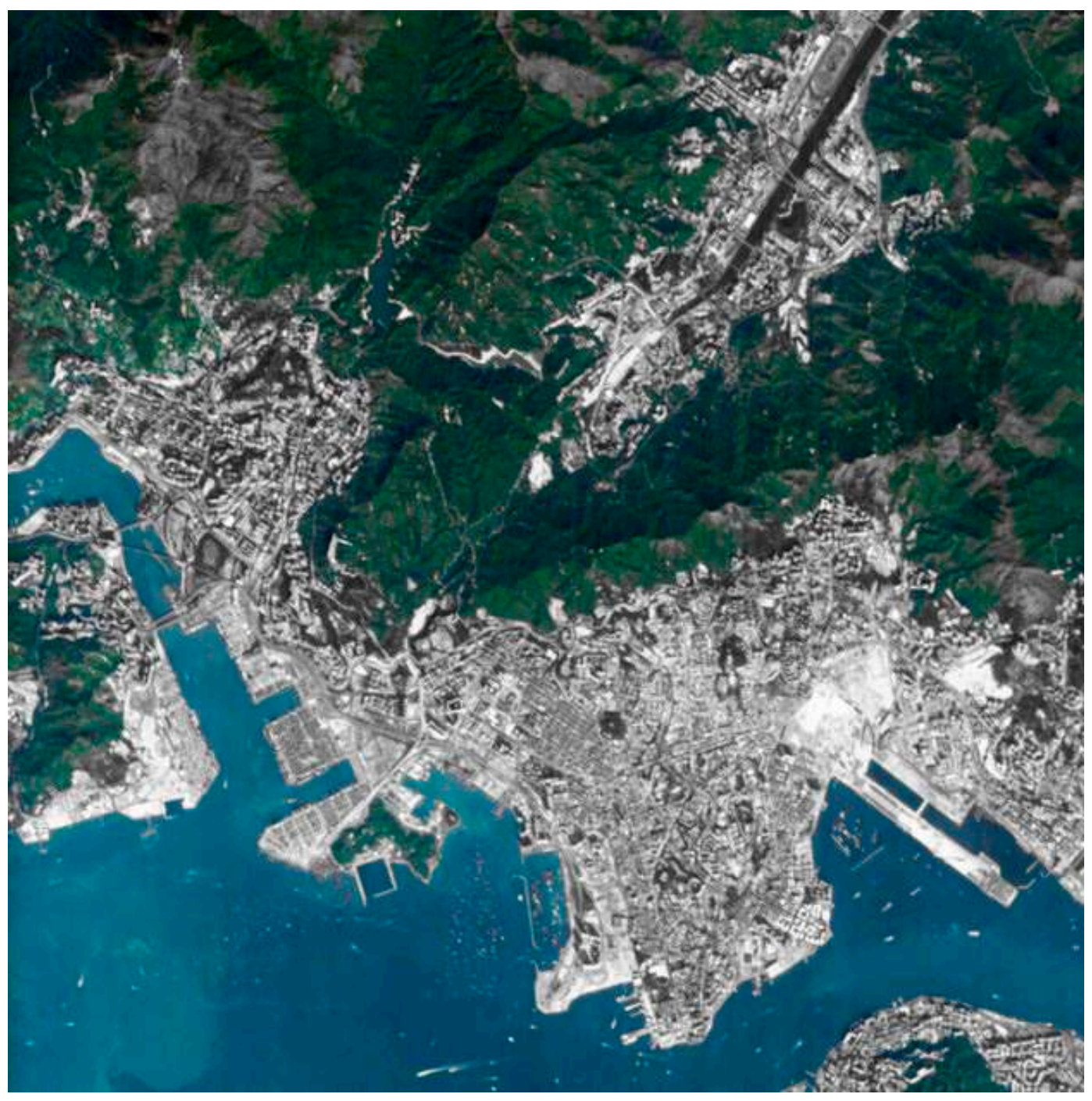


Domestic workers make up 3\% of Hong Kong's population. The same percentage of a 72s.q.m luxury three-bedroom flat in the city is assigned to a domestic worker, a "space" too small for an adult to extend his arms and barely big enough for a single bed. Domestic workers are poorly treated. In addition to poor living conditions, many face physical and sexual abuse. Thankfully organizations such as Coalition to Combat Violence Against Migrant Workers, have formed to demand more protection and force the government to investigate abuses. Even so, domestic workers, a majority of which come from the Philippines, still face deportation if they do not find another employer within two weeks of leaving the previous one or if they become pregnant while working for a family.

\section{«The migrant worker policy has been flawed from the start. It was meant to be a quick fix for our changing economy, but little thought was given to how [Hong Kong] could handle the sudden influx of foreign workers.» -Jason Y. Ng in No City for Slow Men, Hong Kong's Quirks and Quandaries Laid Bare (p213)}

The unauthorized use of the elevated streets of Hong Kong is not surprising when one considers the conditions that domestic workers face. Furthermore where do these workers reside when between jobs? This group needs more than cardboard boxes for floors and walls and "pop-up" stands on skywalks. 


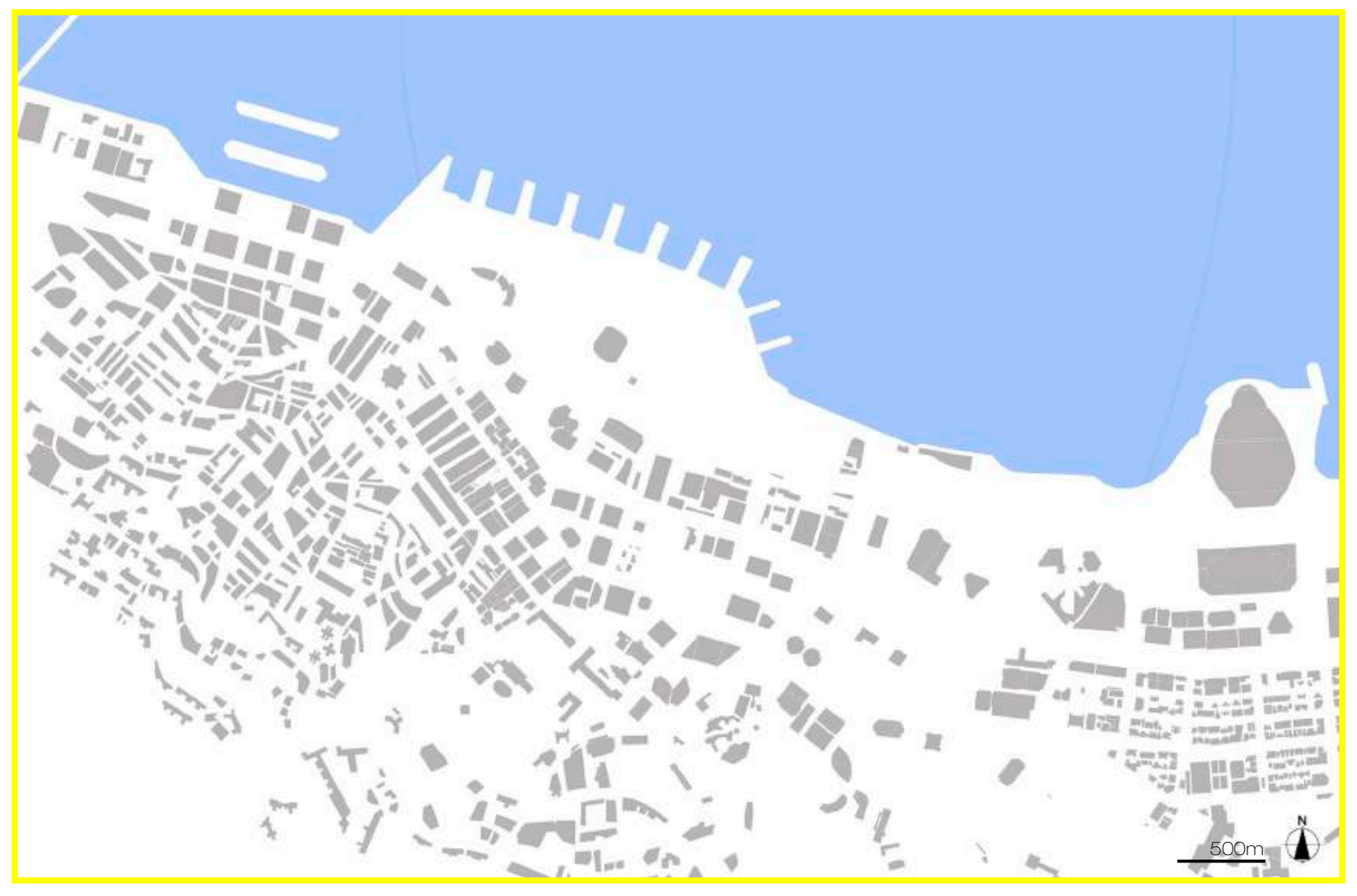




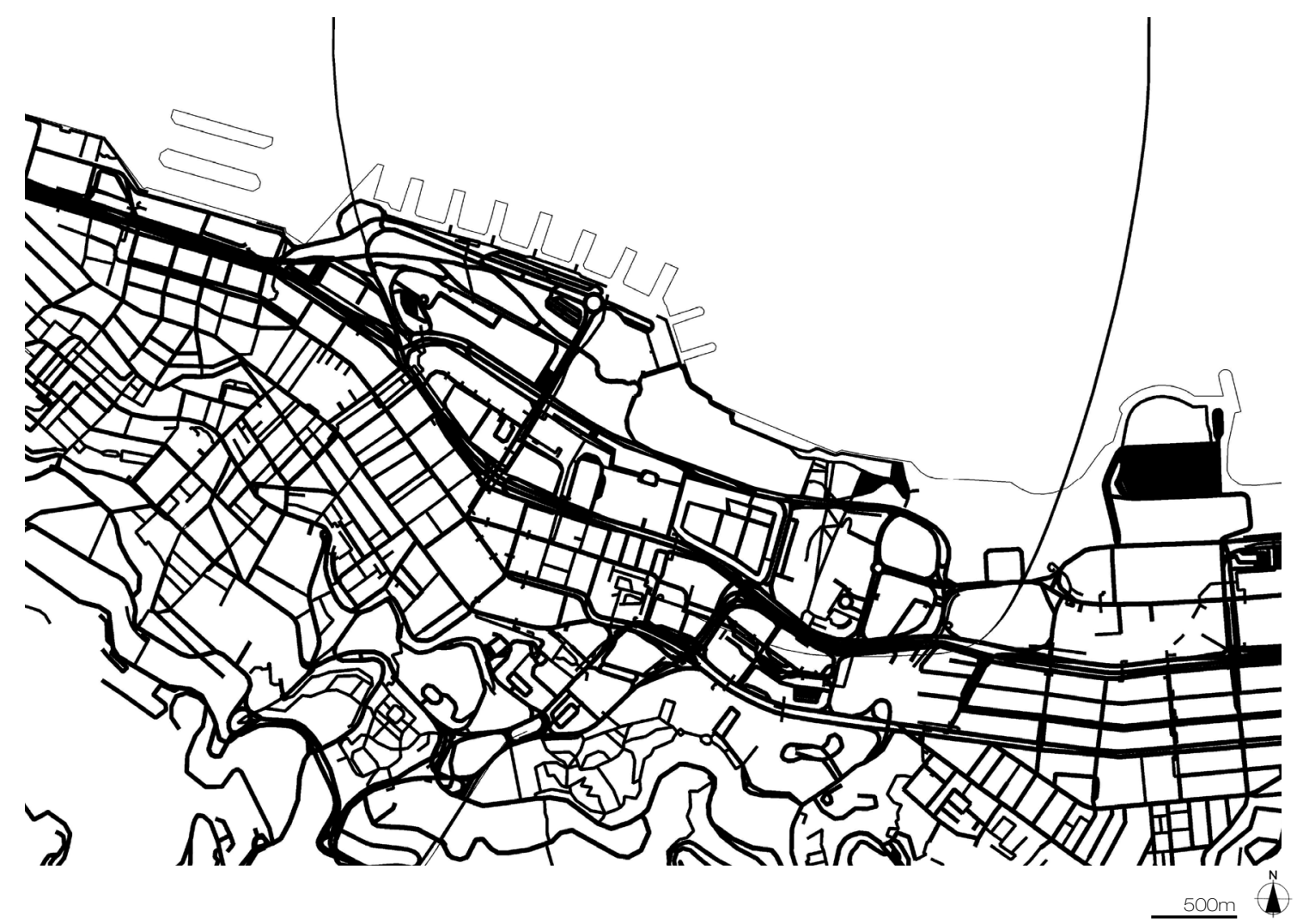




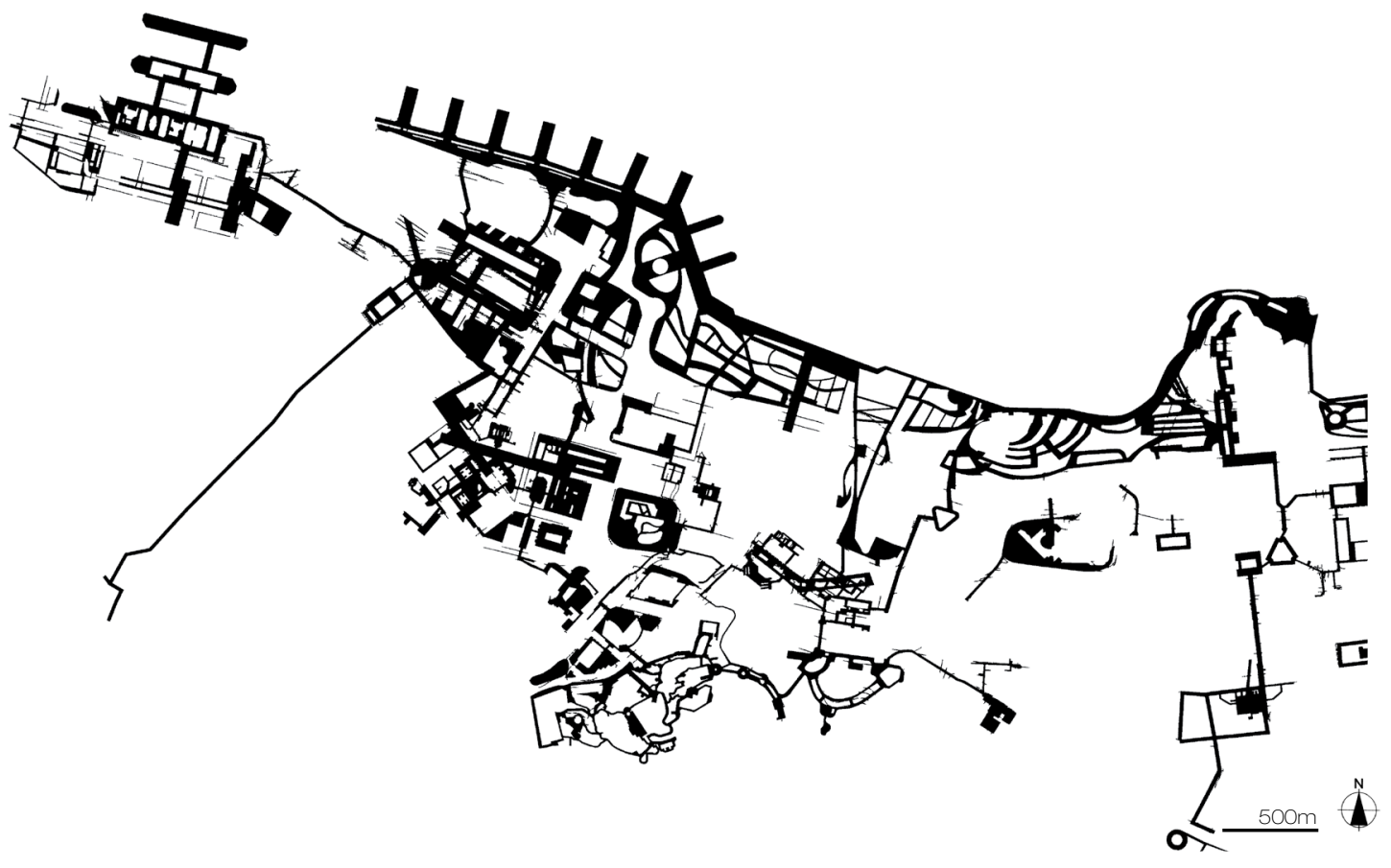


Hong Kong's elevated walkways are also frequently used for protests. The city's residents regularly vent their discontent over the current, unstable democracy of the Special Administrative Region. China’s central government exerts a significant influence on Hong Kong's governmental affairs, keeping close control of elections. The summer of 2014 witnessed Hong Kong's largest pro-democracy rally, the "Yellow Umbrella Revolution".

\section{«The main demand is full democracy.»}

The list of candidates is usually pre-"screened" by the mainland government. While nomination and election of the head of the Hong Kong government should be direct, residents do not choose the candidates among whom they are asked to choose. The current chief executive, Leung Chun-ying was elected indirectly and is considered to favor China's priorities over Hong Kong's. This explains the protester's second demand, namely that the head politician resign. Hong Kong has become so powerful and important at an international level that the People's Republic of China cannot afford to let it influence the rest of the country. If an opponent of the Communist party gets elected as chief executive of Hong Kong, the possibility of democratic change might seem available to the rest of the country.

Hong Kong differs significantly from the People's Republic of China with respect to the freedom of the press, freedom of information, laws, the independence of its judiciary, etc. With an increasing number of students returning from university exchanges with westernized ways of thinking there is an increased desire for democracy in Hong Kong. The "Umbrella Revolution" was largely led by two student groups: Scholarism led by Joshua Wong and the Hong Kong Federation of Students led by Alex Chow. Older generations, by contrast, fear that policital demonstrations will only encourage Beijing to further restrict Hong Kong's freedoms. Also, Hong Kong being an expensive city in which to live in (ranked 12th worldwide), locals fear even greater challenges where the city became a completely independent and free of China's communist control. 


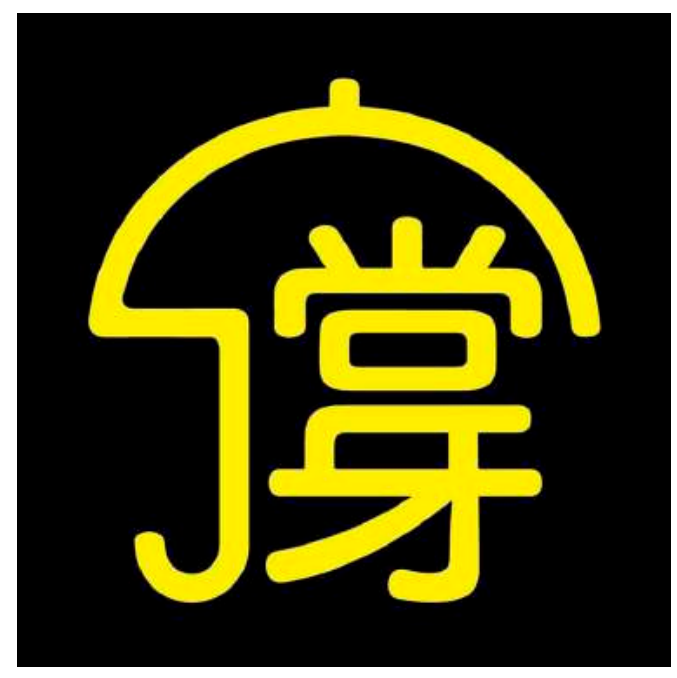


Protesters symbolically occupied the Central neighborhood in the summer of 2014, occupying highways and elevated walkways and interfering with the usually dense circulation. Tents pitched throughout the Business District were a nonviolent way to demonstrate the demonstrator's discontent. The umbrella, initially used as a defense against pepper-spray yielding police, quickly became a symbol of the revolution.

«We already live in the era of the self-destruction of the urban environment.»-The Society of the Spectacle by Guy Debord'

The Umbrella Revolution was intended as a non-violent protest; compared to May '68 it was not aggressive. Wanting to block circulation, protesters occupied many of Hong Kong's busiest streets and highways. Back in Paris, protesters set up barricades and tore the cobblestones from streets to use as weapons against the police.

«The city is the locus of history because it embodies at once a concentration of social power, which is what makes the historical enterprise possible, and a consciousness of the past. The present urge to destroy cities is thus merely another index of the belatedness of the economy's subordination to historical consciousness, the tardiness of a unification that will enable society to recapture its alienated powers.») -The Society of the Spectacle by Guy Debord?

figure 29: "We will be back", occupy Central, photo by Pedro Ugarte, 2014 (p35)

figure 30: Office workers walk through streets closed by protesters in the business district of

Central in Hong Kong, China, on Monday, Sept. 29, 2014. (p36)

figure 31: mapping the Umbrella Revolution sites in the district of Central in Hong Kong, 2014 on this aerial view of a street in the central business district appear multiple elevated walkways on which protesters had no trouble installing stands and occupying the space in favor of the Umbrella Revolution (p37)

\footnotetext{
${ }^{1}$ from The Society of the Spectacle by Guy Debord, chapter 7: Envrionmental Planning, paragraph 174 .

${ }^{2}$ from The Society of the Spectacle by Guy Debord, chapter 7: Envrionmental Planning, paragraph 176.
} 


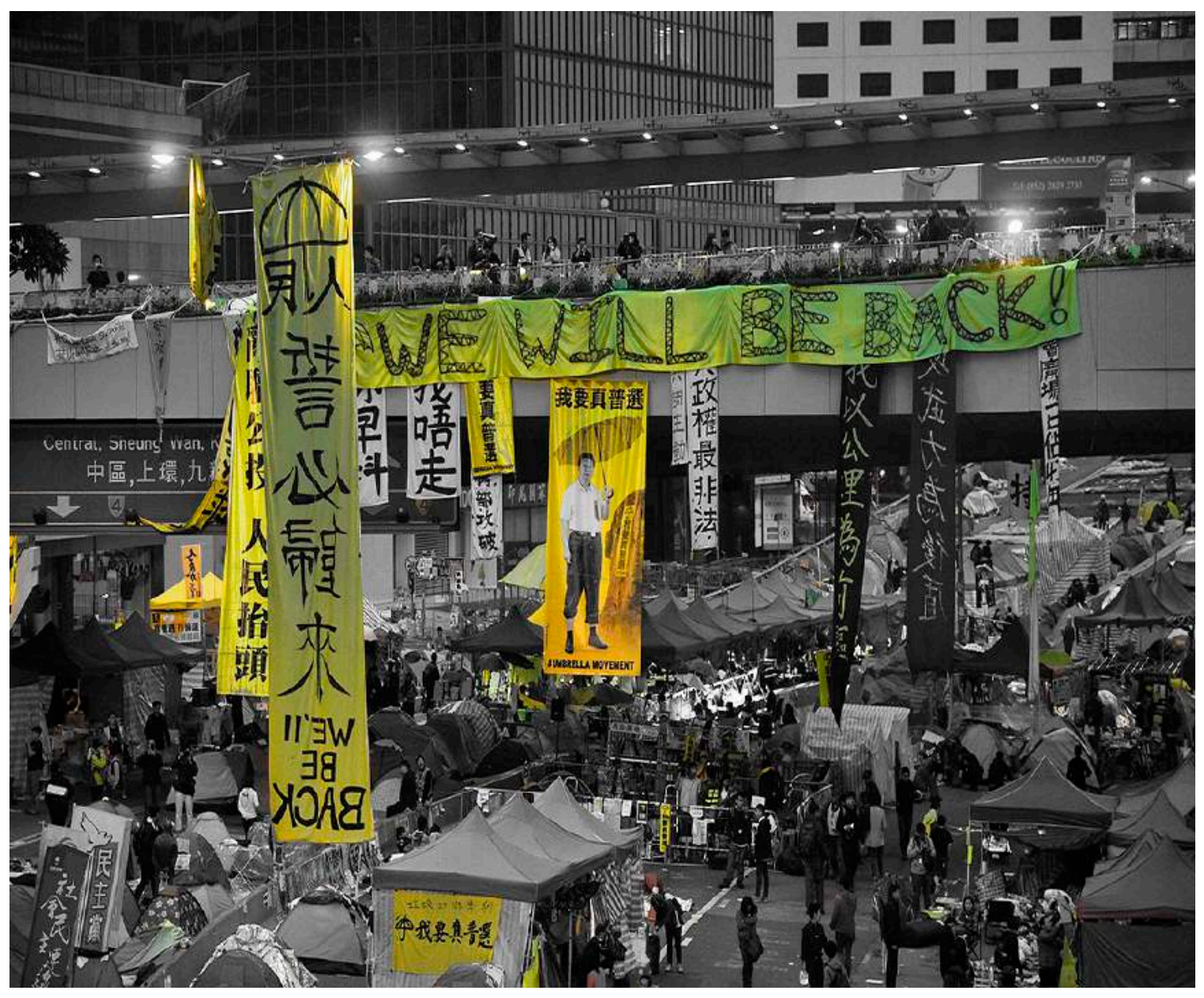




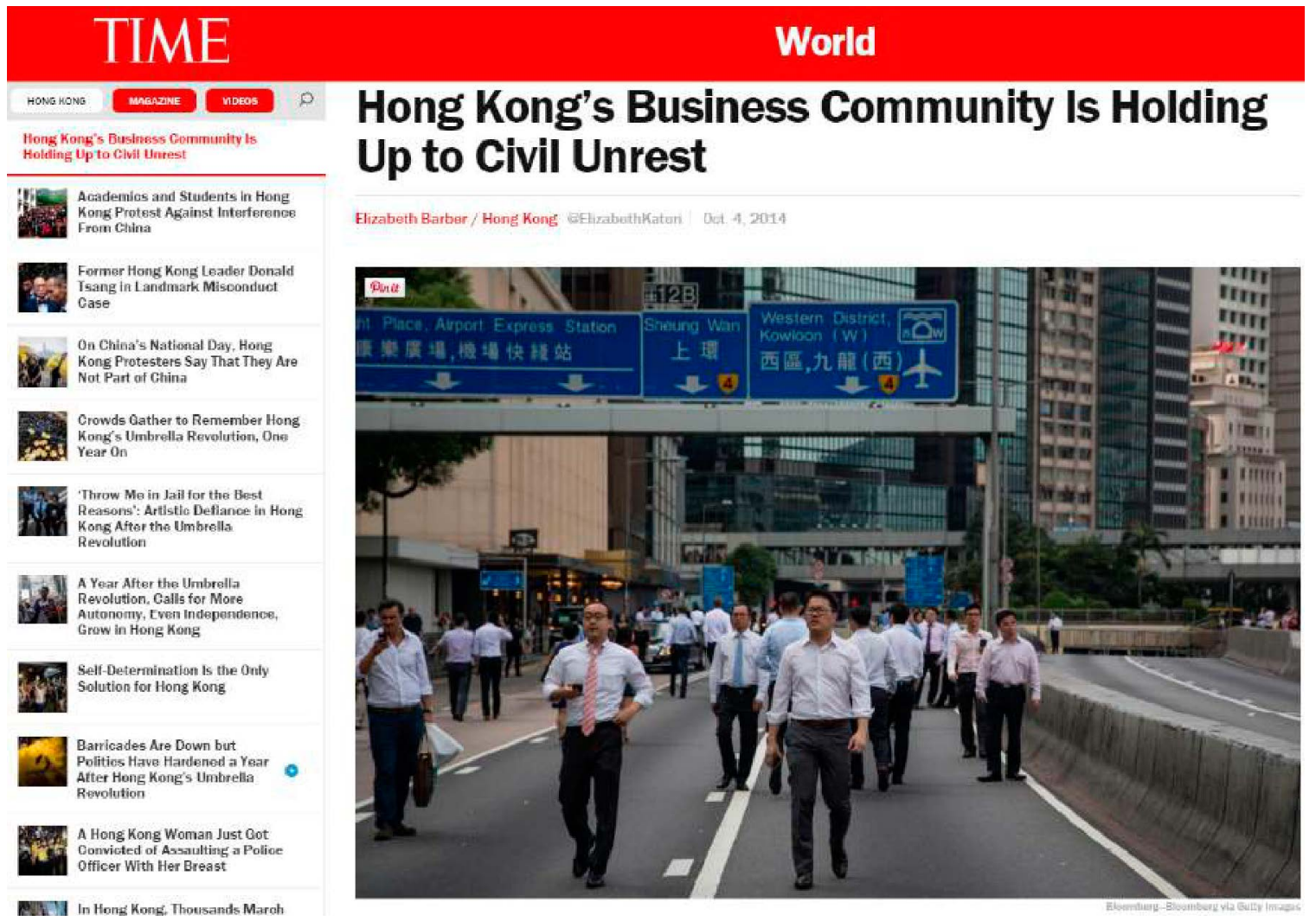




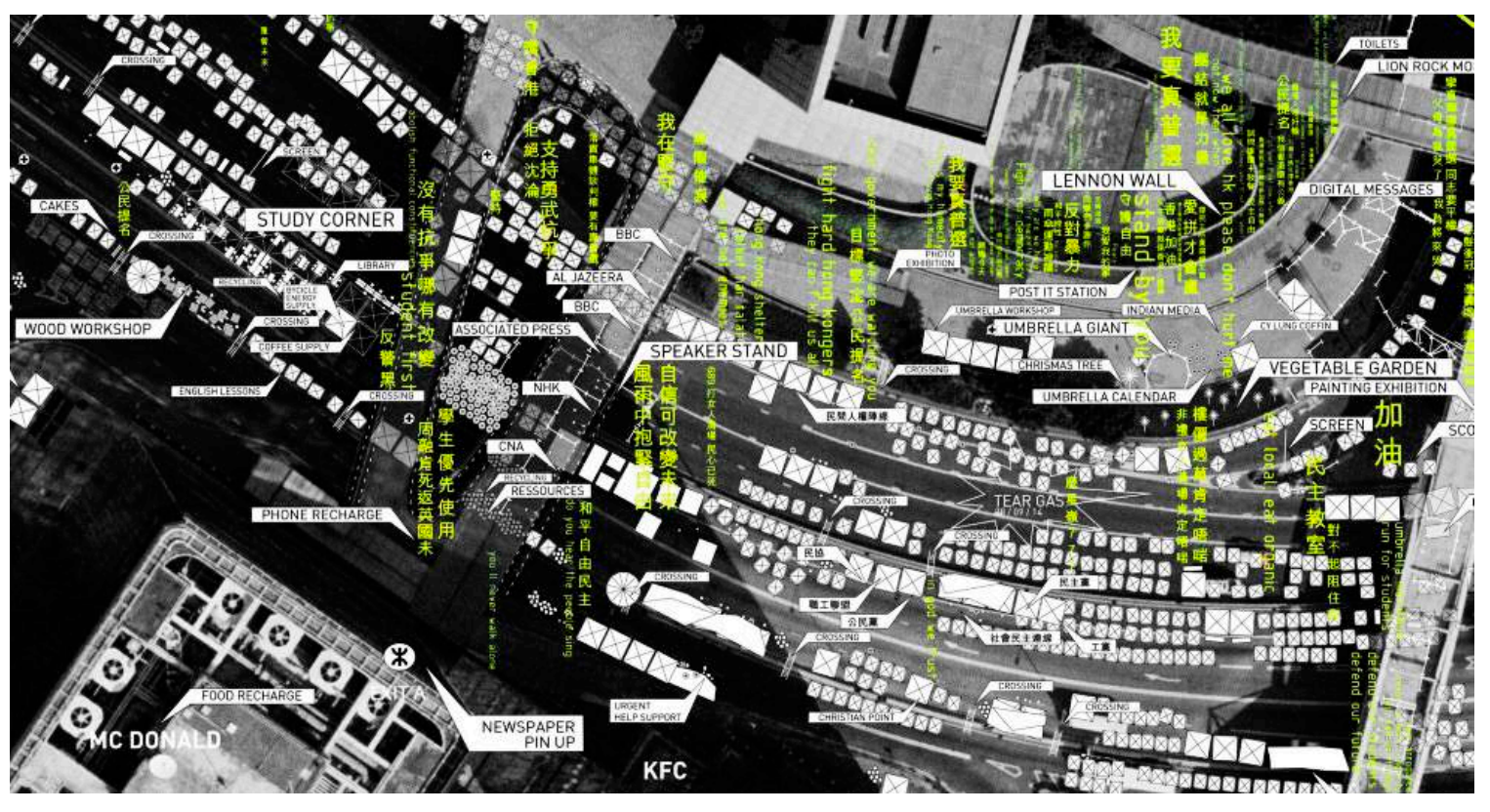


In Hong Kong social power is concentrated in the street, whether during the Umbrella Revolution or any other time. The street, and this includes highway networks and elevated walkways, is double-sided. On one hand city streets exist to facilitate the movement of people and goods to the benefit of the urban economy. On the other hand, residents are capable of using this «capitalist tool». Tsung-Yi Huang writes in Walking between Slums and Skyscrapers:

«the invading power of global capital and its indelible imprints on the urban landscape. [...] such skyscrapers compress space and time according to the various requirements of capital» (interpretation of Lefebvre's words)

Of course, Tsung-Yi Huang's writing is almost partial but the idea becomes a fact: "capitalistic urbanism" does form the city and ensures its successful functioning. On the other hand, the people of the city are capable of using this "capitalist tool" against the economic development by overcrowding networks. The latter become an accessory in favor of protesting and therefore introducing urban disorder. 


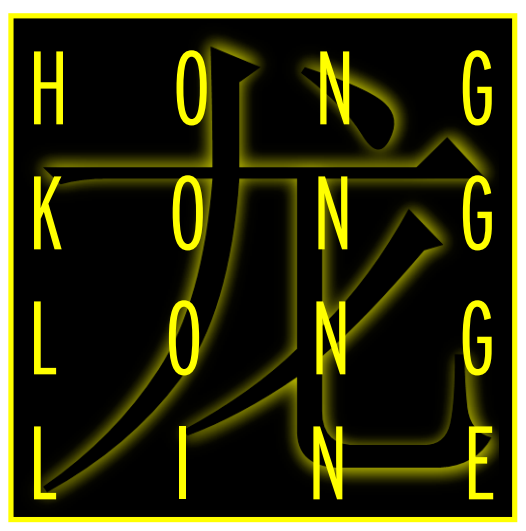




\section{Reviving the City's Façade with the Authentic Hong Kong}

Hong Kong has worked since the 1880s in creating its iconic skyline. Firstly by establishing a harbourfront appropriate for accomodating merchant vessels and later in the 20th century by building, up front, financial towers and grand hotels that are representative of these commercial exchanges and investments at an international level.

However impressive and imposing of an image this panorama reflects, the more of these buildings are constructed the less space there is for the «authentic» Hong Kong which has gradually been pushed further and further into the hillside, hidden behind this forest of glass and steel.

Eventhough this has created an intricate, intriguing and enchanting organisation of the space and especially of the activities that take place in and through these areas, for example these infinite «ladder streets».

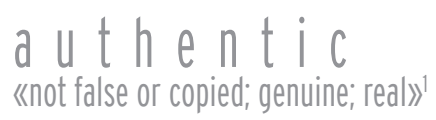

«being what it is claimed to be»²

The modern architecture of Hong Kong, these towers, can be duplicated all along the north land fills, transposed from one point to the other on the perfectly sculpted flat land. However ladder streets and back lanes have adapted to/adopted the original topography, each is unique and cannot be replicated, they are authentic, as are the activities that have appropriated that same space. It is an authentic entity.

figure 32: side alley in Happy Valley, Hong Kong Island, photograph by Zielecki, Chris, 2016 In the same way that this car punctuates its surrounding context with a hint of luxury the Long Line would interrupt Central Business District with a handful of traditional entity. (p41)

\footnotetext{
$1_{\text {definition according to dictionary.com }}$

2 definition according to the Cambridge Dictionary

${ }^{3}$ Christ was researching public staircases and «ladder streets» on the north side of Hong Kong Island: DeWolf, Christopher. «Mapped: Hong Kong.» URBANPHOTO: Cities / People / Place. October 6, 2013. Accessed March 2, 2016. [Online] Available from: http://www.urbanphoto.net/blog/2013/10/06/mapped-hong-kongs-public-steps/.
} 


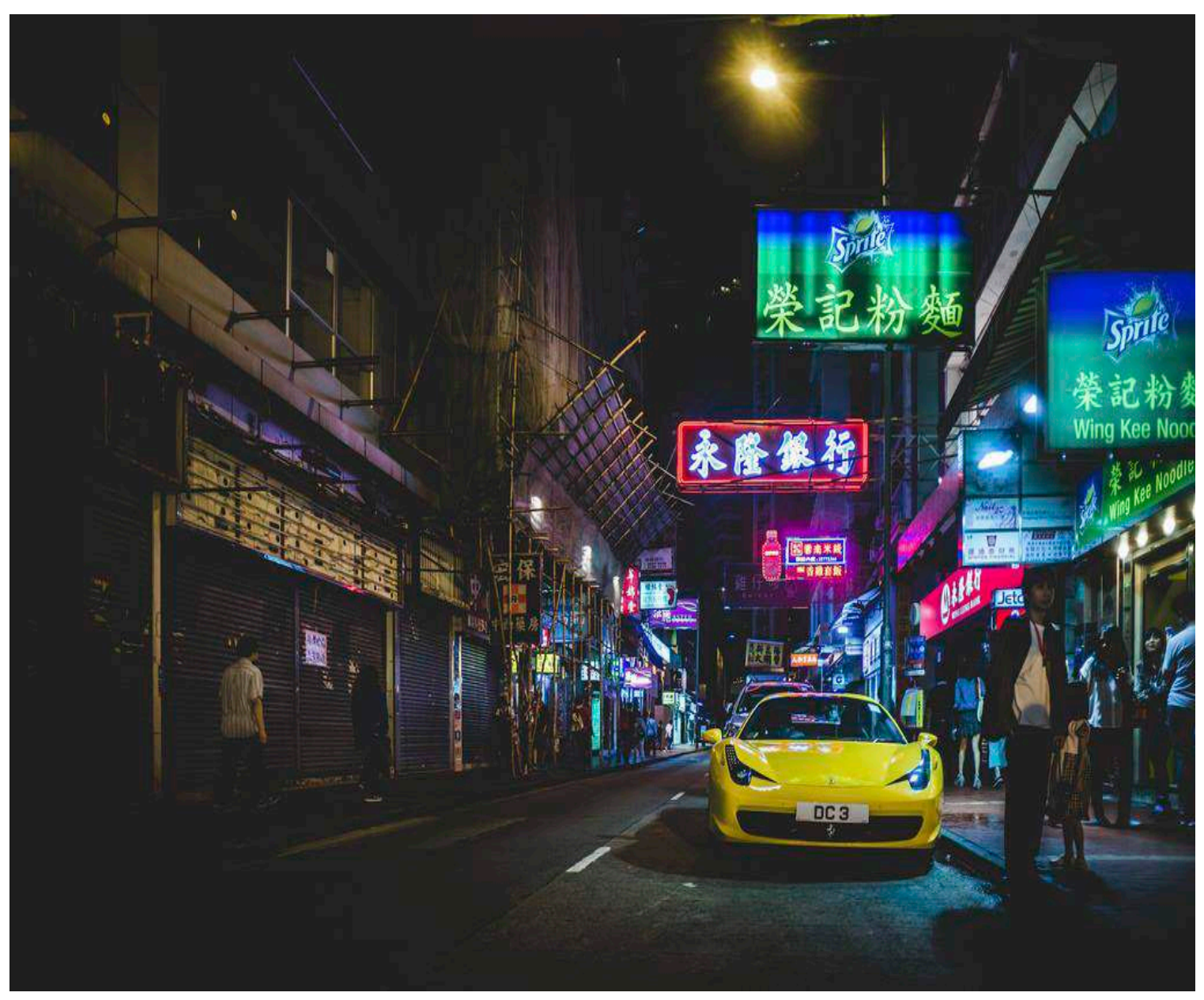


The current façade, which is the first impression of the city one gets if arriving by sea transportation, is only partly reflective of what Hong Kong really is. This project of the Long Line would act as an «injection of authenticity», enhancing the "only remaining signs of Hong Kong as it once existed» as professor Melissa Cate Christ from the University of Hong Kong's architecture school would $\mathrm{say}^{3}$. These steps that constitute ladder streets «preshadow» the towers around them by decades; however these same buildings currently cast a shadow over these primary areas. 


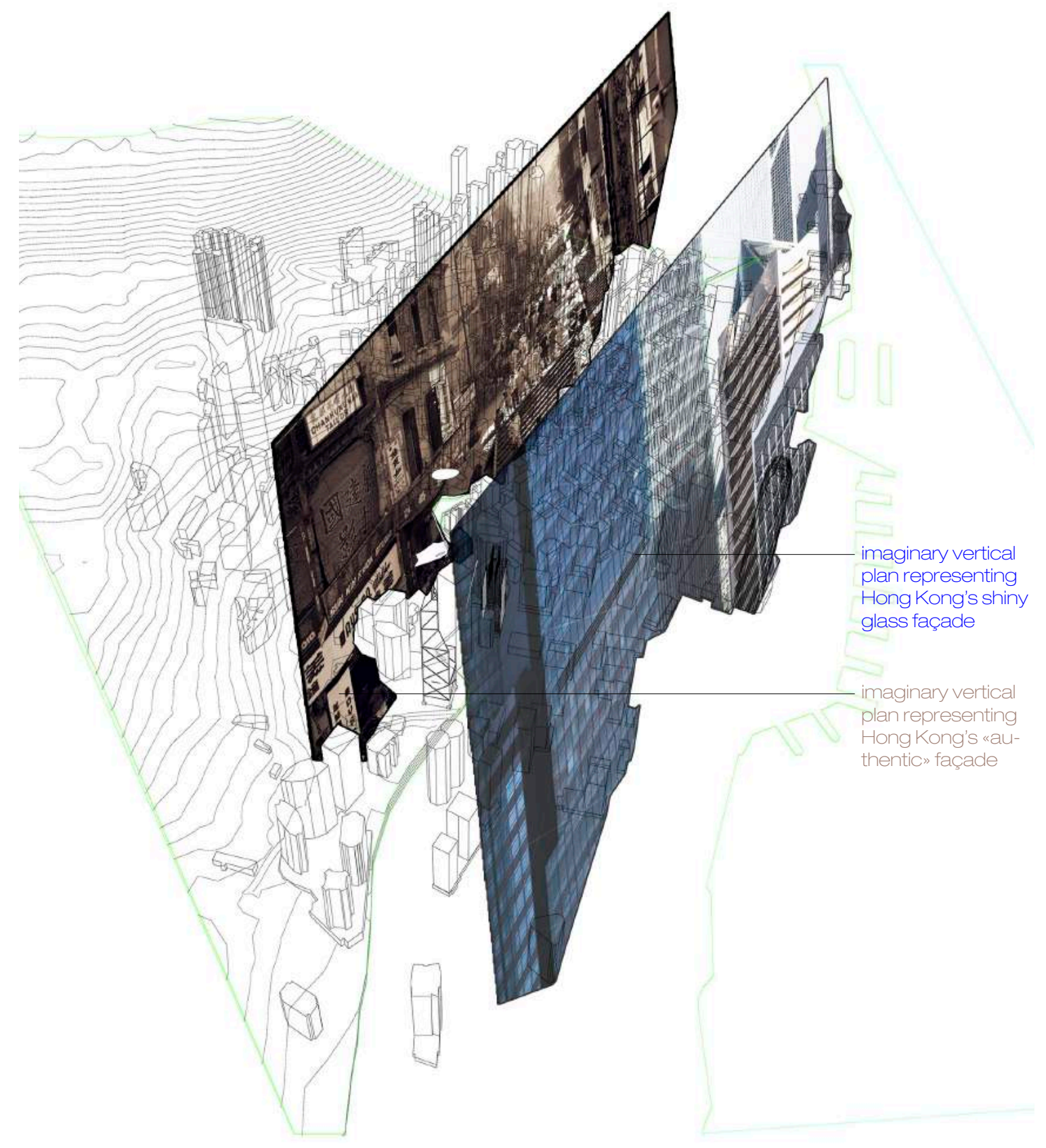




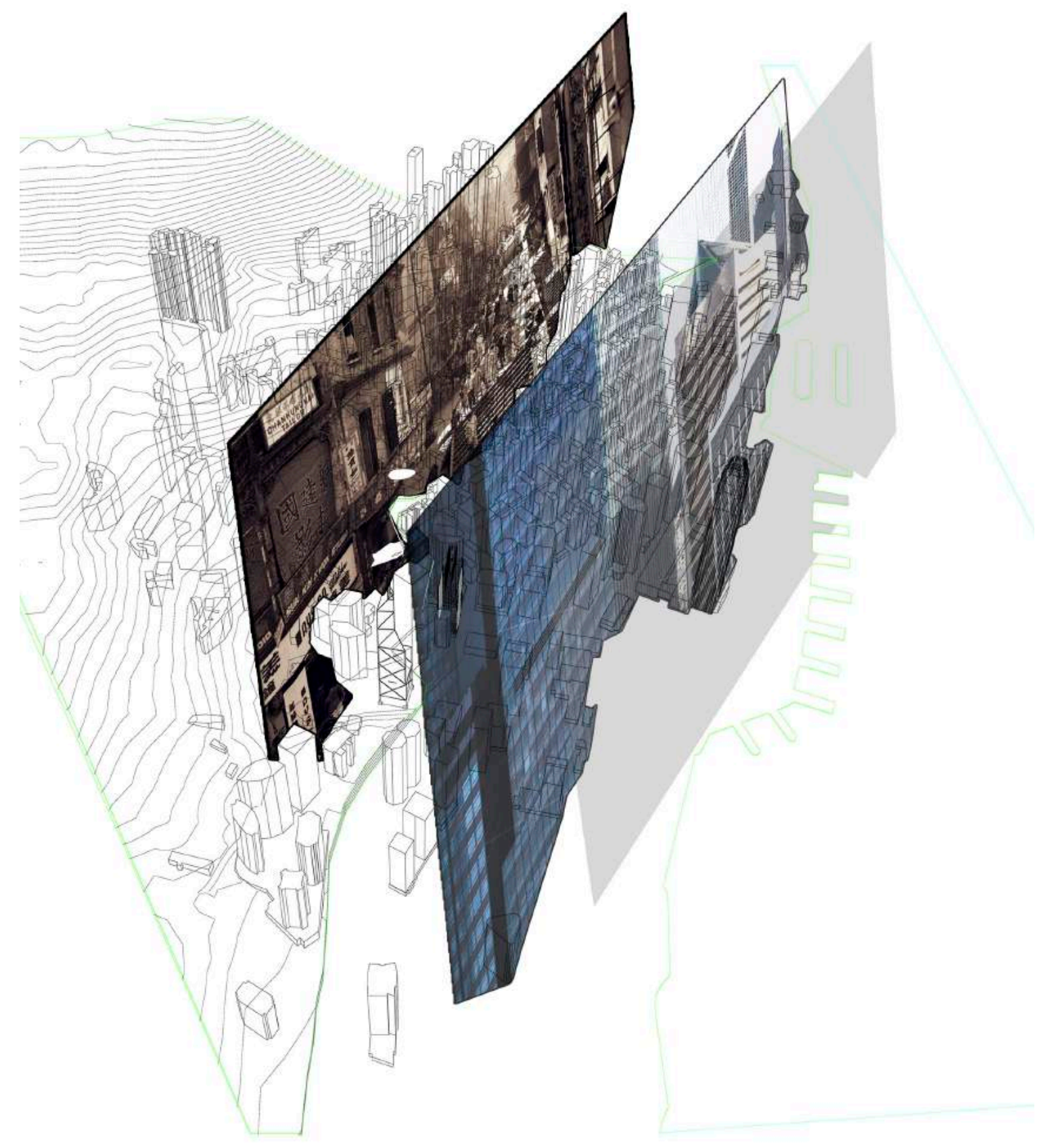




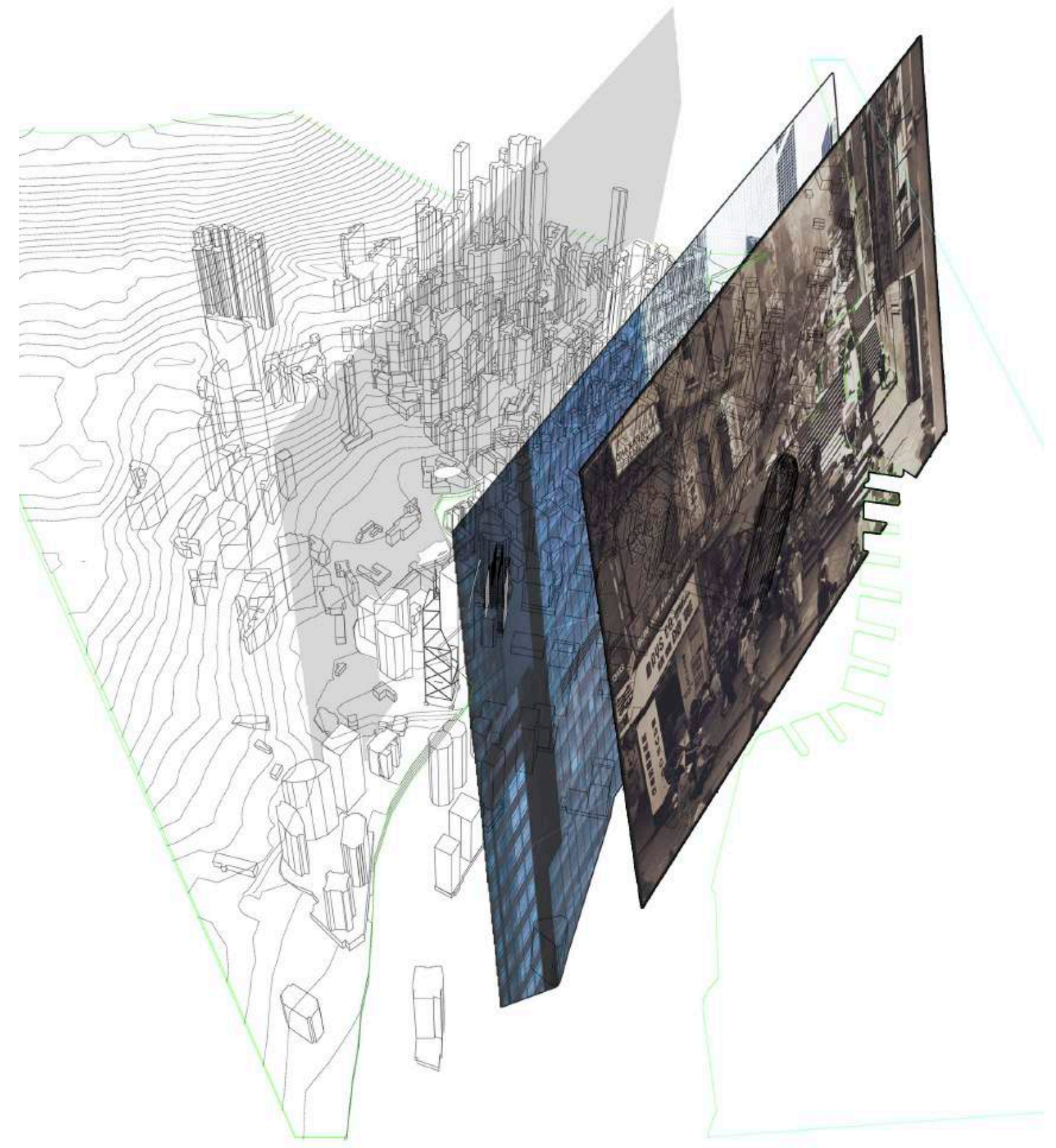




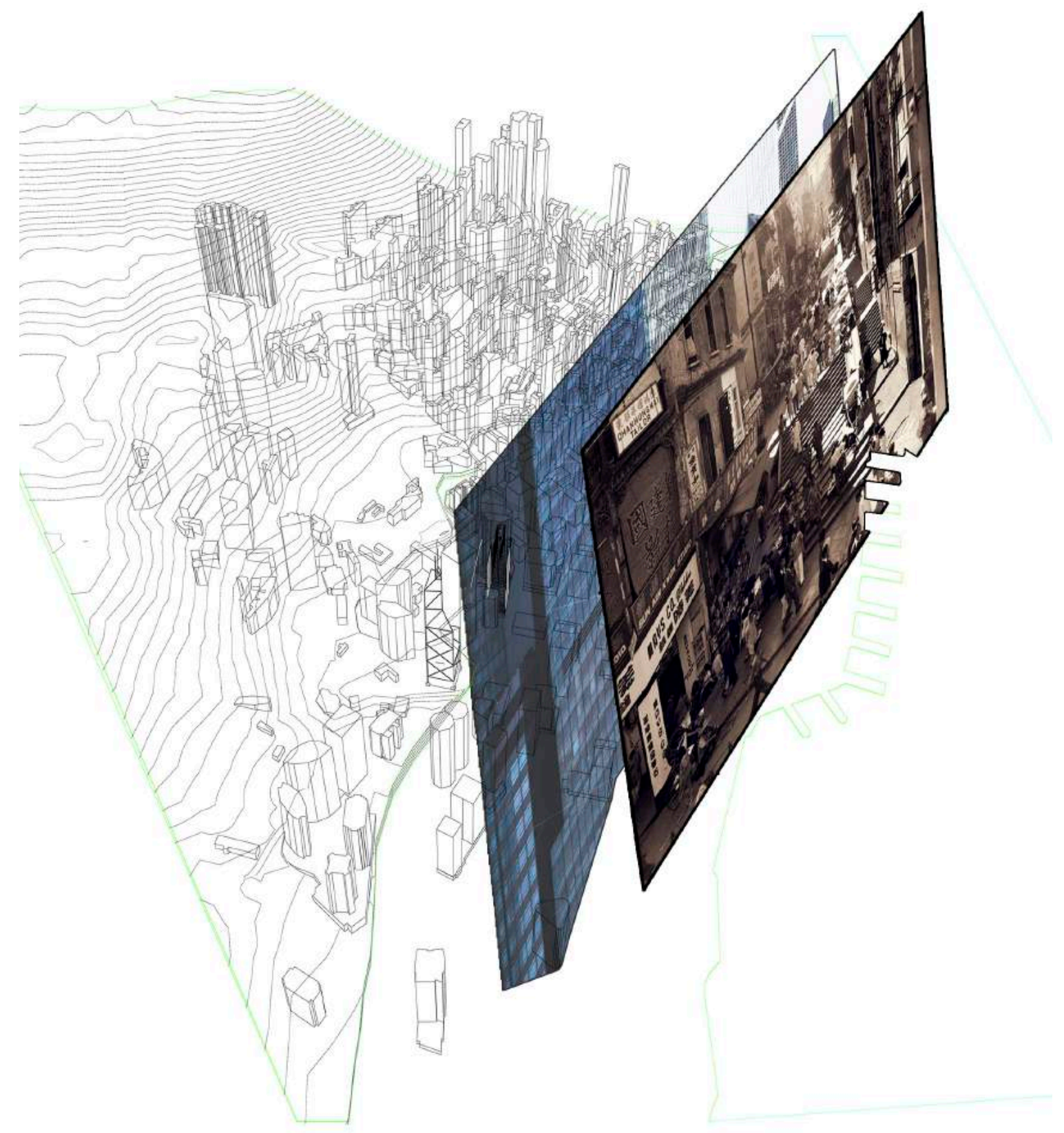


Ladder streets demonstrate Hong Kong's steep topography. They recall Central's original contour lines eventhough a few of these streets have been extended towards the north shore and now encounter flat reclaimed land. The hillside is their point of origin. Origin which the Long Line has for purpose to accentuate/enhance. Granite steps usually facilitate climbing up these paths. Pottinger street, one of the oldest streets of Central, is referred to by locals as Stone Slabs Street which litteraly depicts what these networks are made of.

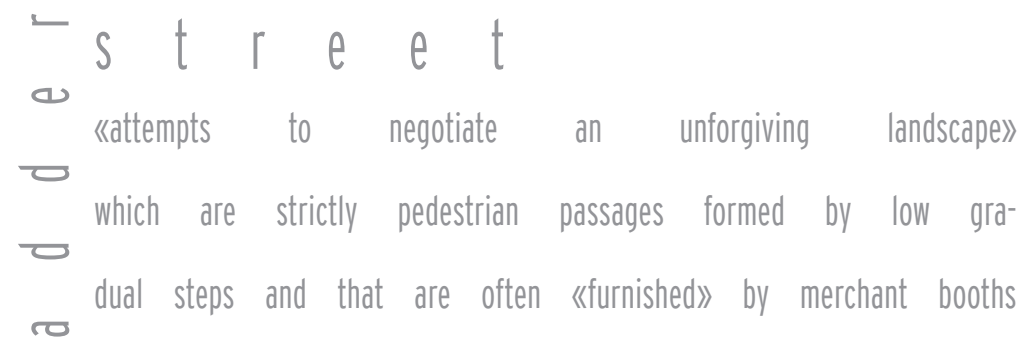




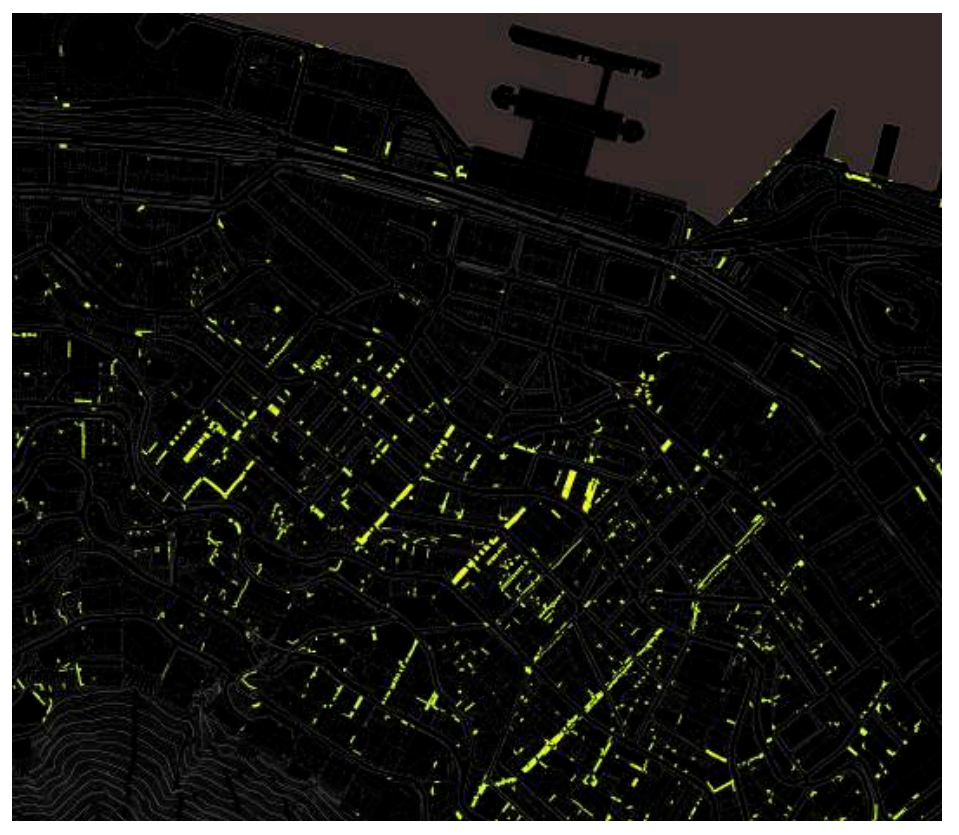




\section{One Bridge, Two Identities: a dual experience through the urban jungle}

In order to bring back to the front these intricate spaces along with the population that occupies them, the Long Line must gather this entity from the district's back lanes, further up into the hill side, and must guide it all the way to the north elevation of the city formed by megastructures and monumental architecture as well as vast voids. Hence, even though being one single line all the way, the path has two opposing identities.

On the hill side, the Long Line struggles, almost, to find void between buildings because of an extremely high density but lower rises. Its only option to get through the architecture at some points is to merge partially with it. It uses it to hoist itself up. The Long Line's width varies with these differences of proximity between skyscrapers but it is constantly in contact with the existing urban fabric.

On the sea side, the Long Line is instantly freer in the sense that it starts to navigate around towers and takes advantage of monumental voids to easily bypass buildings. It is able to choose where to go. Along with these great distances comes necessary infrastructure for which the basis was acquired from the Valmy pedestrian bridge at La Défense in Paris region, designed by architect Dietmar Feichtinger and engineers from Schlaich Bergermann Partner (sbp). In that way, it strategically drills through or passes right by specific nodes to demonstrate a more theoretical concept which follows. 


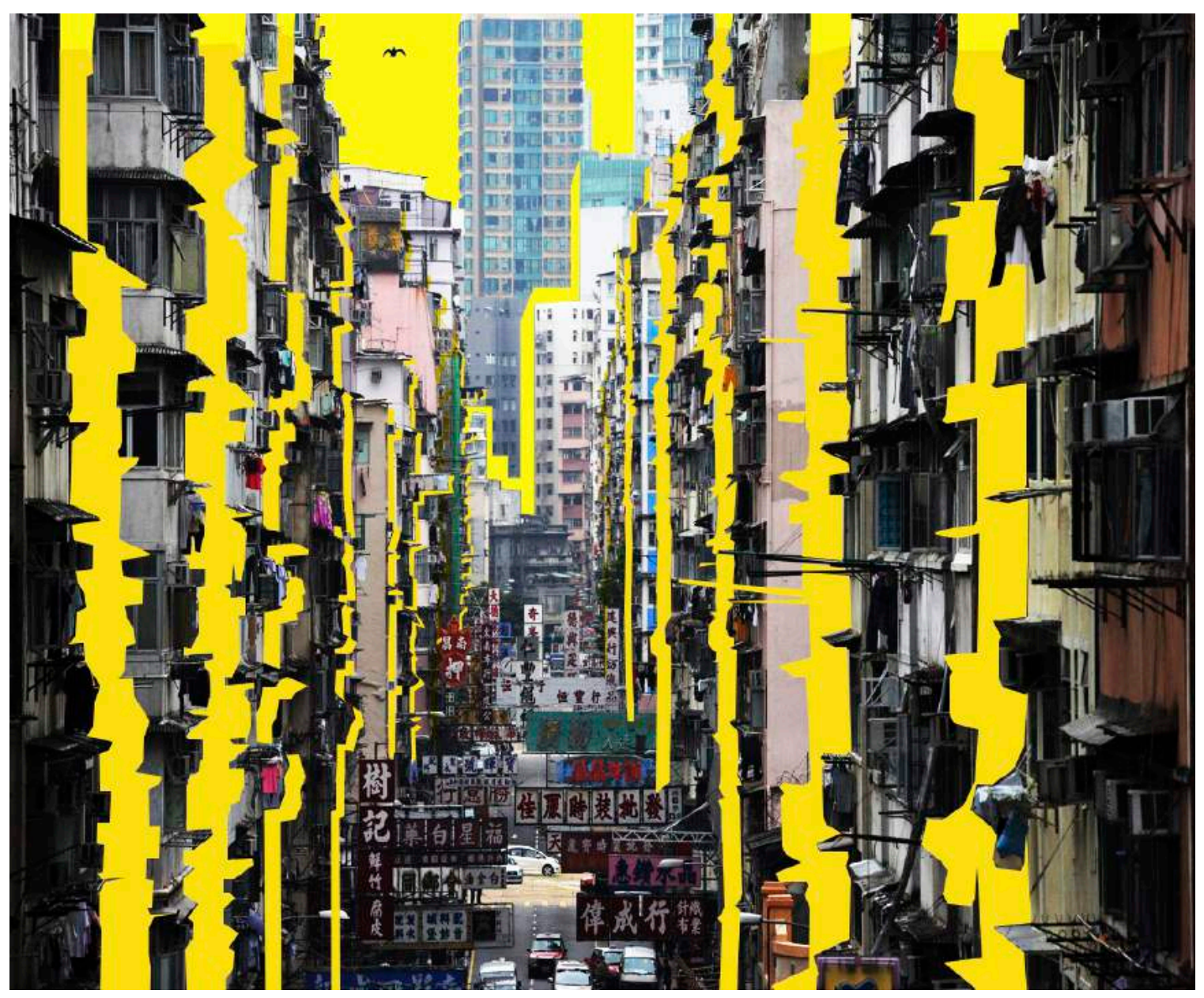




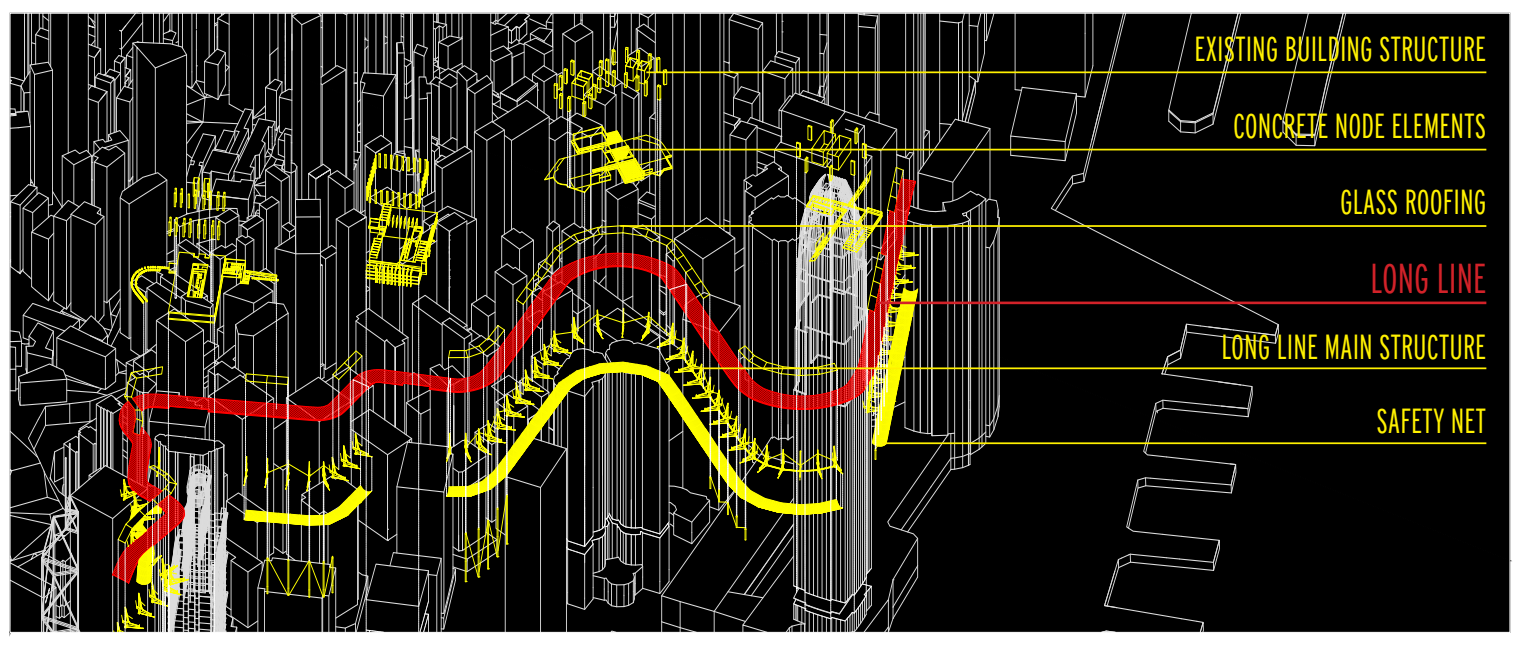




\section{Hong Kong Population: a proposal for all}

What has led Hong Kong to be ranked amongst the first five countries/dependent territories with the highest population density? Who is predominant in the population of Hong Kong today? And how does this proposal contribute to dealing with such an issue: extreme density?

To qualify as «developed,» a country must have gone through the following phases which accomplish a demographic transition:

-phase 1: Predevelopment. High birth and death rates;

-phase 2: Transition. Birth and death rates decline, with

death rates declining more rapidly;

-phase 3: Post-transition stationary population.

Birth and death rates are both at low, stagnating levels.

The massive influx of people into Hong Kong between 1945 and 1950, coupled with the baby boom enabled the city to make these transitions. Demographic transitions induce economic growth (demographic dividend) and Hong Kong benefited from a relatively young population throughout much of the second half of the $20^{\text {th }}$ century. Statistics indicate, however, that Hong Kong's population will decrease as of the middle of this century. With a negative average annual growth rate the only sector of the population that is expected to grow is those 65 years and older. Elderly dependency ratios will increase from 198 to 567.

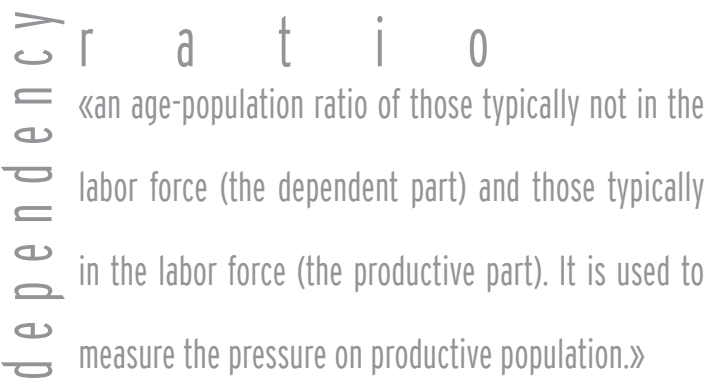




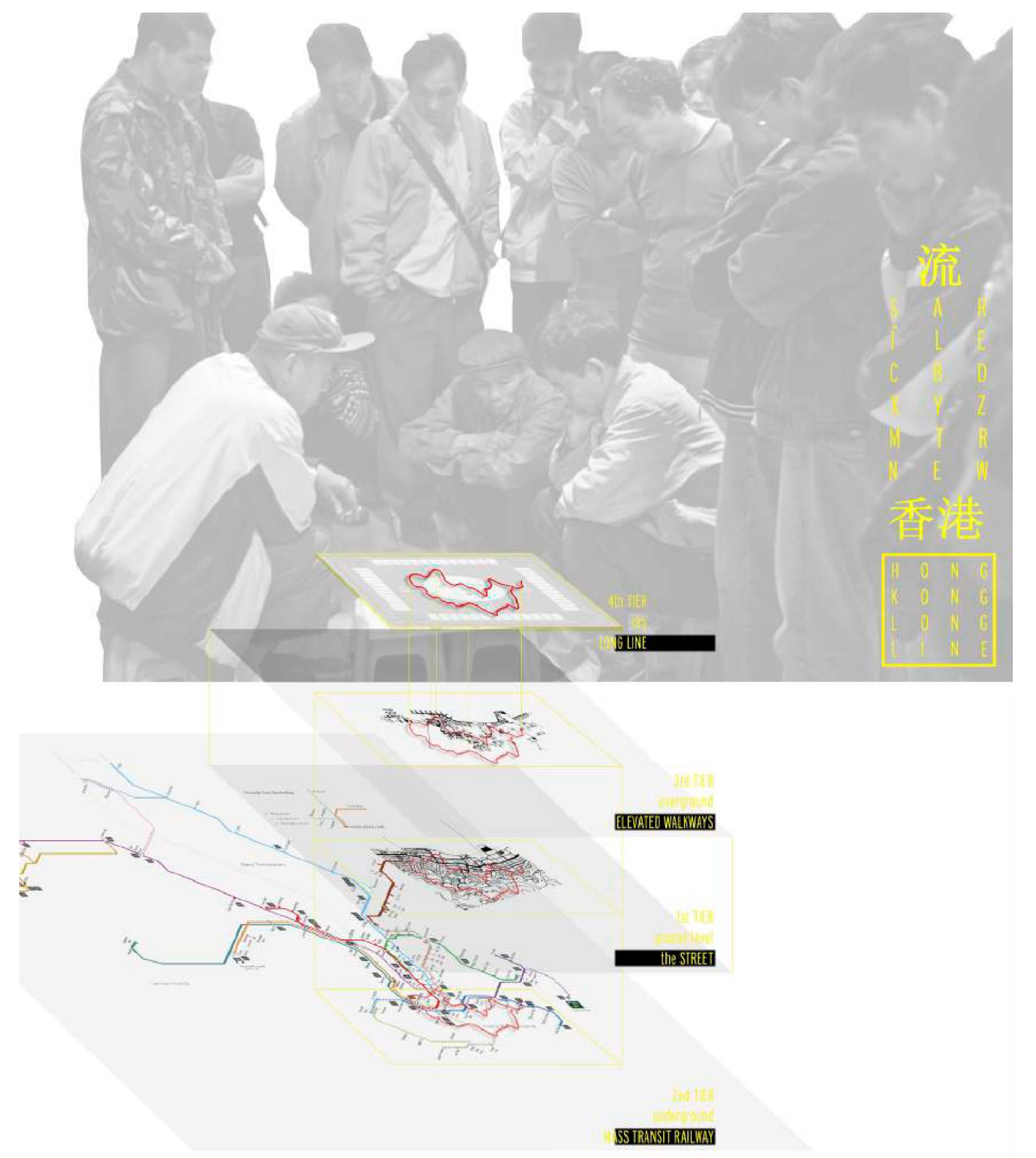


Hong Kong is ranked number eleven among the best countries in the world in which to conduct business $^{1}$ (note that Hong Kong is listed as a country). By the 1990s Hong Kong was one of a group of newly industrialized countries in Asia known as the Asian Tigers (along with Singapore, Taiwan and South Korea), while only twenty years earlier it was still considered to be a Third World country. Today it ranks among the world's most highly developed economies with an unemployment rate of only 3.1\%. Like Singapore, the almostcity-state relies on foreign investment and import/export policy. The downside of an open economy, however, is exposure to global economic crises, such as the one in 2008.

To a large degree Hong Kong's success is a function of its preparedness. Early on the city laid the groundwork to attract and accommodate this commerce (factories, roads and universities). It also benefitted from an excellent natural harbor. Hong Kong is now ranked 4th among the best (and largest) ports in the world (especially with respect to container shipping).

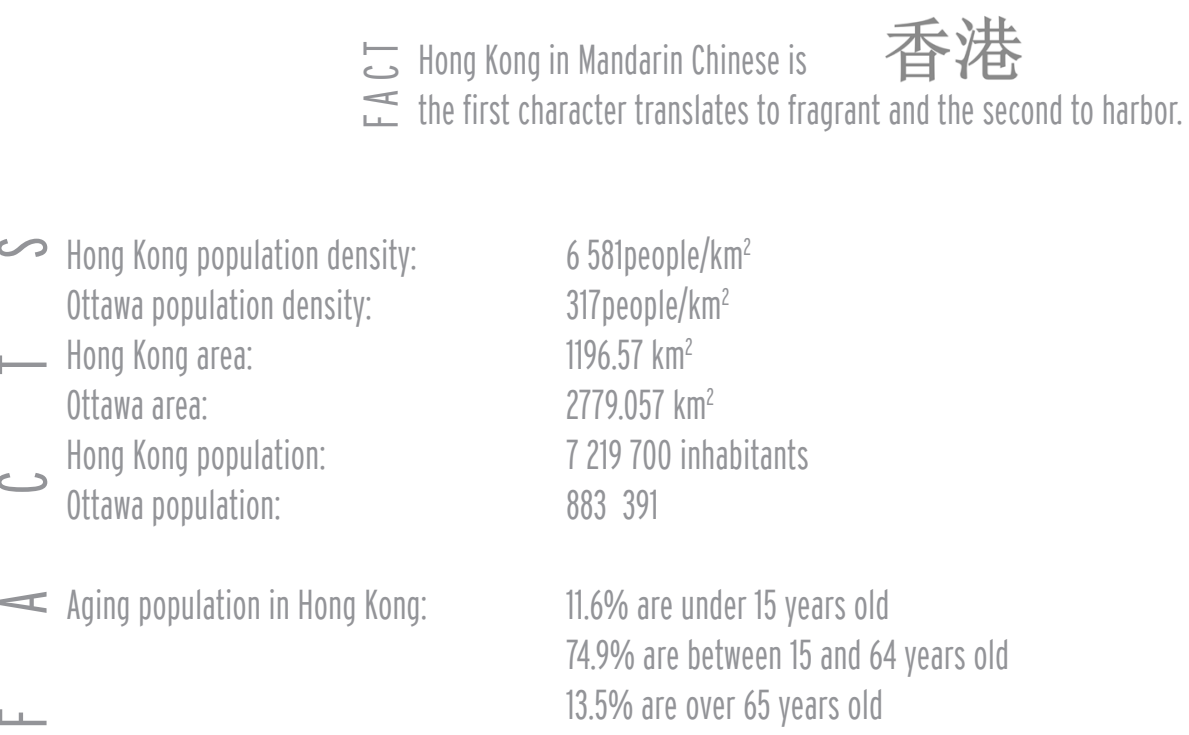

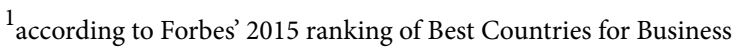


The city's location, coupled with a systematic investment in infrastructure, enabled Hong Kong to become a gateway to Asia -competing against Singapore to the south and (more recently) with Shanghai to the north. Where there is shipping there is also frequently banking. Greatly helped by its connection to Great Britain, Hong Kong established itself as a key financial center in Asia. The city's central district (Central) is occupied primarily by banks and financial institutions, most of which in towers. In and among them are; upscale hotels catering to those who come to the city to do business. Approaching the city from across the harbor, one is "welcomed" by a battalion of gleaming high-rises, which the coastline has been extended and "sculpted" for.

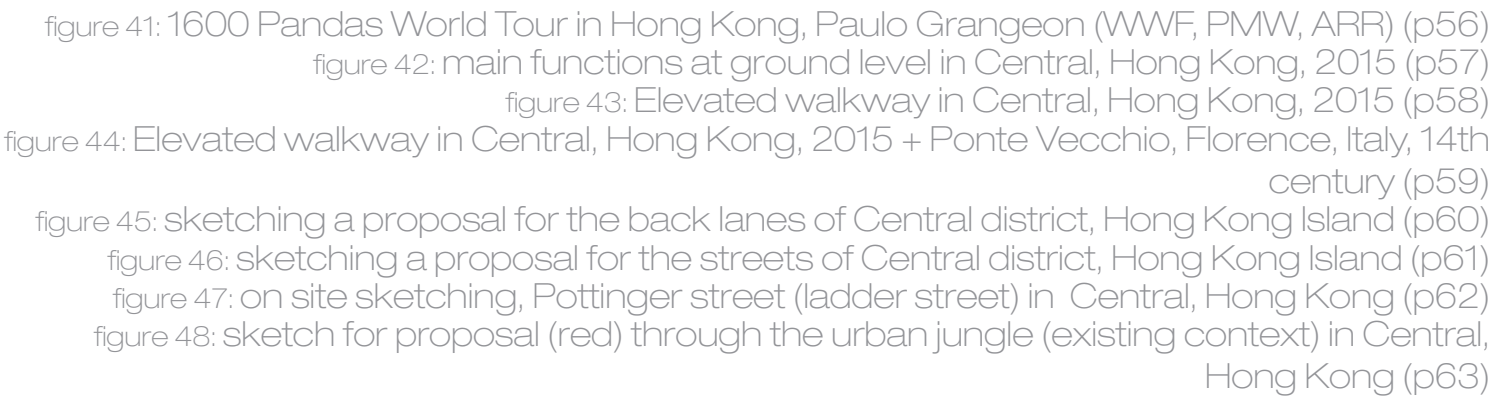




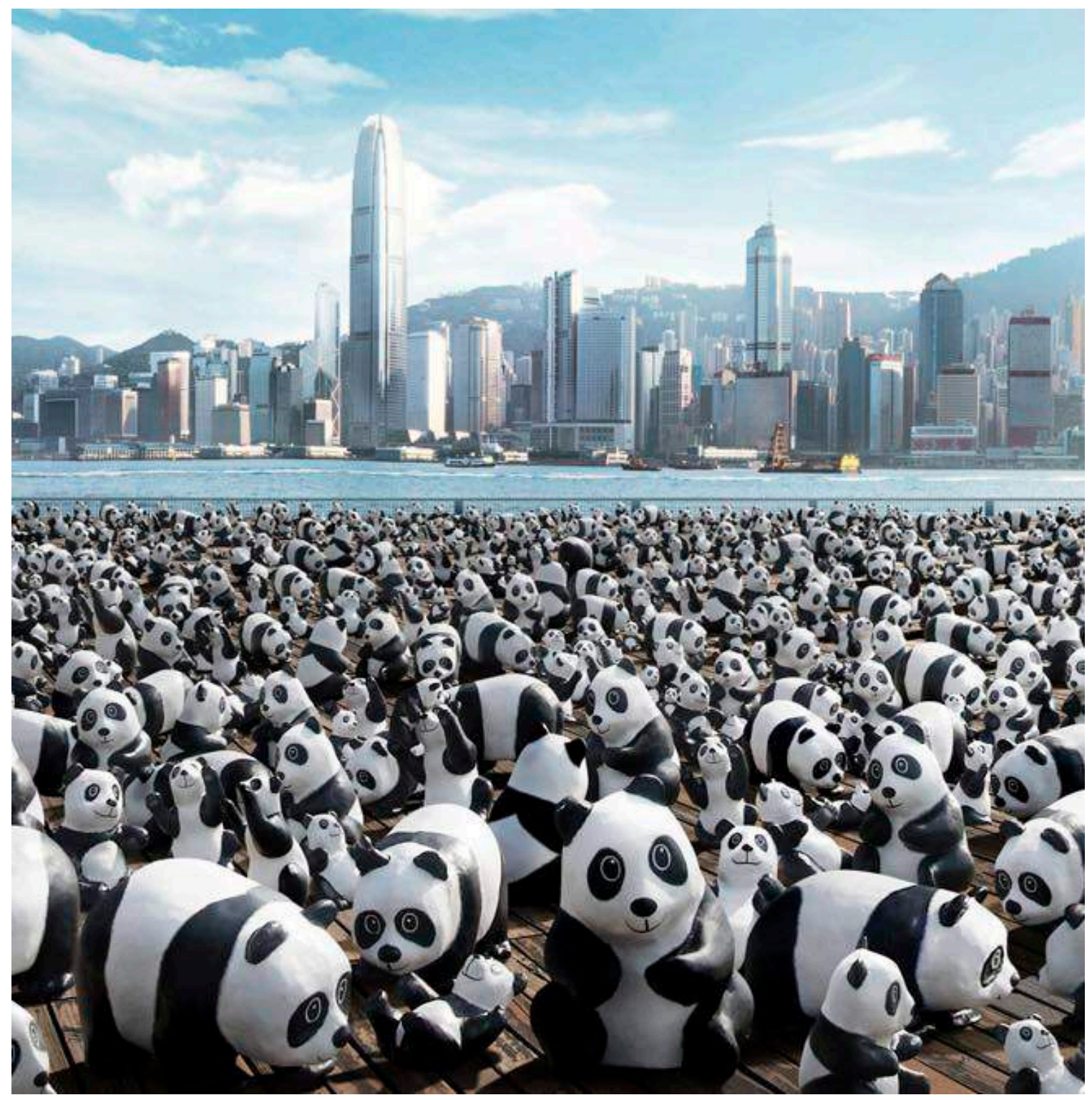




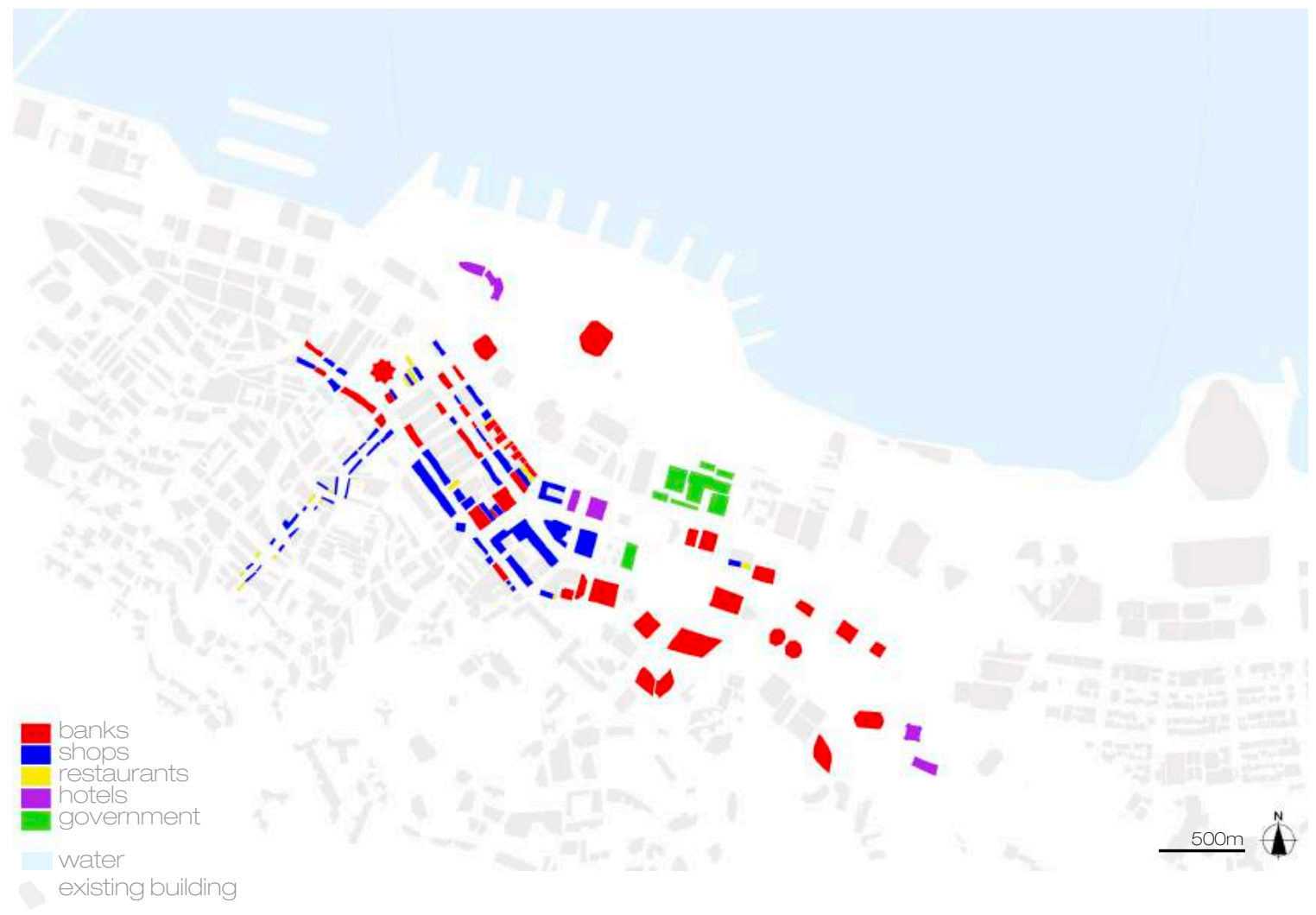




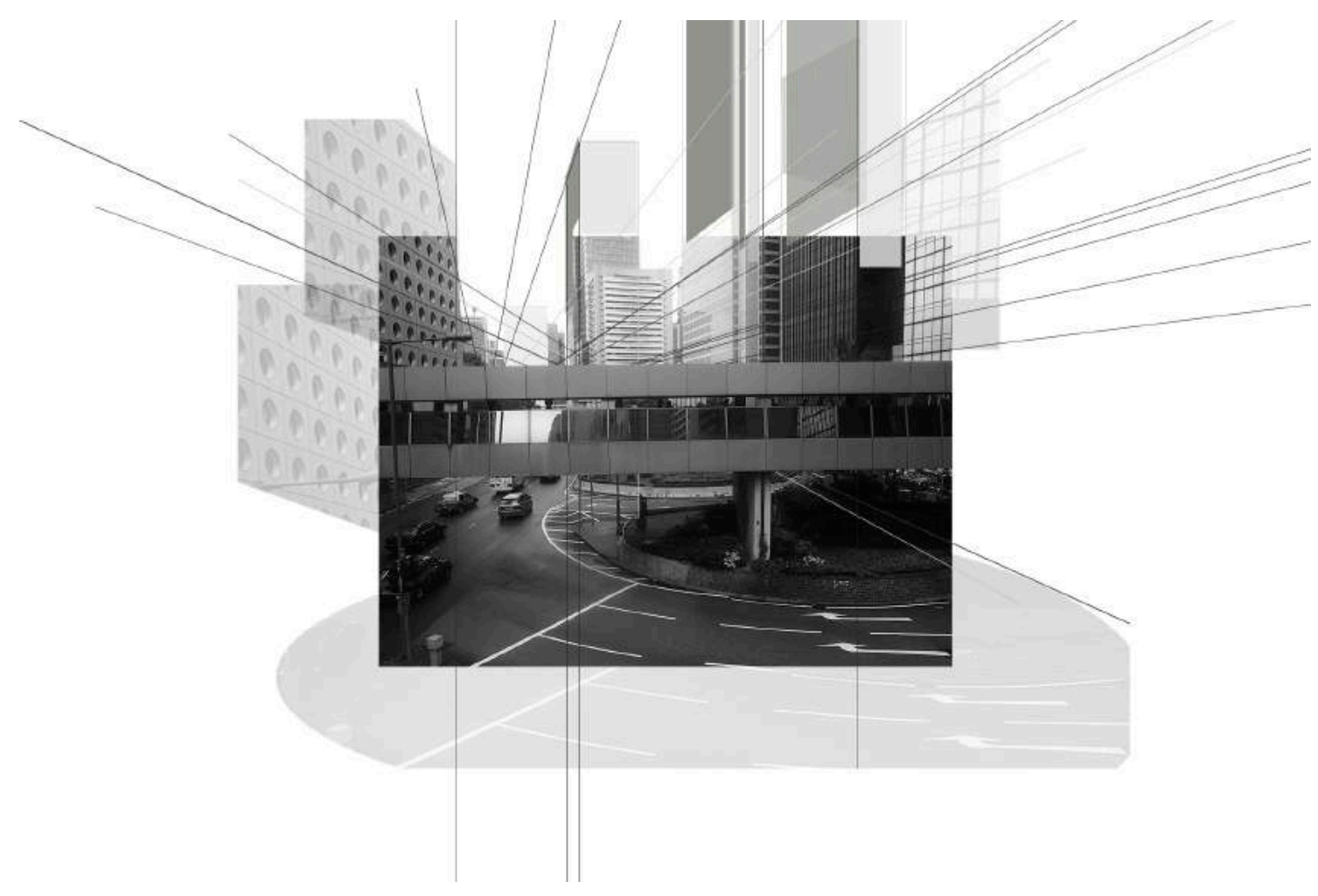




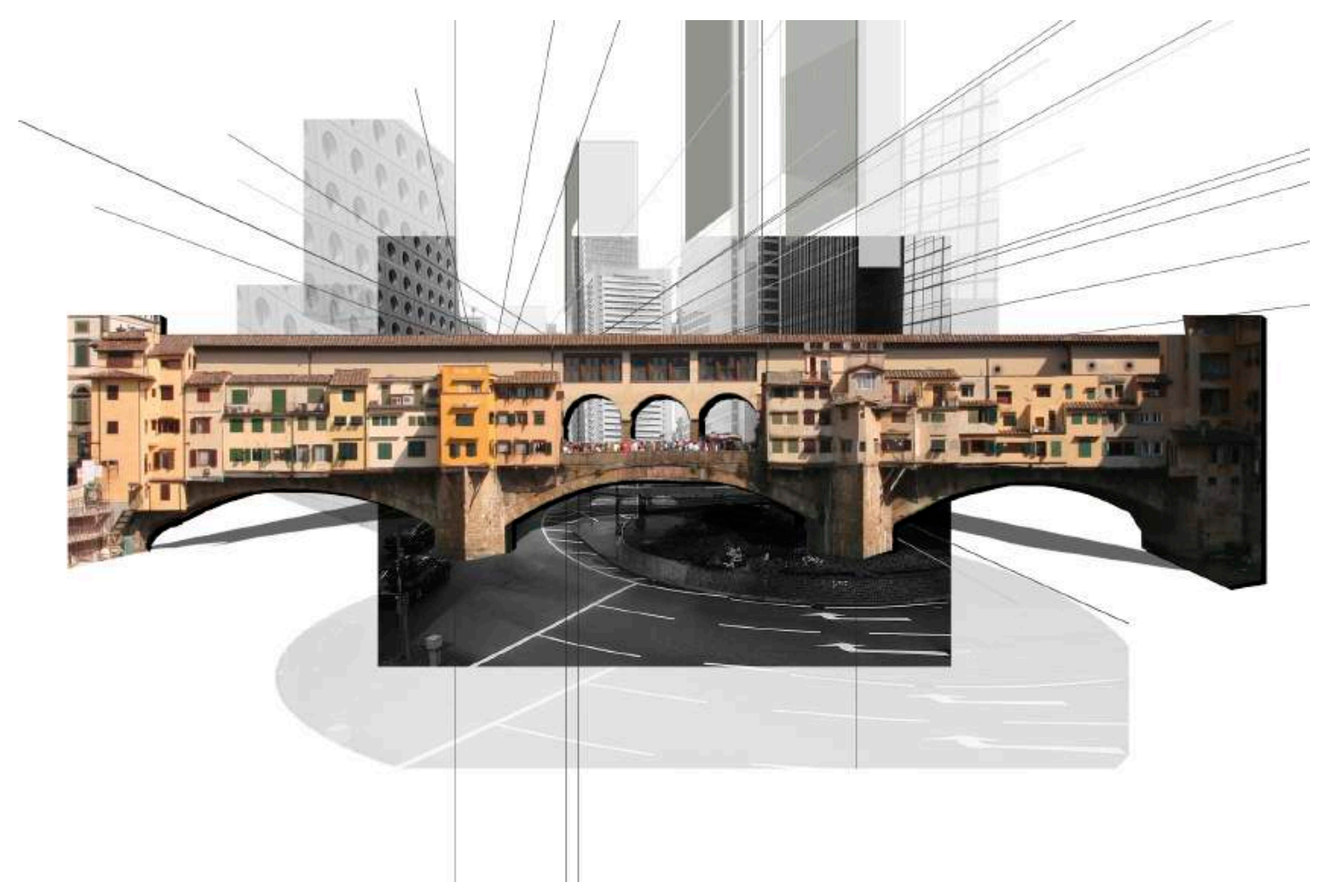




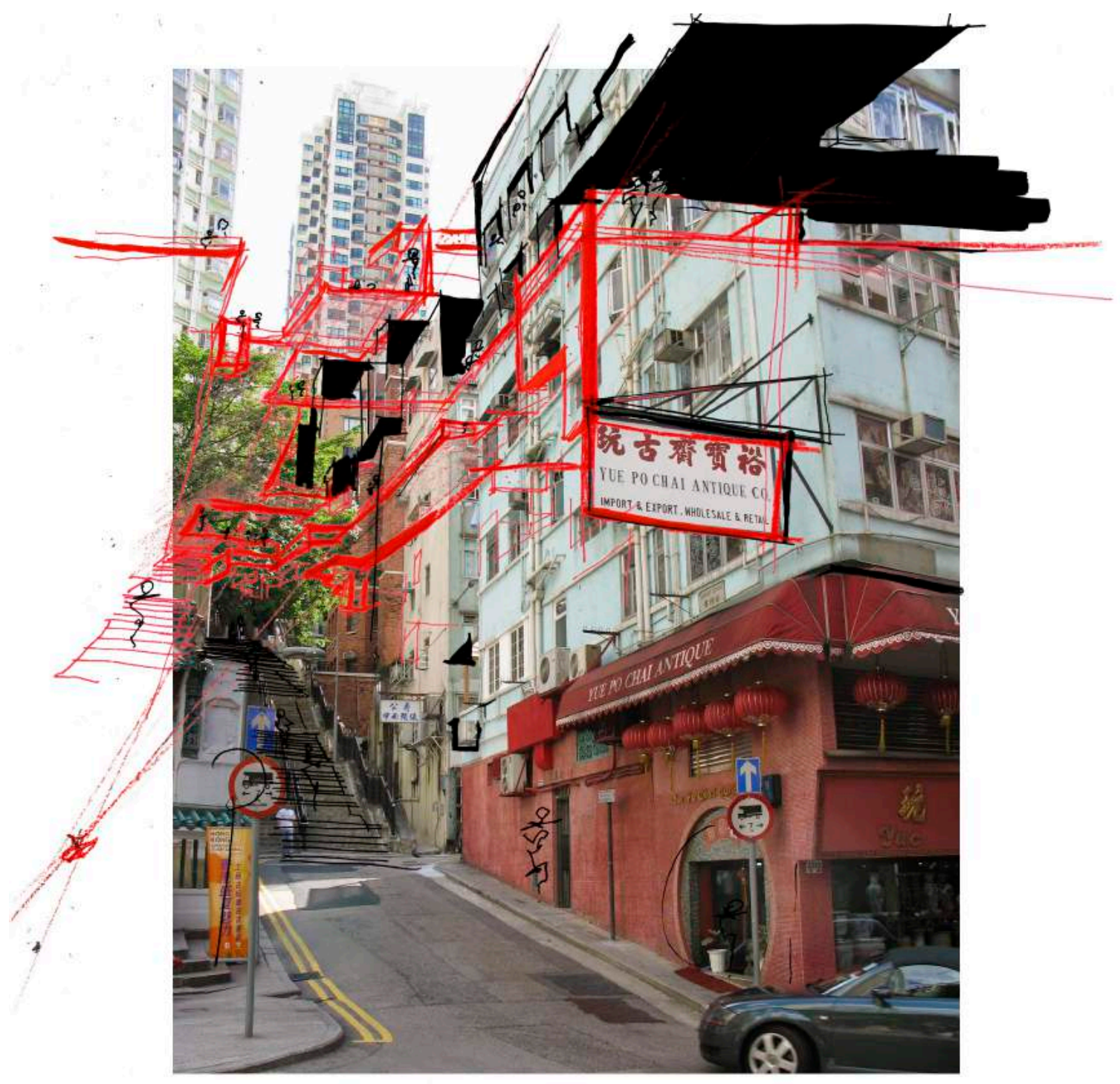




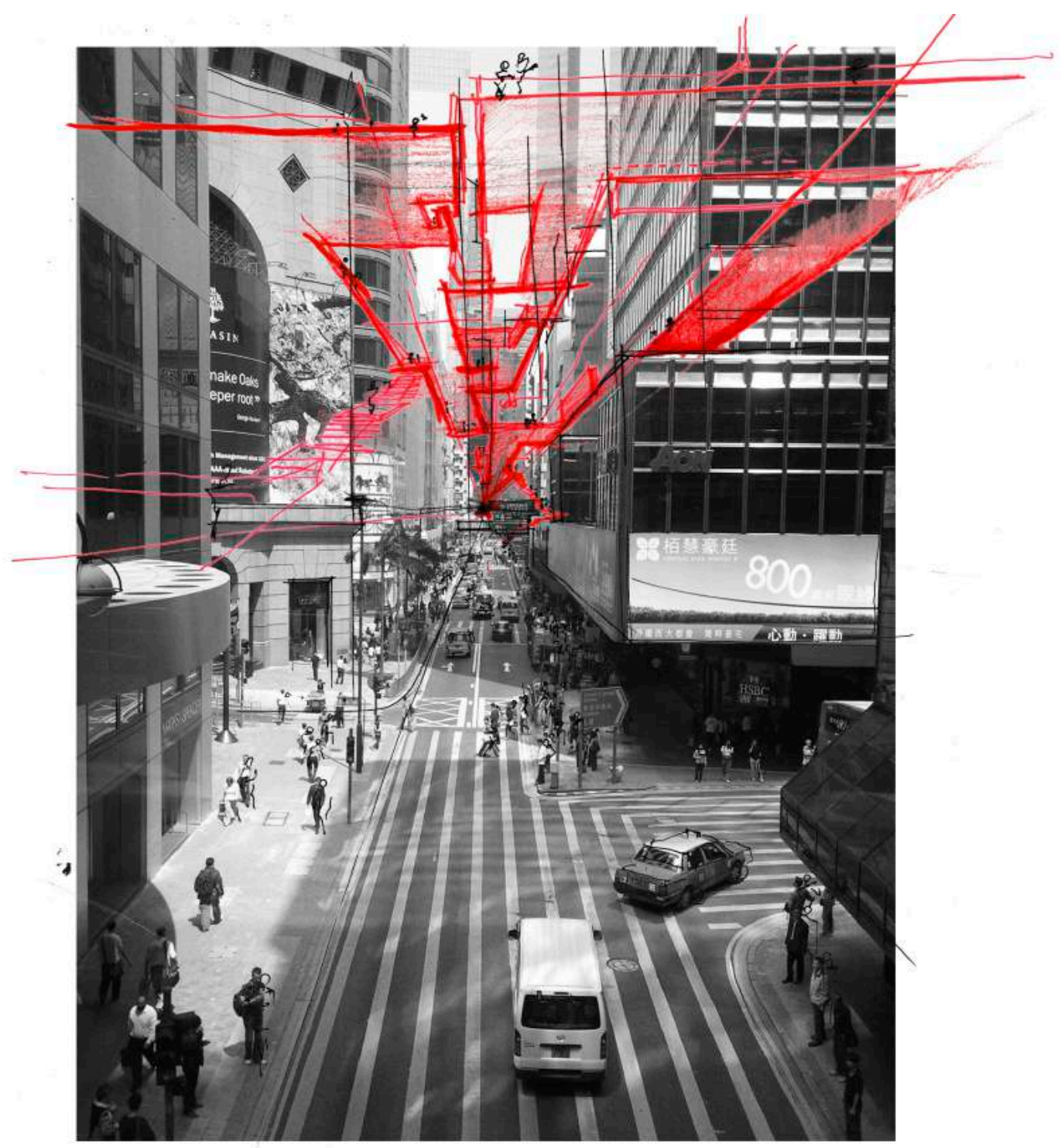




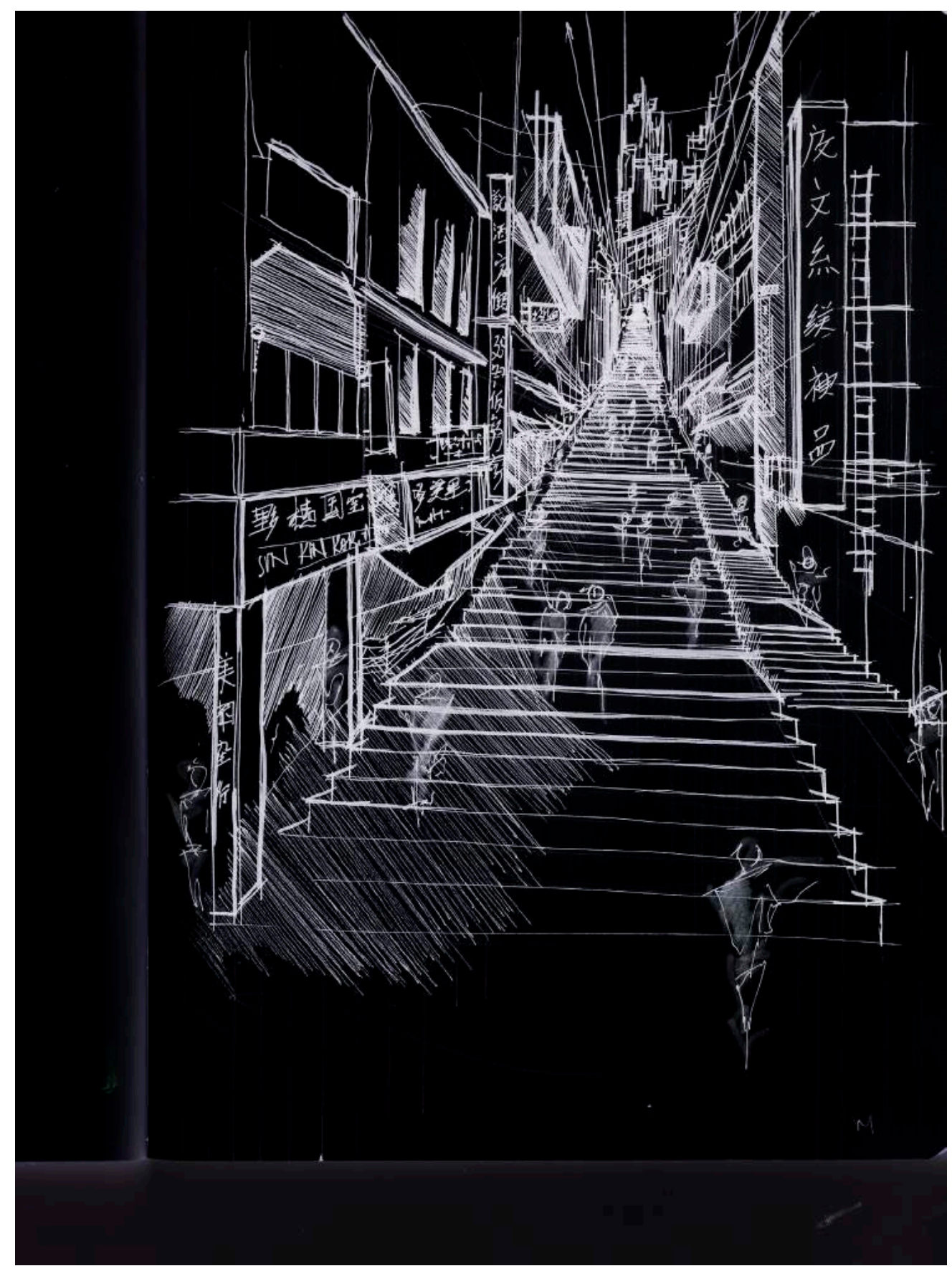




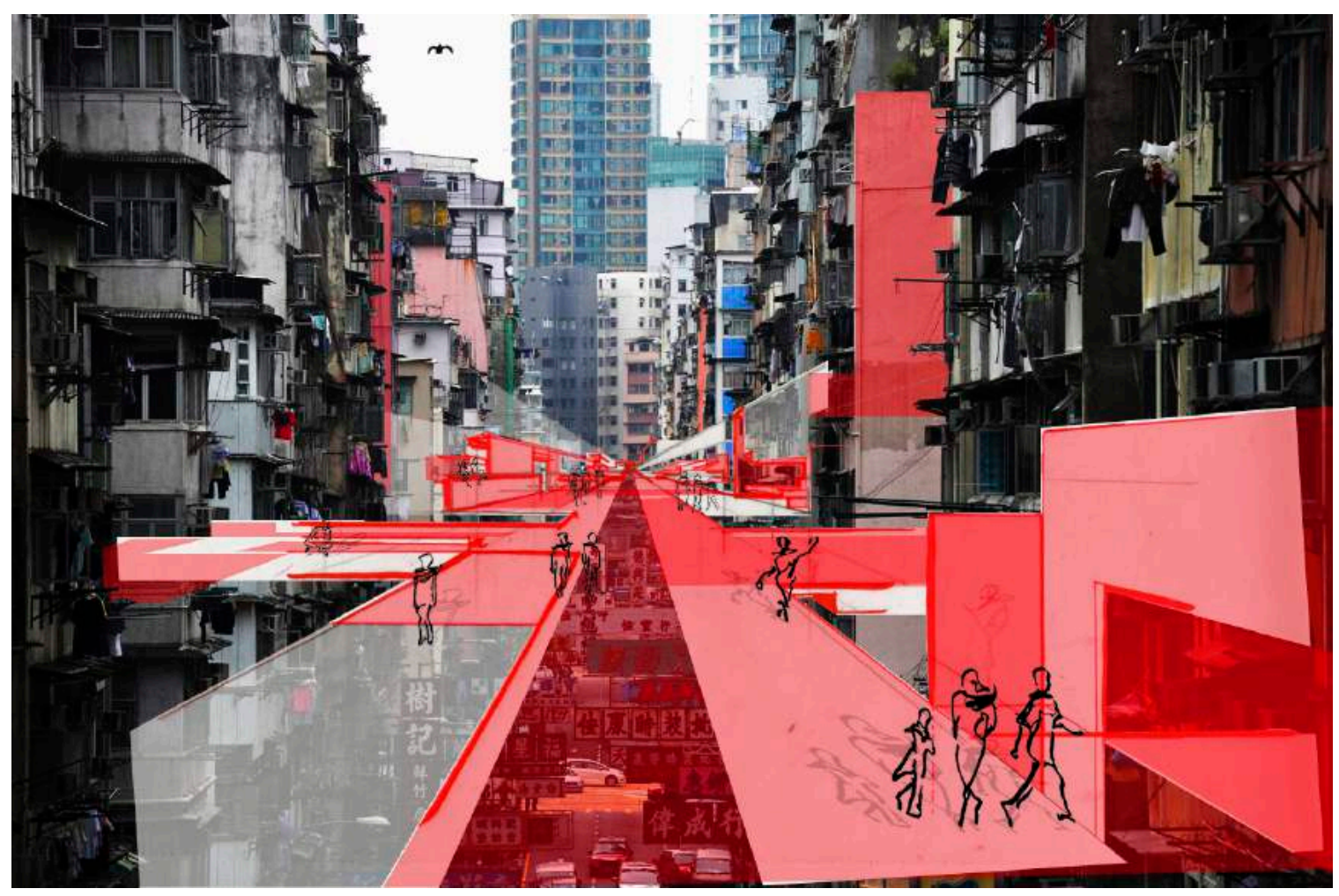


On the slopes behind these towers, however, the fabric reverts to a tangle of older, more traditional streets including the city's famous «ladder» streets. This is where the more "down to earth" and predominant in number, population resides. Outdoor markets fill the narrow streets which are furnished by «booths» and are too tight to accommodate cars. Buddhist temples appear at various street corners. Nightlife gurgles out from this district, home to Lan Kwai Fong.

Among its many aspirations, the Long Line presents an opportunity to weave together different, complementary and contradictory aspects of Hong Kong, stitching together the city's "back of house" with its façade of gleaming towers. Crossovers are already occurring inasmuch as foreign migrant workers occupy elevated walkways and lobbies of office towers in the central business district, as do elderly residents playing Mah-jong or practicing Tai-qi. The use of Central's skyways by a diverse cross section of the city's inhabitants, however, is problematic to the extent that they were designed primarily (exclusively?) for circulation. At most times they are crowded with businessmen and women hurrying between buildings.

In addition to circulation, then, there is a strong social agenda to my proposal for the Long Line. Not only will it carry out primary concepts which Le Corbusier or Hilberseimmer described almost a century ago; it will be designed both to enable and encourage users to discover the urban jungle that is Hong Kong's northern shore; nodes at key points along the elevated path will accommodate a diverse range of functions to finally shelter, in a formal way, previously stated activities that currently occur spontaneously on the third tier which are the existing elevated walkways. These include communal areas for foreign migrant workers to relax on their days off, temporary quarters for workers who are between jobs, nurseries at the "foot" of a tower for working parents to drop off their children, spots

\footnotetext{
${ }^{1}$ from Gutierrez, Laurent, Valérie Portefaix, and Laura Ruggeri. HK Lab 2: An Exploration of Hong Kong Interior Spaces. Sheung Wan: Map Book Publishers, 2005.
} 


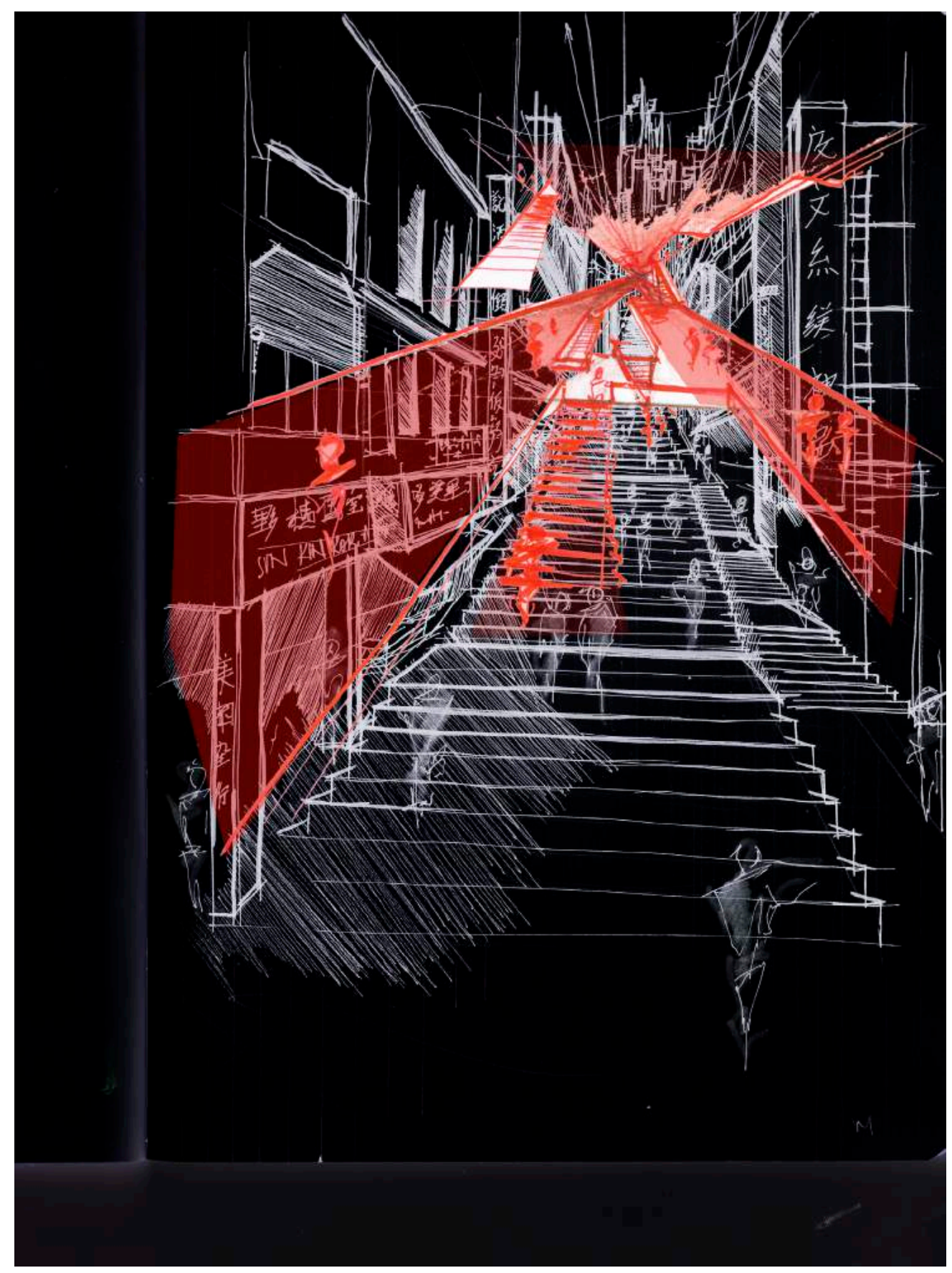


b $00 \quad$ t $\quad h$

«An anonymous vernacular form, a makeshift construction somewhere between architecture and

furniture? A booth is a minimum working space - three by four feet - serving a large group of people

- some 10000 according to a recent official survey. They usually come in series, forming a line,

parallel to the traditional rooted shops. They were set up by the government at the beginning of the

last century to extend the range of commercial activities and spaces. By 1970, more than

\section{0 licensed or unlicensed hawkers provided a specific character to the streets of Hong Kong..»}

to eat lunch rather than eating in the lobbies of office towers, communal areas dedicated mainly to the elderly and prolonged markets based on the «ladder street» model.

These nodes are located solely on the sea side of the Long Line. They occupy between one to three floors (depending on the function) of iconic towers of the city's skyline as the Long Line penetrates or skirts their glass façades. Whereas on the hill side, the path «respects» the architecture and looks for void between buildings to avoid having to disrupt them, on the sea side the Long Line makes a social statement. The bridge «congregates» the mass from the south side and brings it forward to the north side of Central, offering it and these functions proper public space «up in the air» and at the forefront of the city since these are currently congested in the back lanes or on the existing elevated walkways.

Even though the Long Line is designed to be completely public, open to all and offering a spot to anyone who takes its path. However it is intended primarily for the elderly, foreign migrant workers, the young and tourists. In this way, four nodes have been planned and set up as an example for future settlements up in the air along the Long Line. 


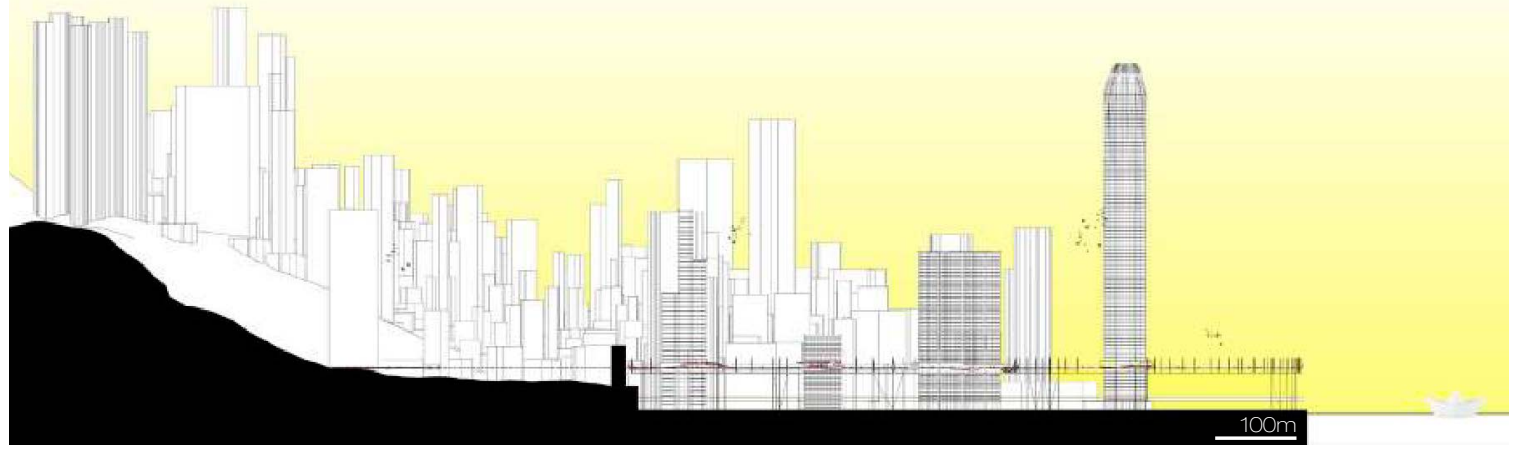


Node1: $L L+H S B C$

The Long Line meets the Hong Kong and Shanghai Bank Corporation building (designed by Foster+Partners) at the building's tenth floor. A communal mahjong area for the elderly grows from the connection between these two infrastructures. My intervention takes advantage of the atrium at the center of the building by partially filling the void with horizontal planes to accomodate the community that does not take part in banking. In this manner, this new social entity is in great proximity with the existing corporation context, getting users to view this development as an encounter between both sides. On the one hand, the absence of parting walls in the HSBC building uncovers on each floor an array of employees working at their desk. On the other hand, mahjong tables are distributed with a similar pattern across the added planes inside (and outside) the atrium. This sitting position on both sides creates a continuity all the while drawing a parallel between the elderly playing Chinese chess and white-collar workers keeping an eye on the stock market. Node2: $\mathrm{LL}+\mathrm{MOH}$

Coming from the Asia Center (which is the start of the Long Line at grade), and having passed Node1, the next intervention goes through the Mandarin Oriental Hotel. The latter occupies a building from 1963 which was at that time, at 26 storeys, the tallest structure in Central district. This node offers shelter mainly to foreign migrant workers who are between jobs. Taking over four floors of the existing hotel and bridging over to the next door building, the Long Line itself partially infiltrates the Mandarin Oriental. In this situation, the previously existing rooms and party walls of the hotel's floors have been rearranged to be able to accomodate more people. However the function stays the same, paralleling the upper class society and often international investors/economists (financial sector) with foreign migrant workers, both from the tertiary sector but with clearly different privileges. This node's location was chosen for its proximity with the World Wide House building, just two streets over, with shops and services greatly dedicated to the filippino culture. 


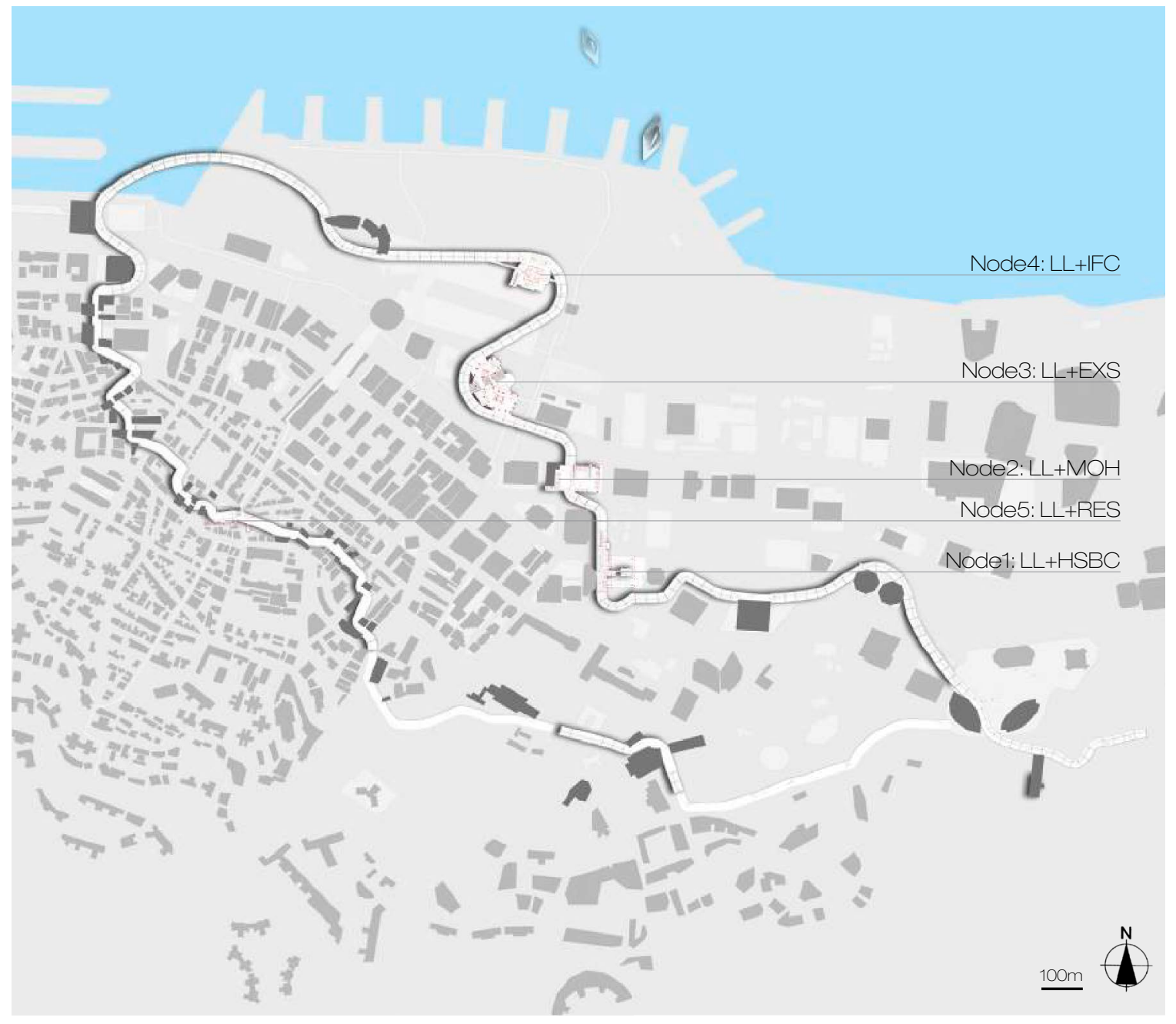


Node3: $L L+E X S$

The Exchange Square (towers 1\&2) is part of a greater complex of four towers (one accomodating the Four Seasons Hotel) that break through a shopping mall and a major transportation node comprising of: a large-scale bus terminus, a subway station where four lines (including the Airport Express) meet and connections to the Central Ferry Piers and the Hong Kong Macau Ferry Terminal. Different segments of the network of existing elevated walkways also join there. The Long Line offsets the curve that both towers of the Exchange Square form together. The existing horizontal planes of the towers at 50 meters above sea level will reach out to the skyway to enable a connection. A nursery is nested up there as part of the proposal. The primary horizontal plane is exploded to spread at three different heights that surround the Long Line.

Node4: $L L+I F C$

The closest node to the shore enters architect César Pelli's International Finance Center (tower 2). It integrates a market directly inspired by those existing throughout the ladder streets of the same district. This explains the slow type stairs used from one floor to the other and along which stalls are placed for possible future merchandise. The LL+IFC node is at the forefront of Hong Kong Island's north coast.

In general, the architecture of each intervention that creates a node wraps around the Long Line's basis height which is 50 meters above sea level. The ramps instead of stairs better prolong the bridge and facilitate movement from one floor to the other especially for the elderly.
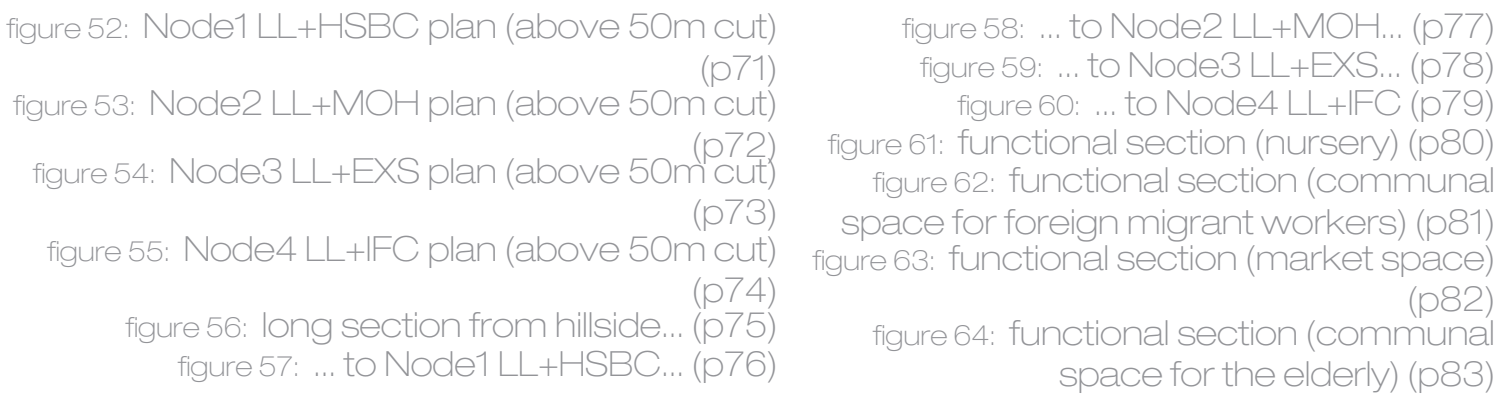


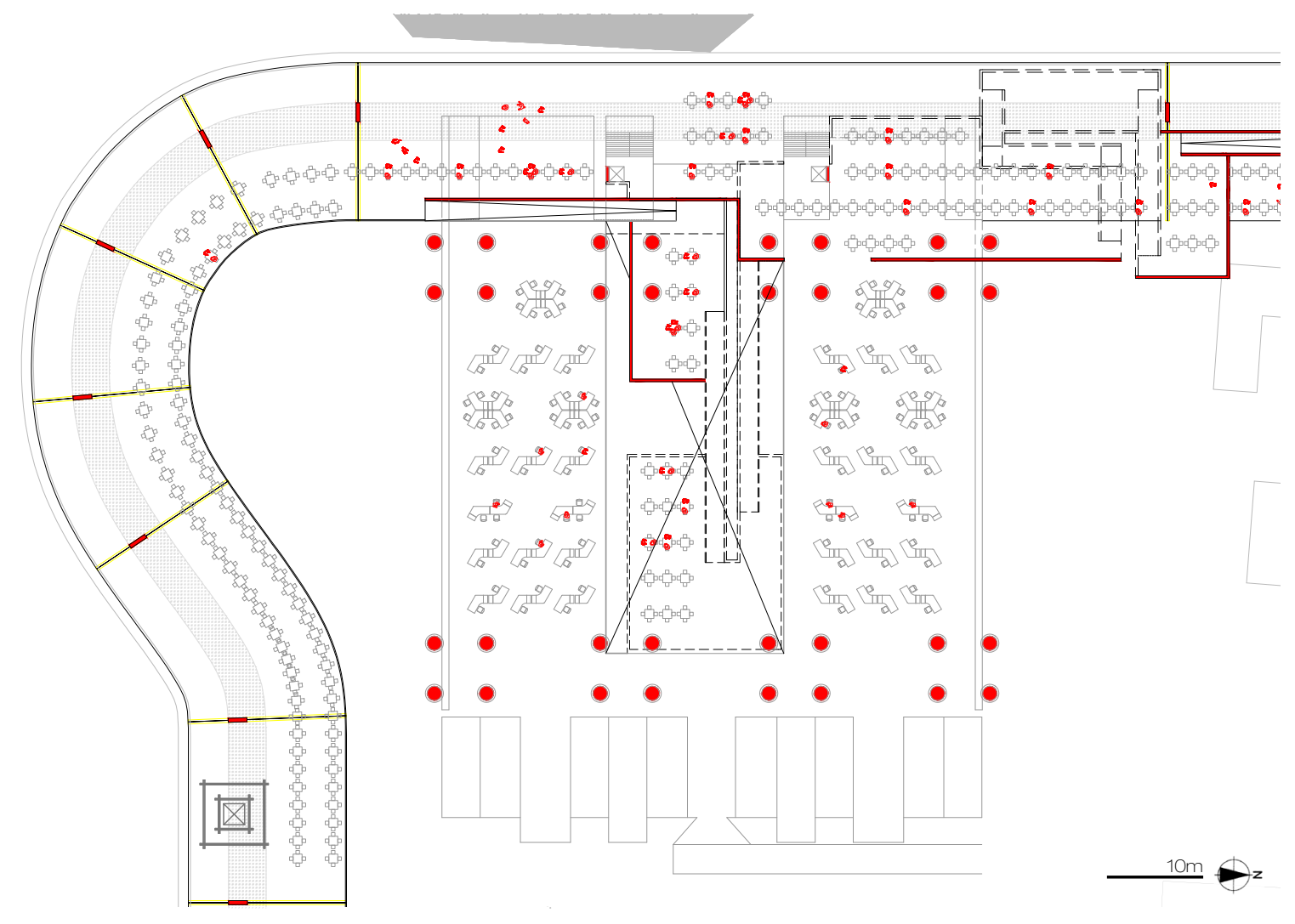




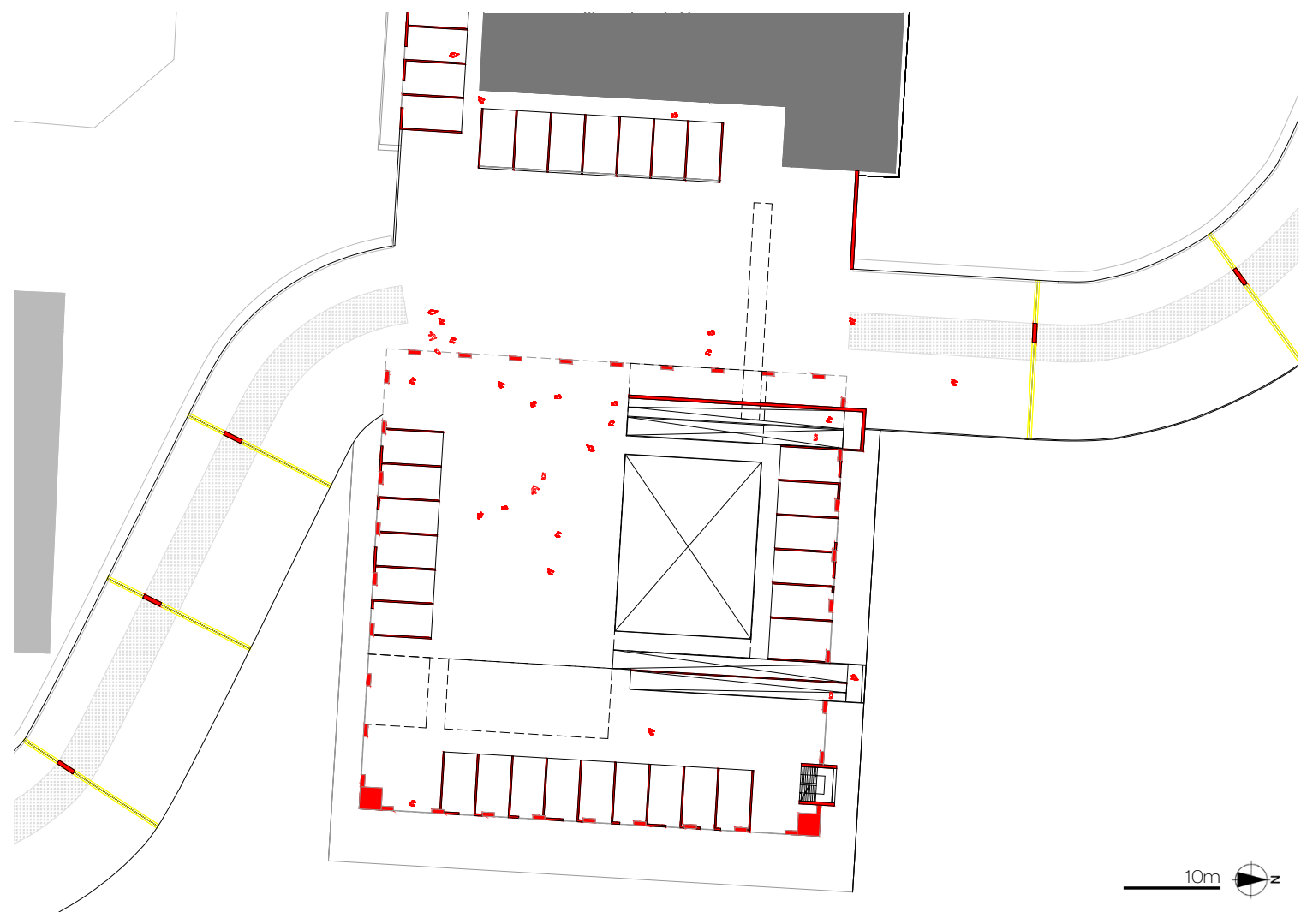




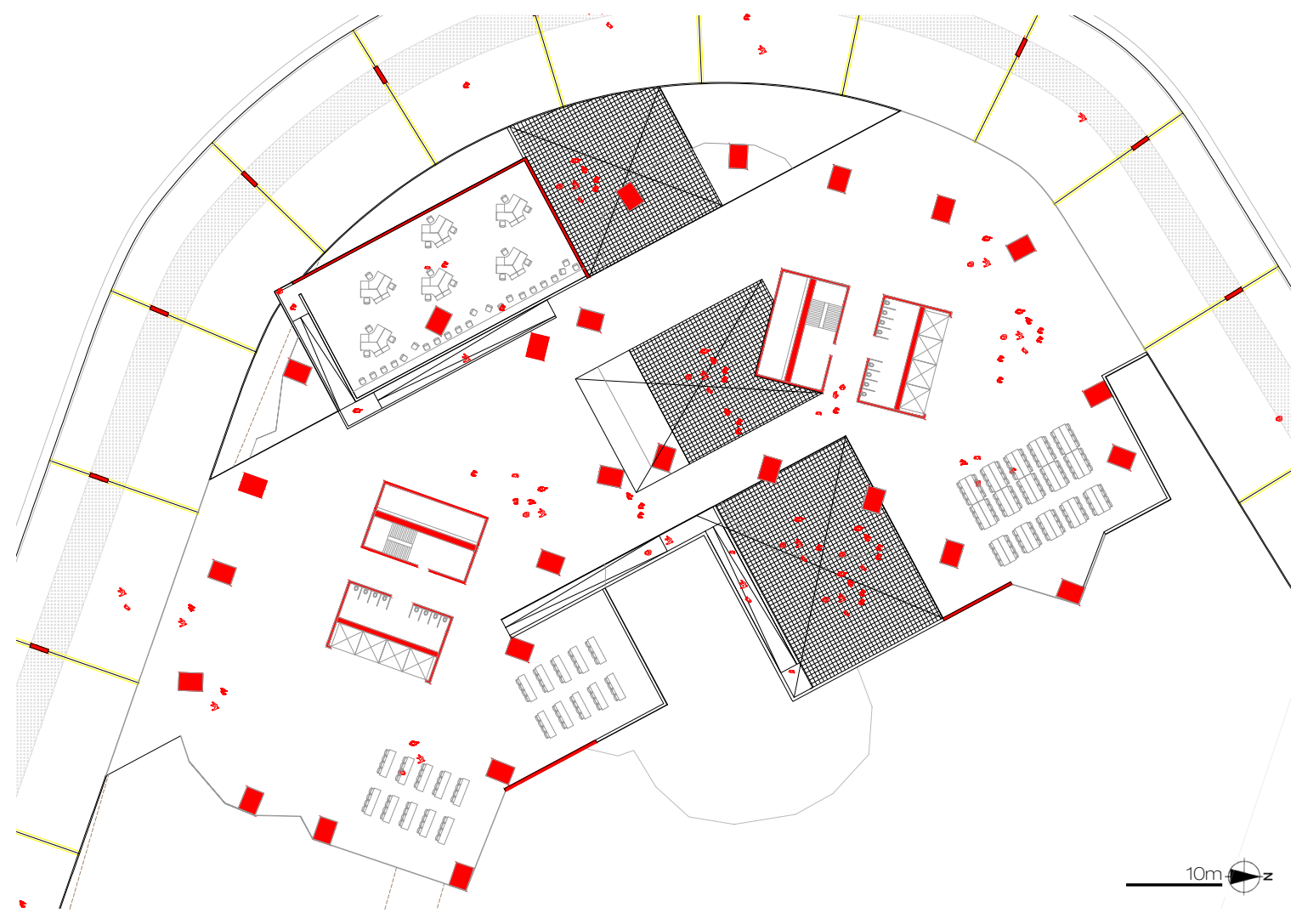




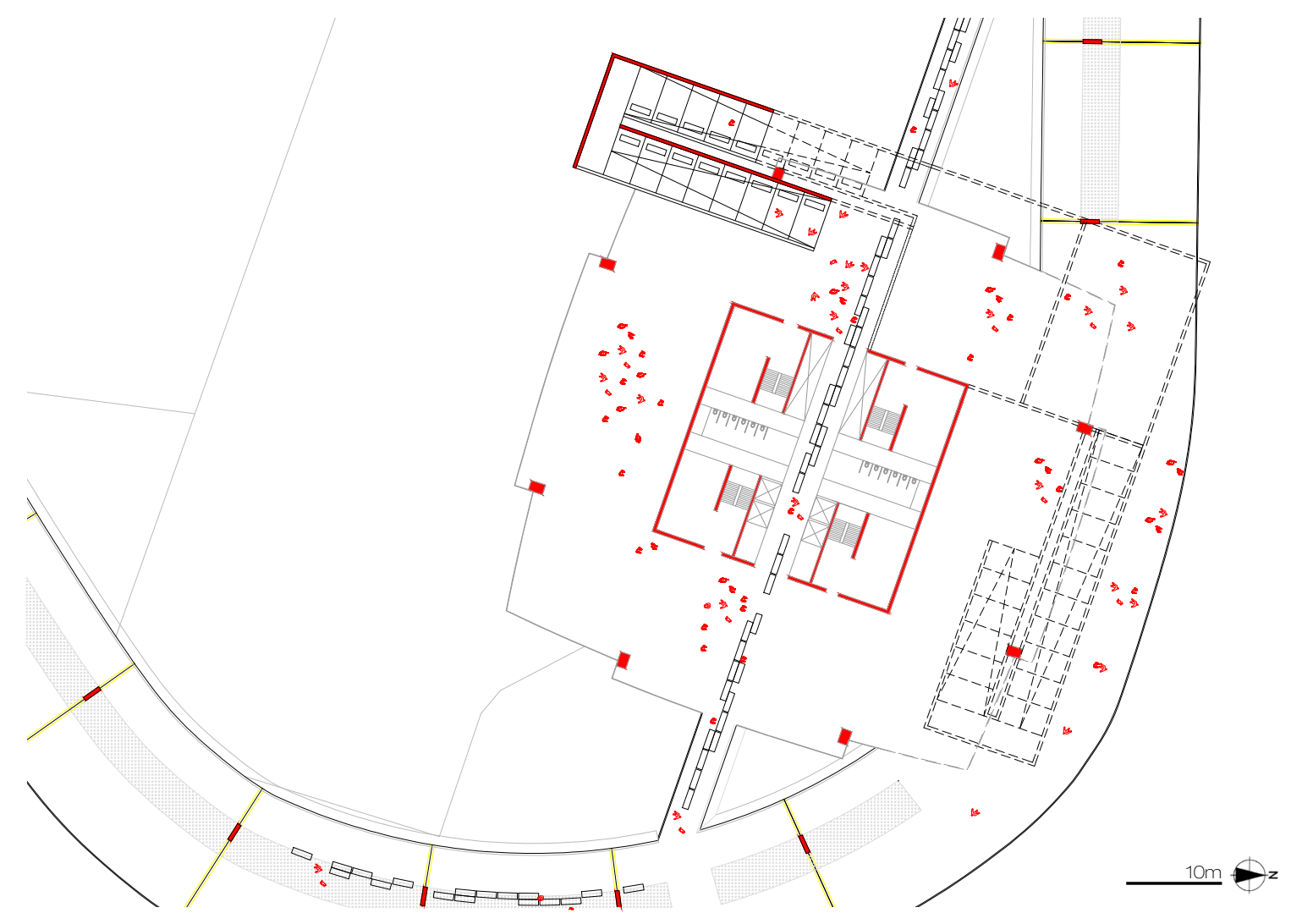




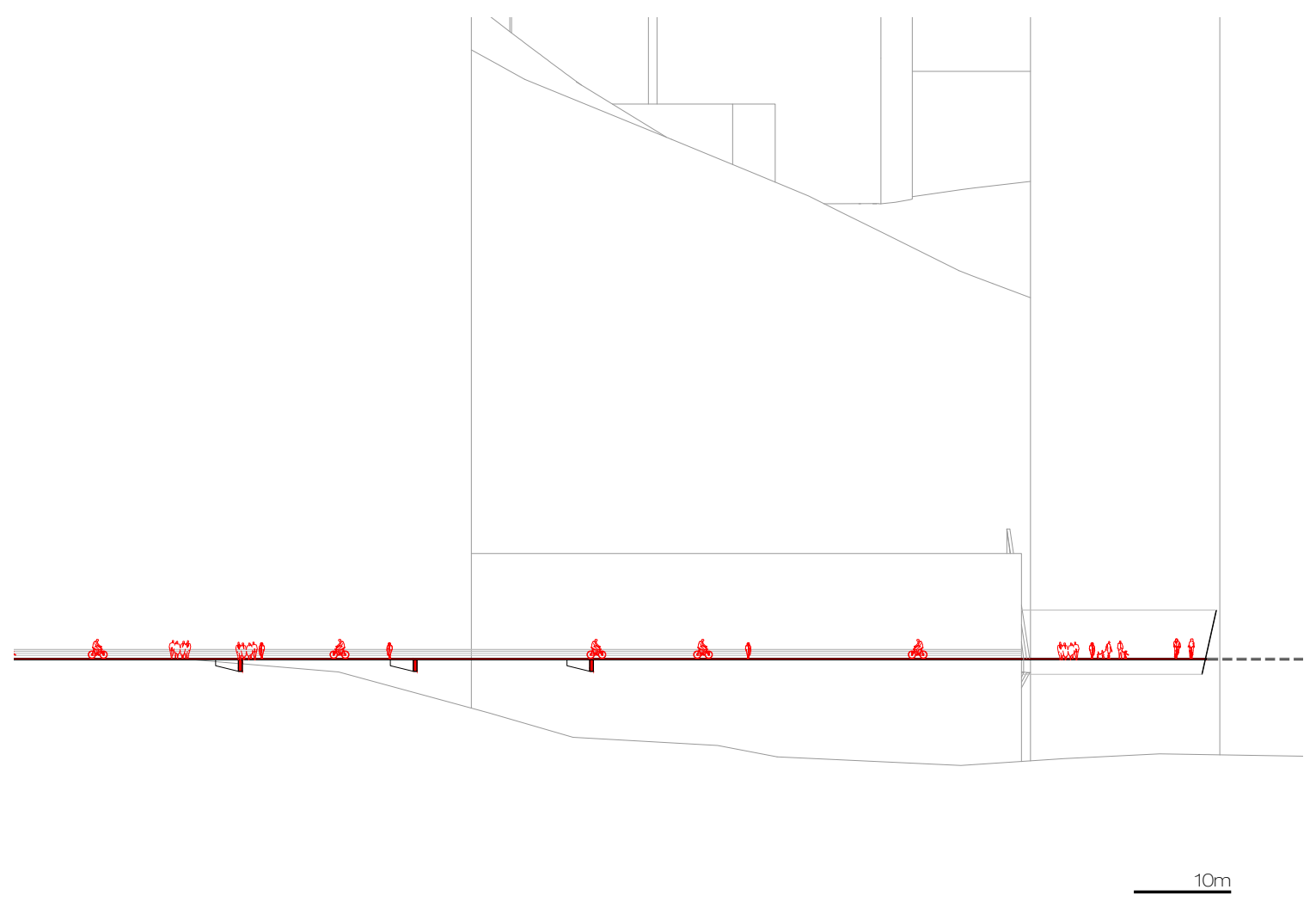




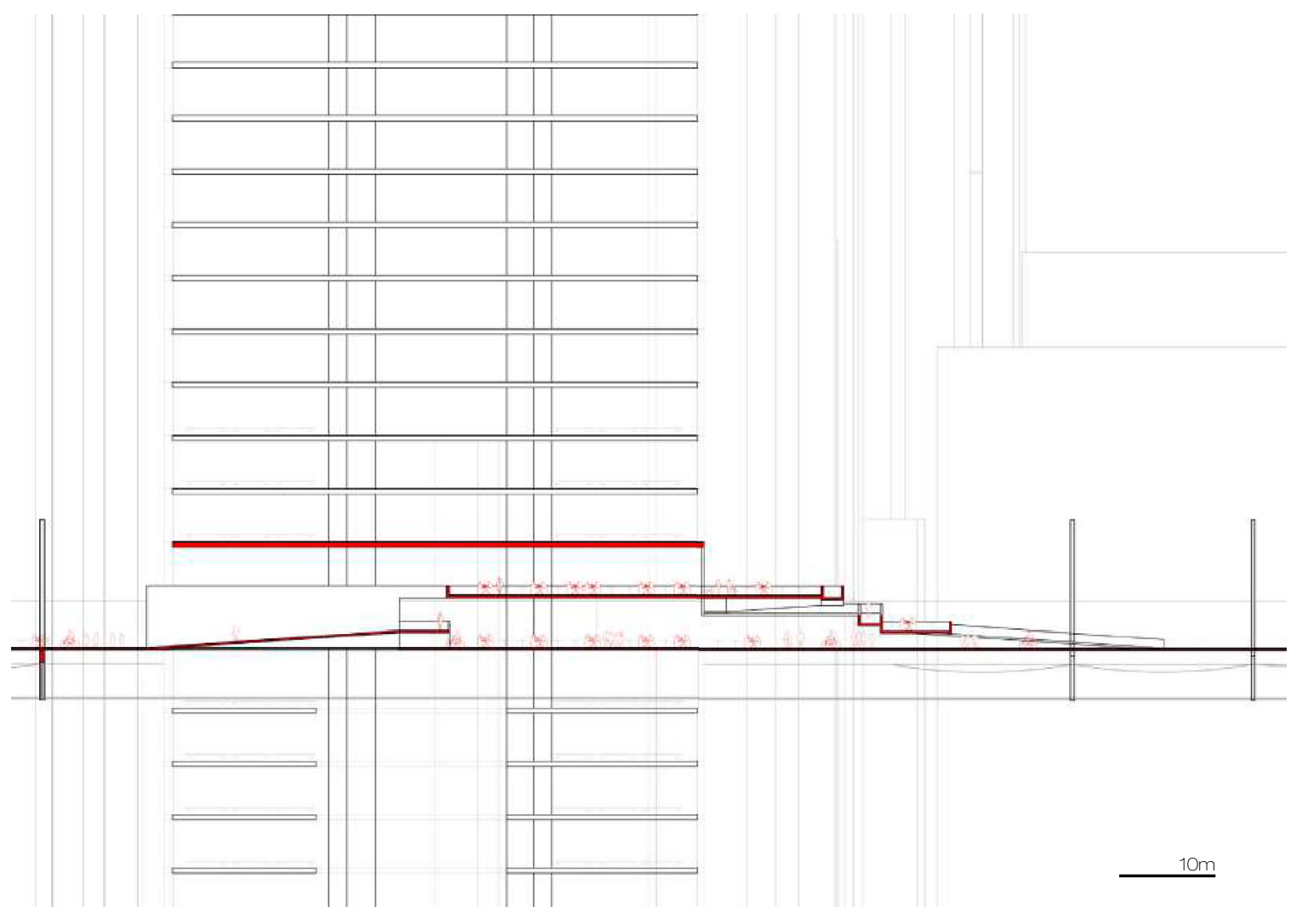




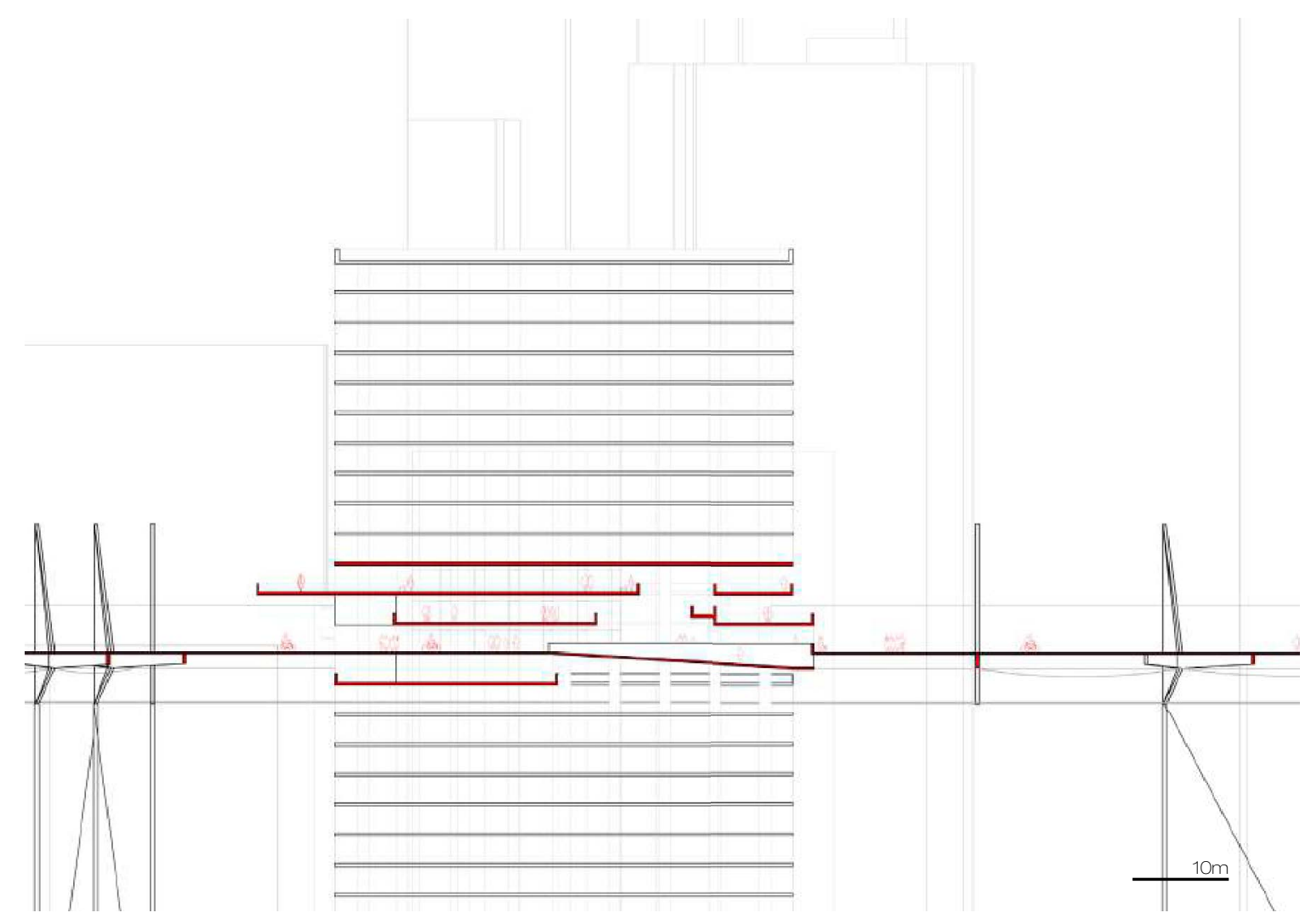



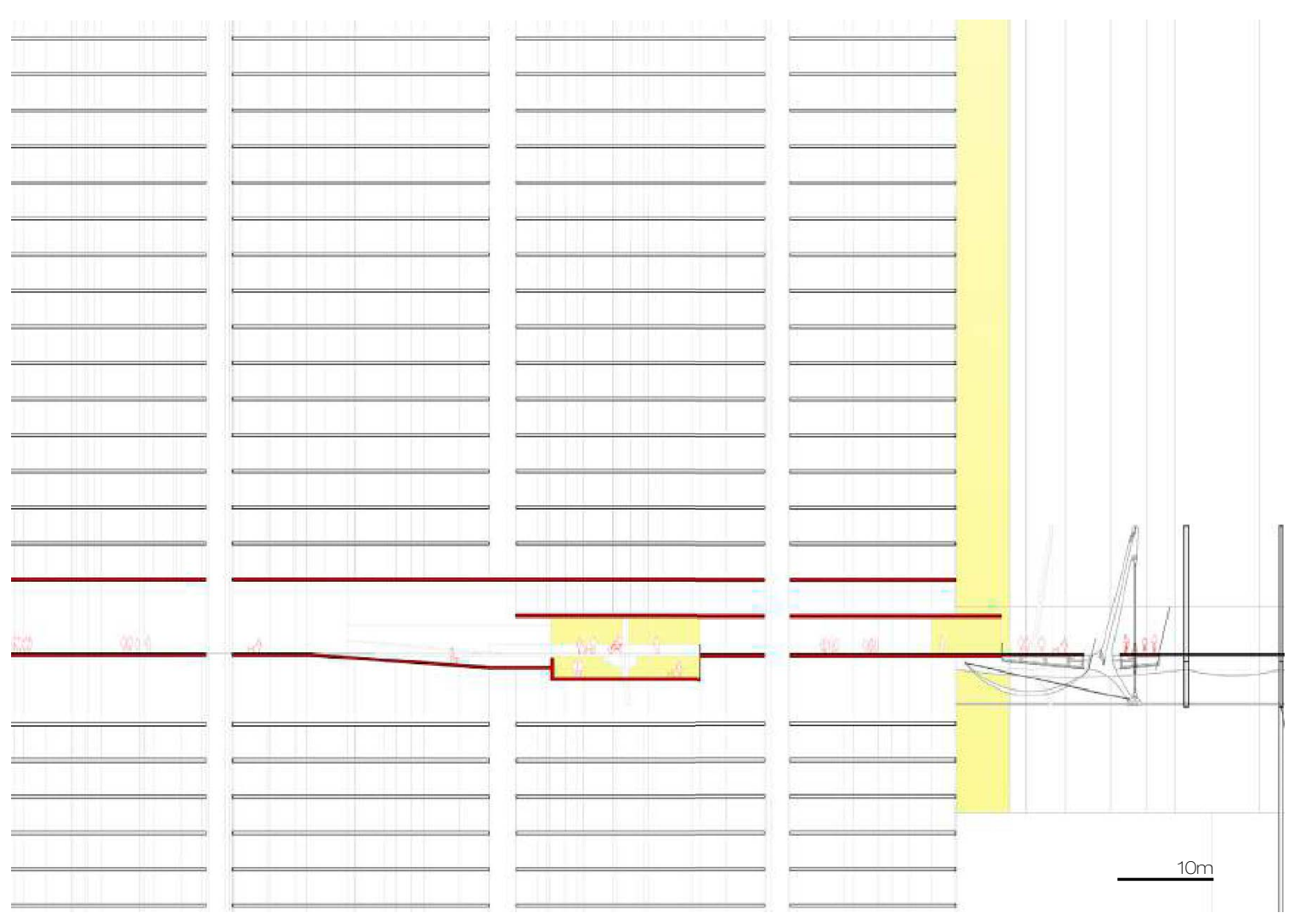


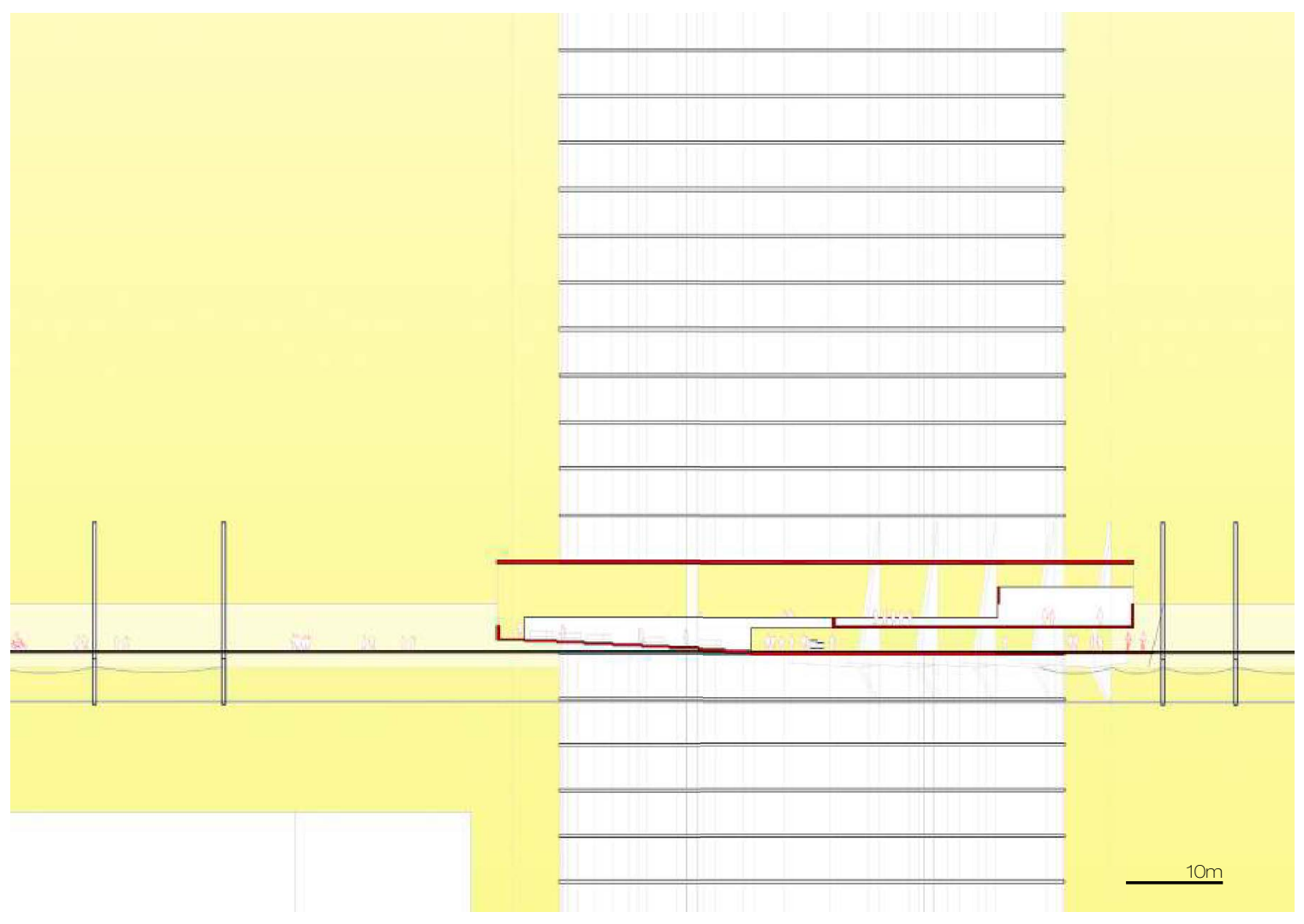




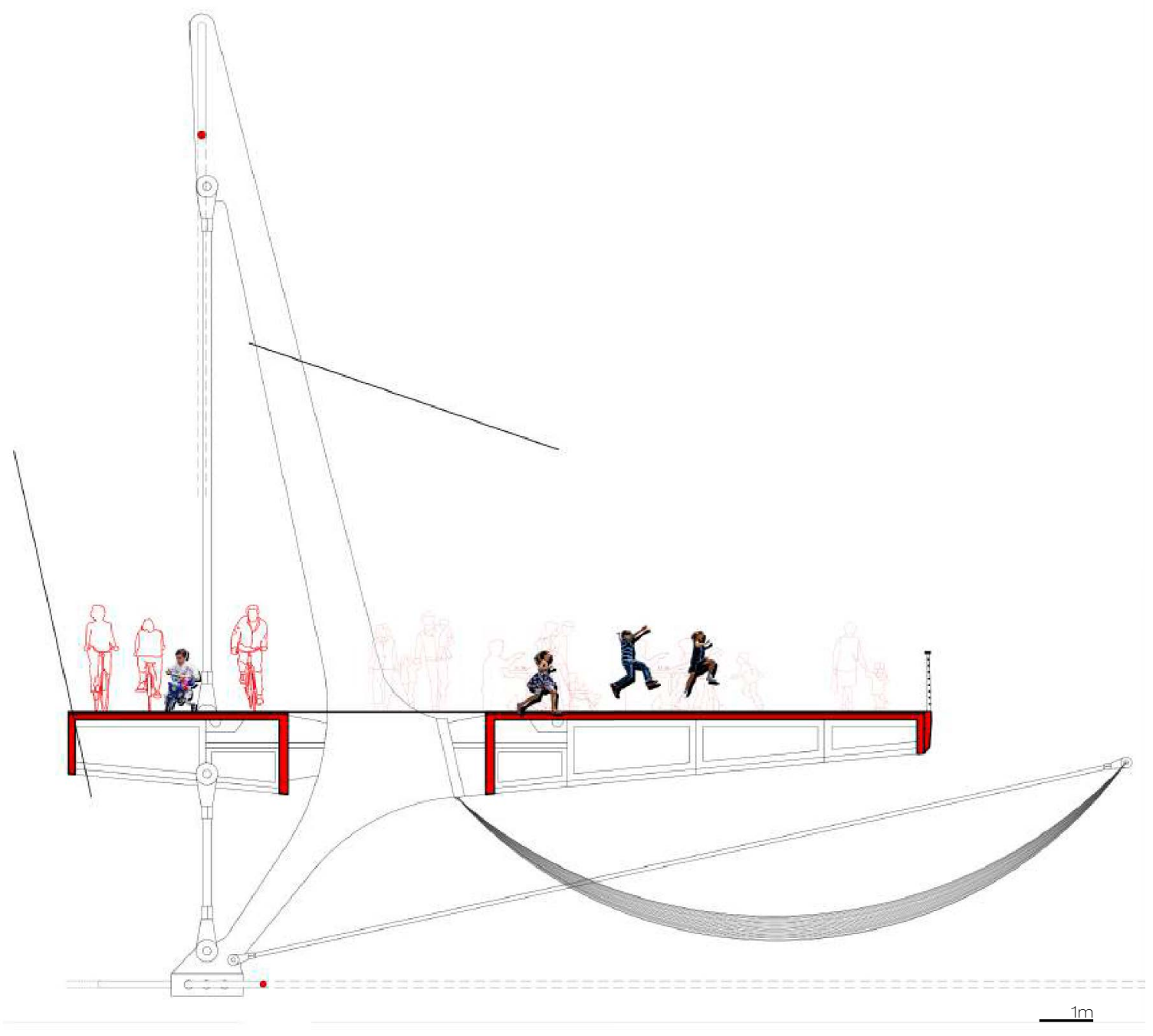




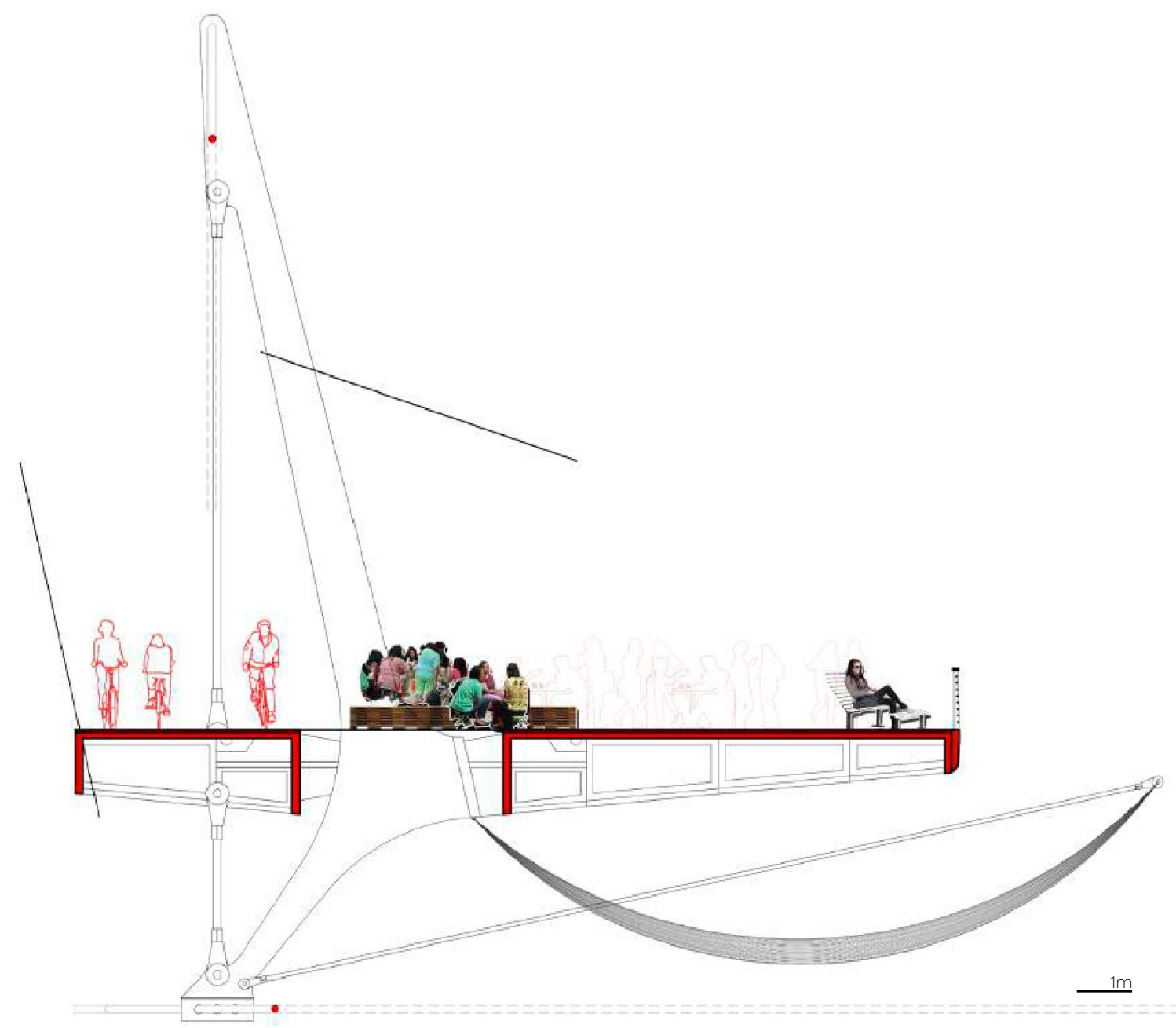




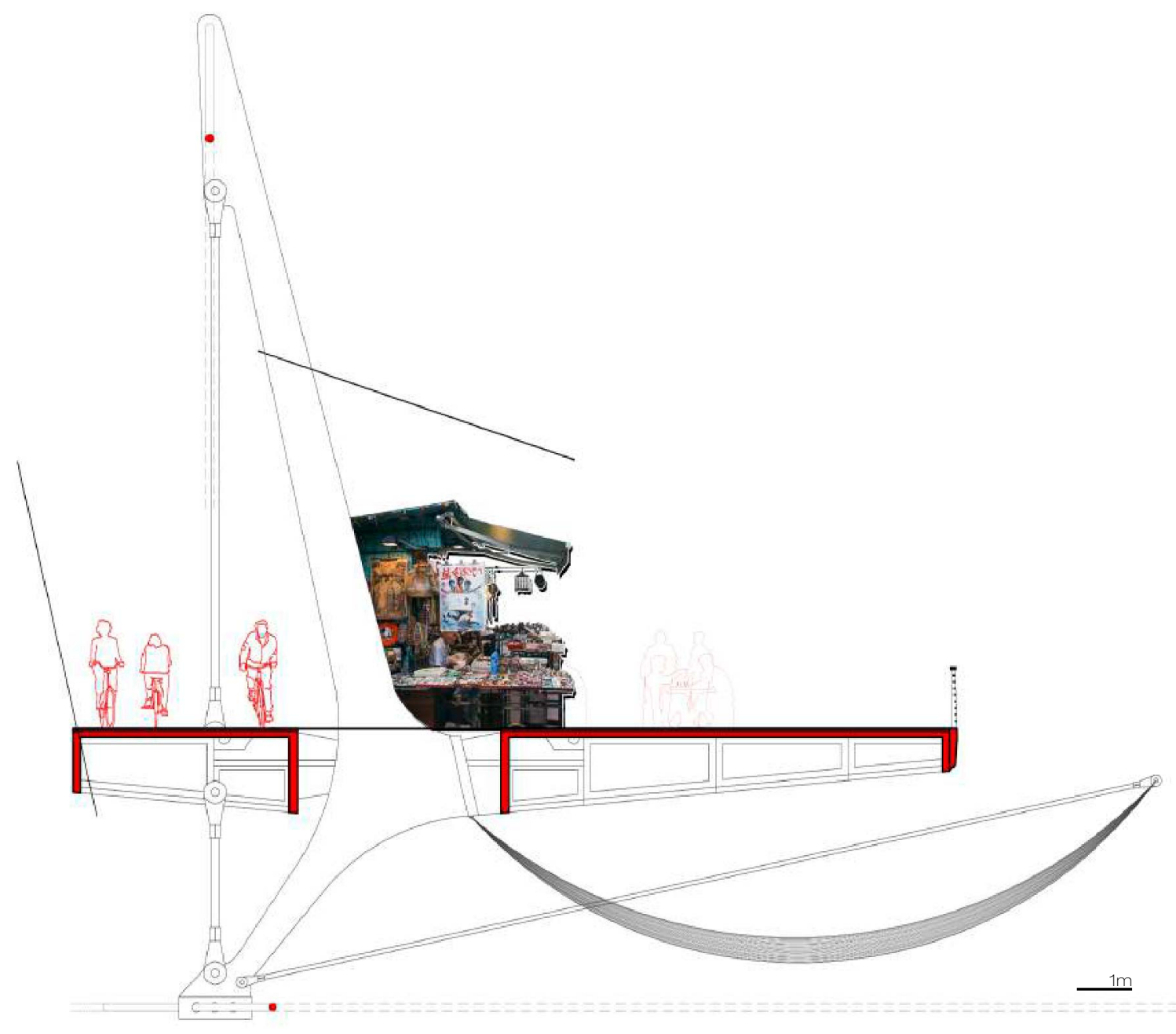




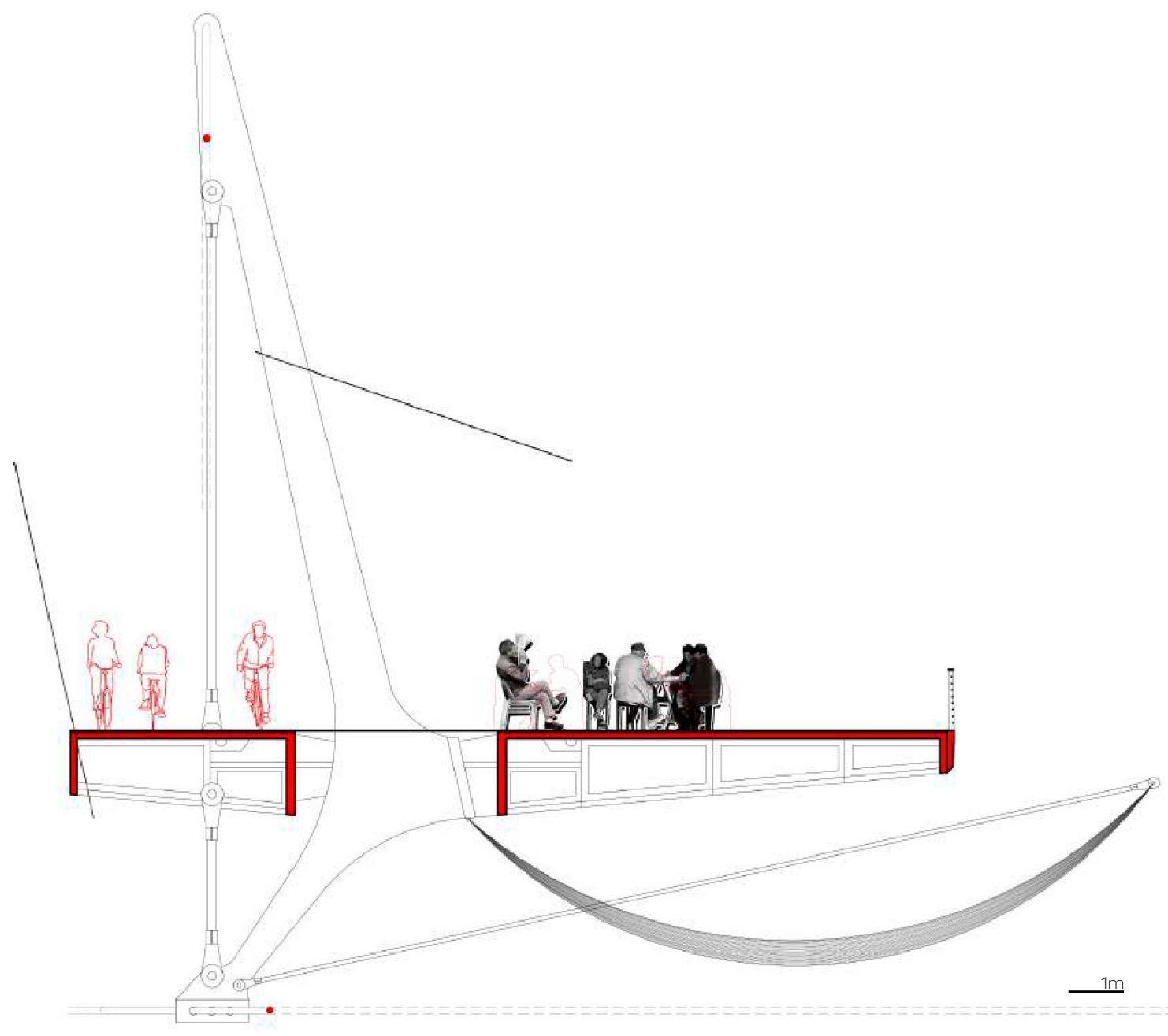




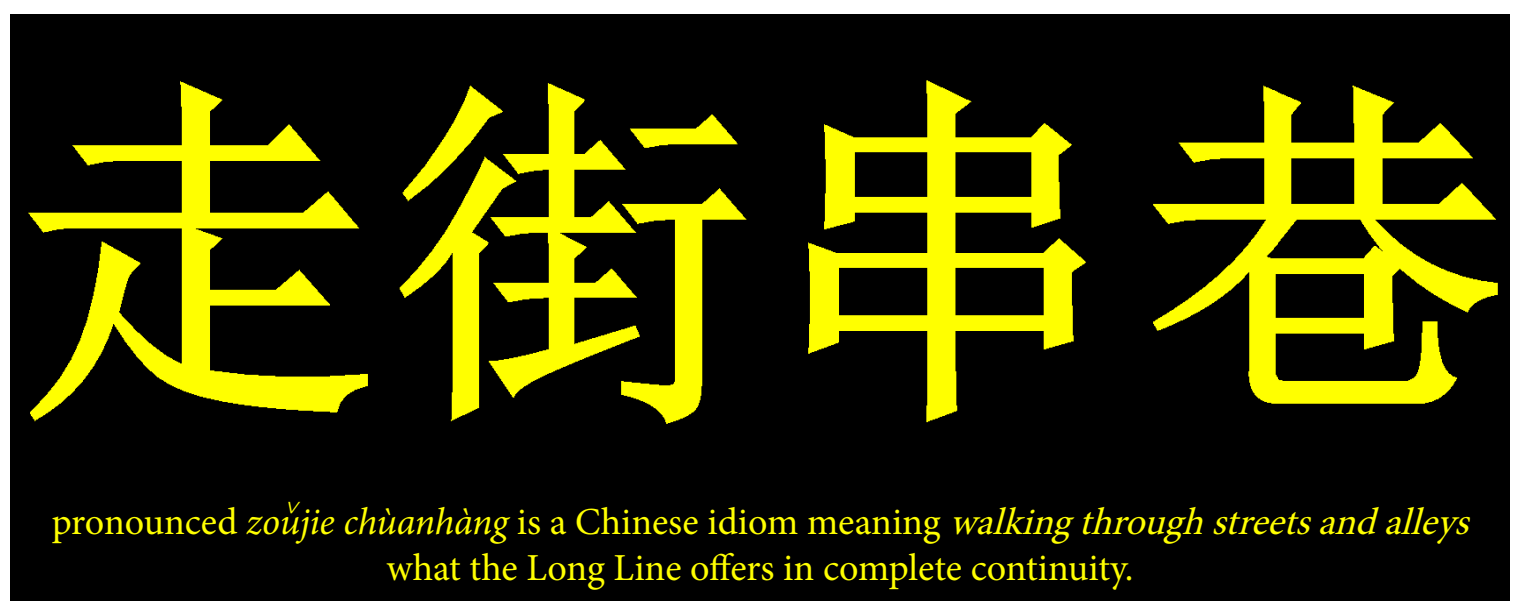




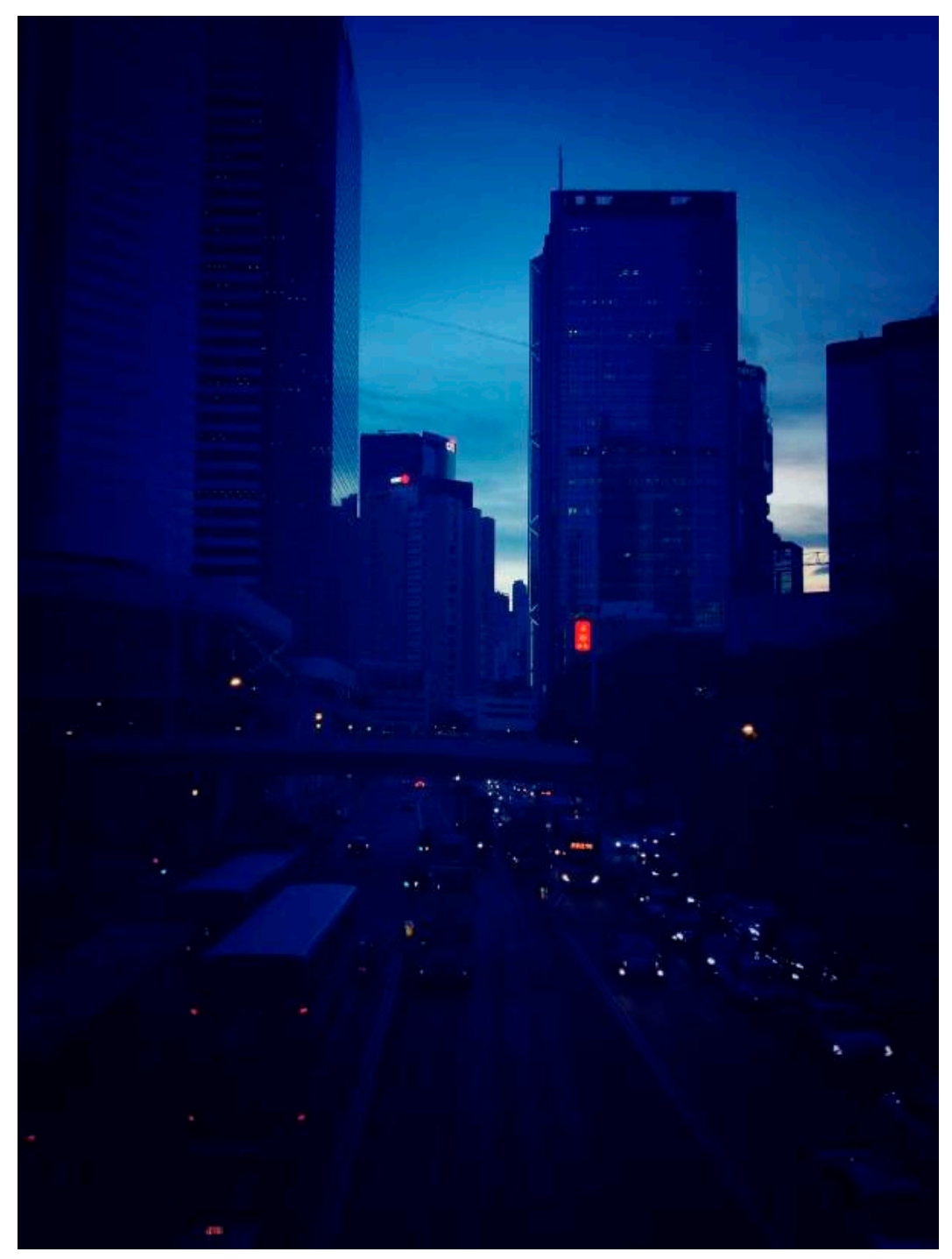




\section{Experiencing Hong Kong's Topography}

Pedestrians using Hong Kong's network of elevated walkways experience it primarily as a sidewalk, albeit at a constant height of approximately six meters above ground. The system extends all the way from Central to Mid-Levels, a residential district which is located higher up on the hill side leading to the Peak (Victoria Peak is the highest point on Hong Kong Island).

Set at a constant height of fifty meters above sea level, the Long Line allows for a different experience of Hong Kong's topography. The latter varies from extremely sloped towards the Peak to completely flat along the shore. The unnatural section, due in part to land reclamation or on the contrary excavation, cut off Hong Kong's CBD's earliest grade but the Long Line recalls the fifty meters contour line that has been artificially modified. This level was strategically chosen since it is the isoheight on which are fixed (or would be fixed at grade before alterations of the ground) key points such as the Asia Society Hong Kong Center (from which the Long Line either begins or ends depending on where the user would be coming from), the Peak Tram Lower Terminus, the Hong Kong and Shanghai Bank Corporation building, PMQ (formally Police Married Quarters) creative center, Pacific Place (major transportation hub, multiple hotels, commercial and business center). It also goes through Hong Kong's botanical gardens, merging with the hill at this location.

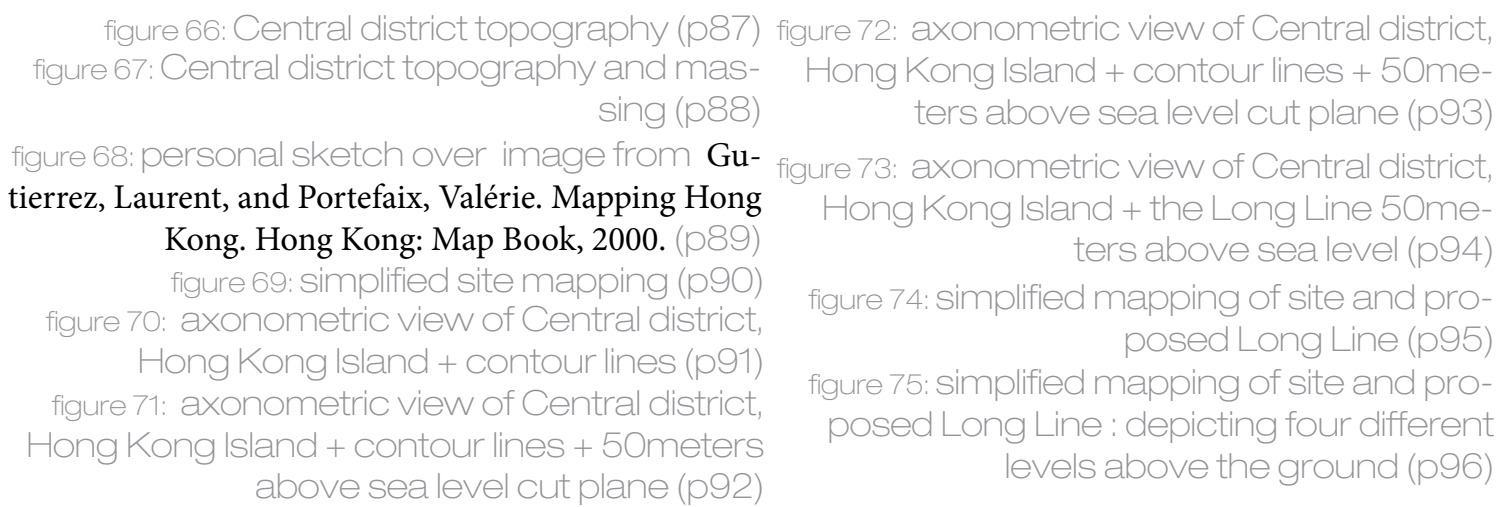




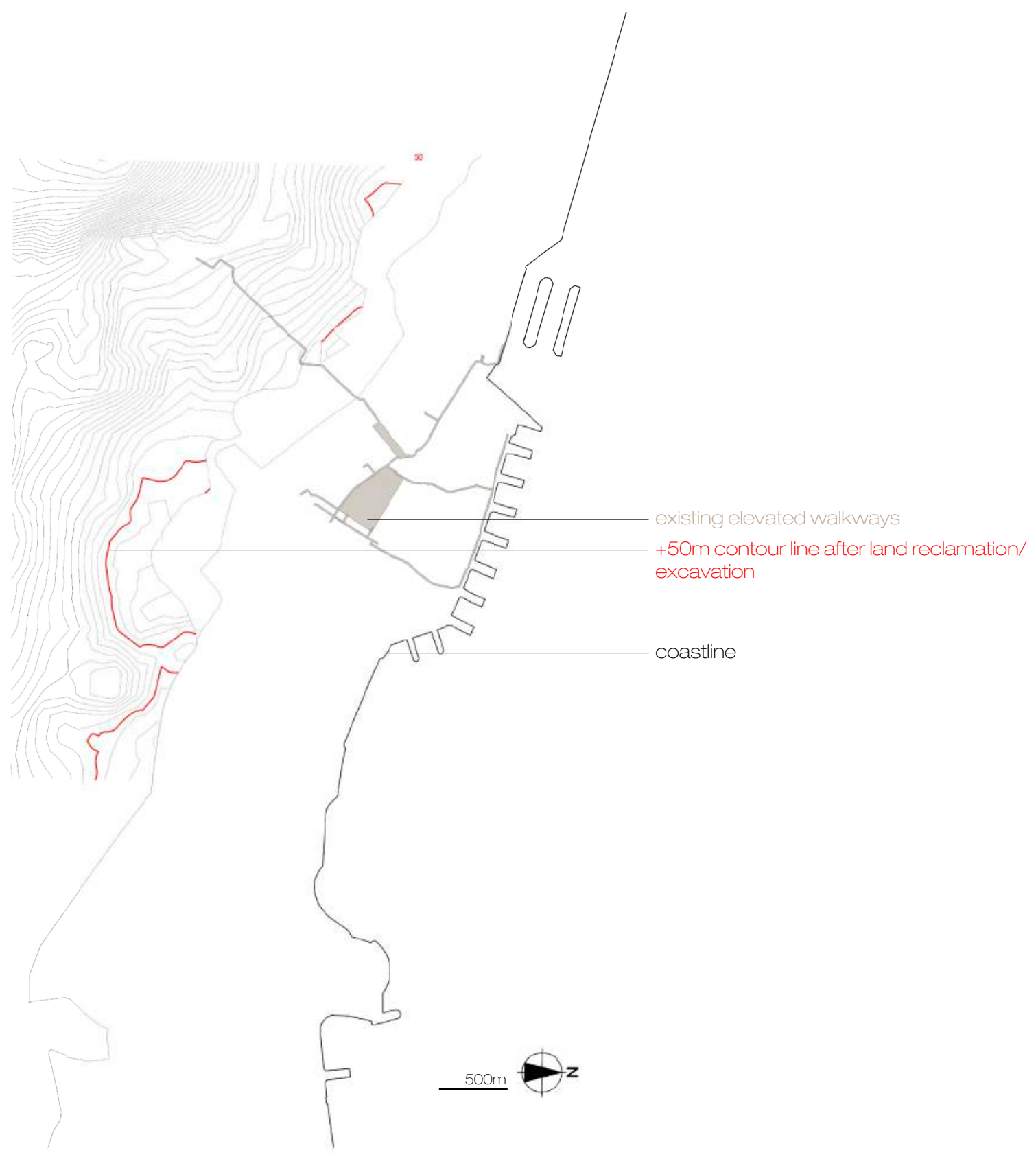


Victoria Peak highest point $=552 \mathrm{~m}$

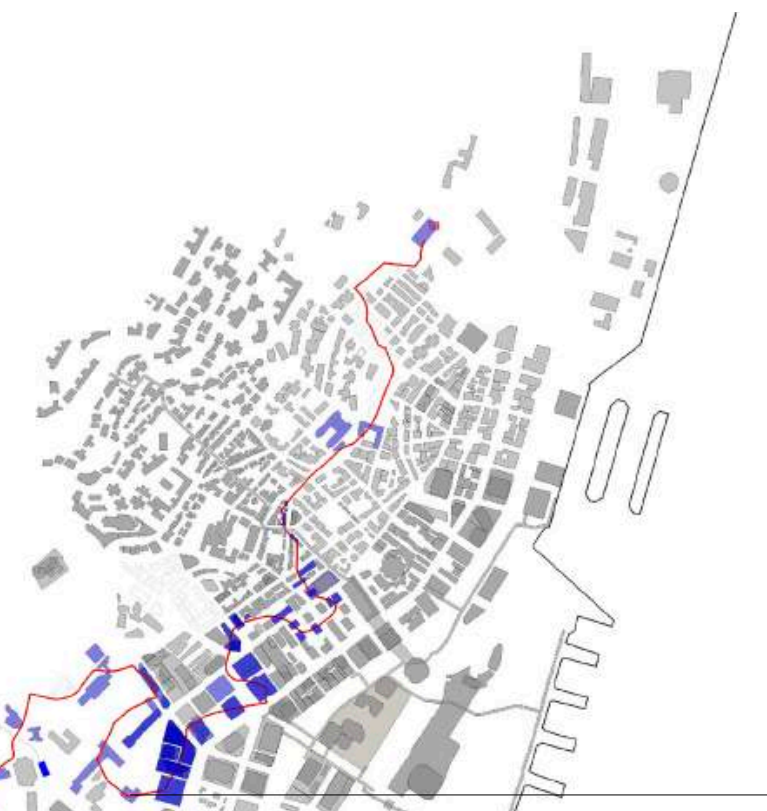

$+50 \mathrm{~m}$ original contour line before land reclamation/

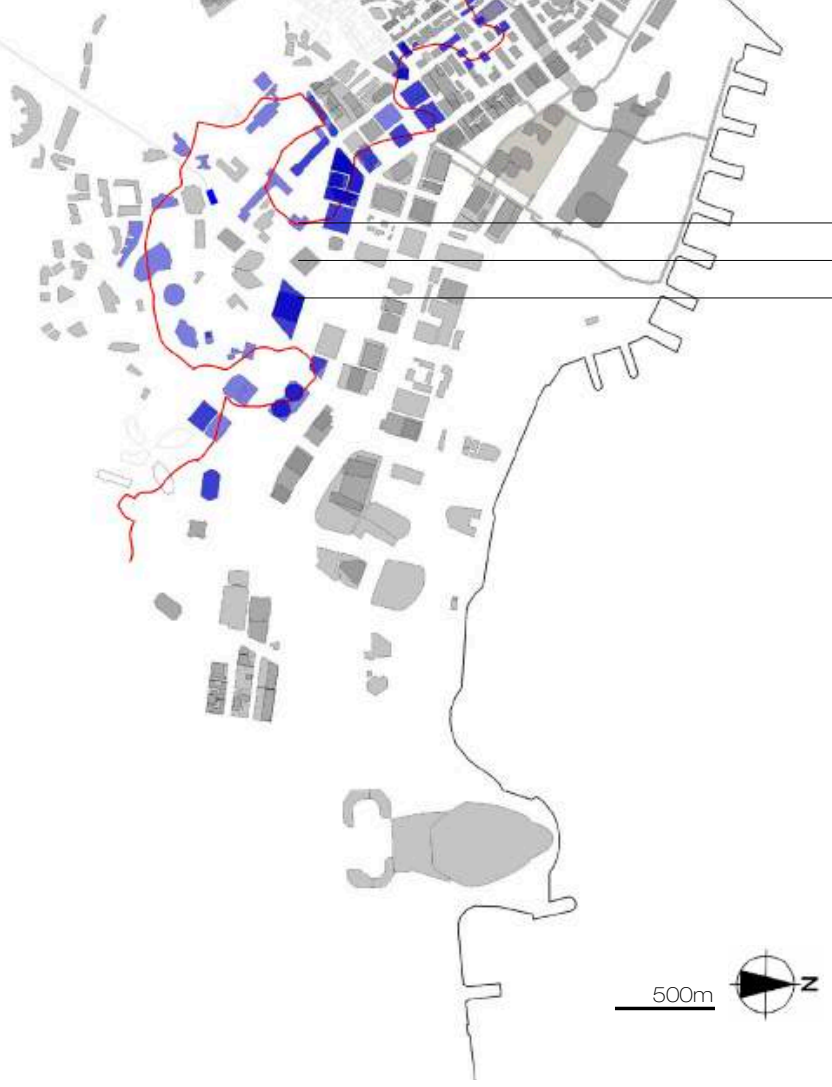
excavation existing buildings - existing buildings along the $+50 m$ contour line 


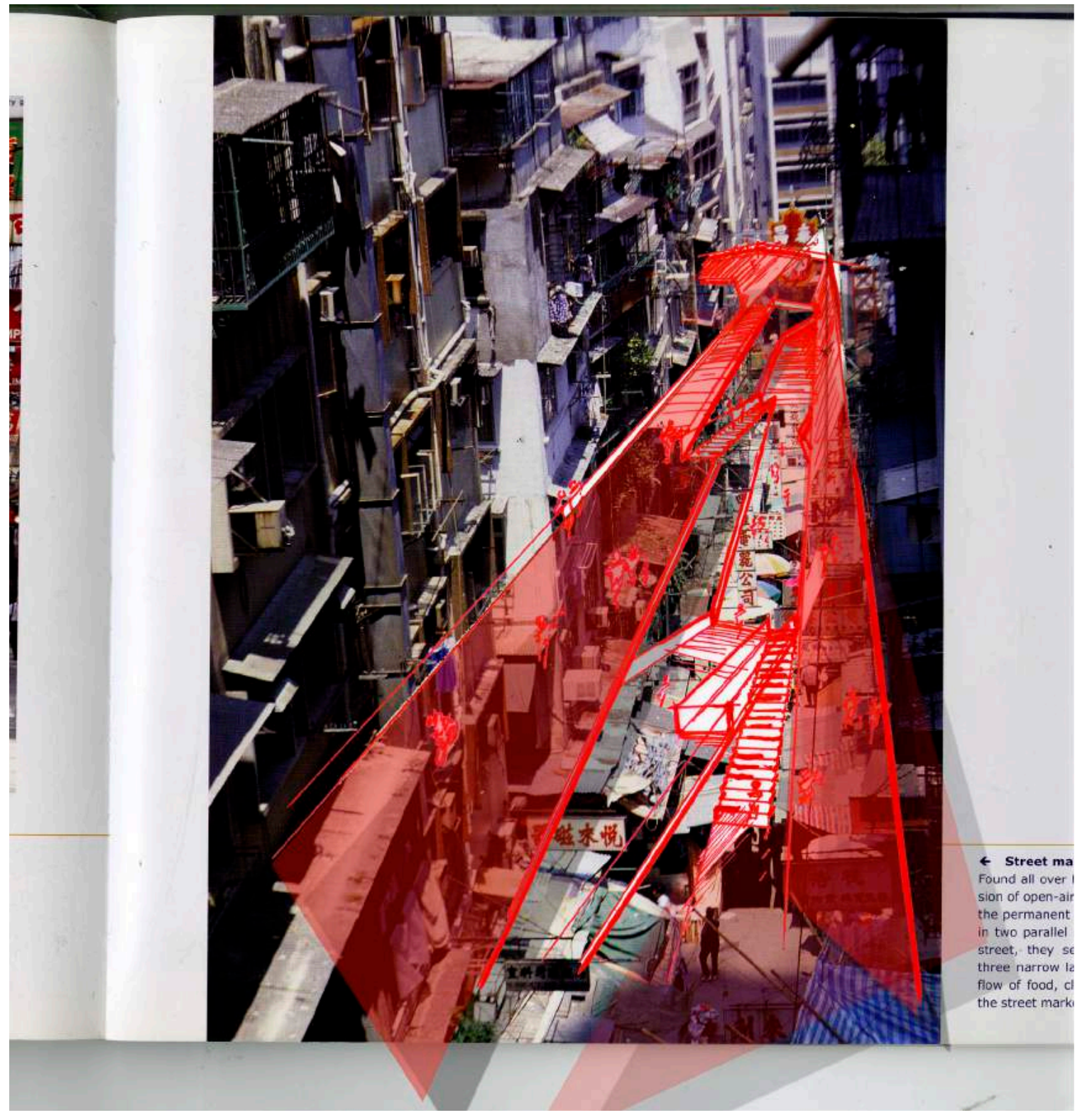




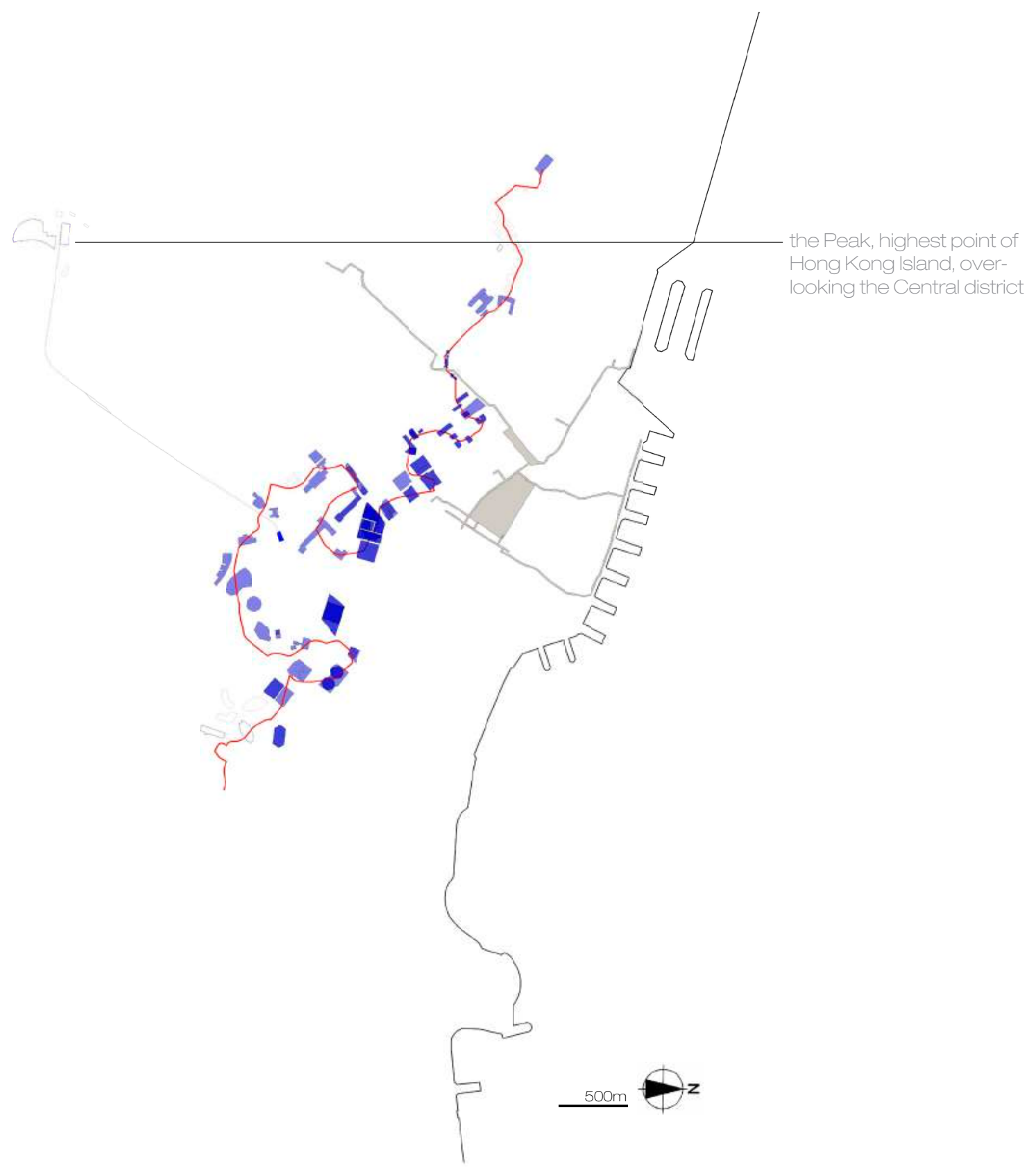




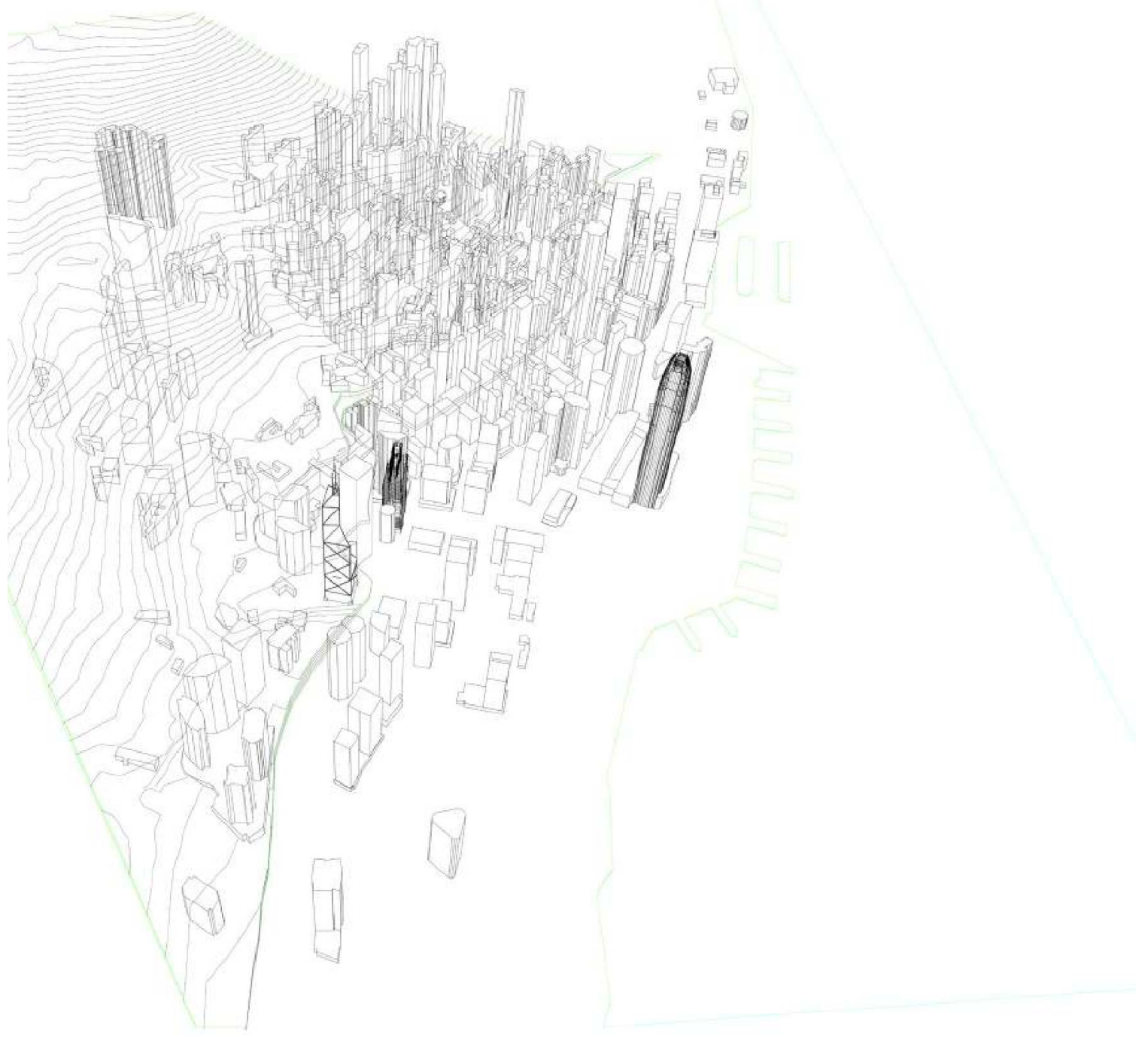




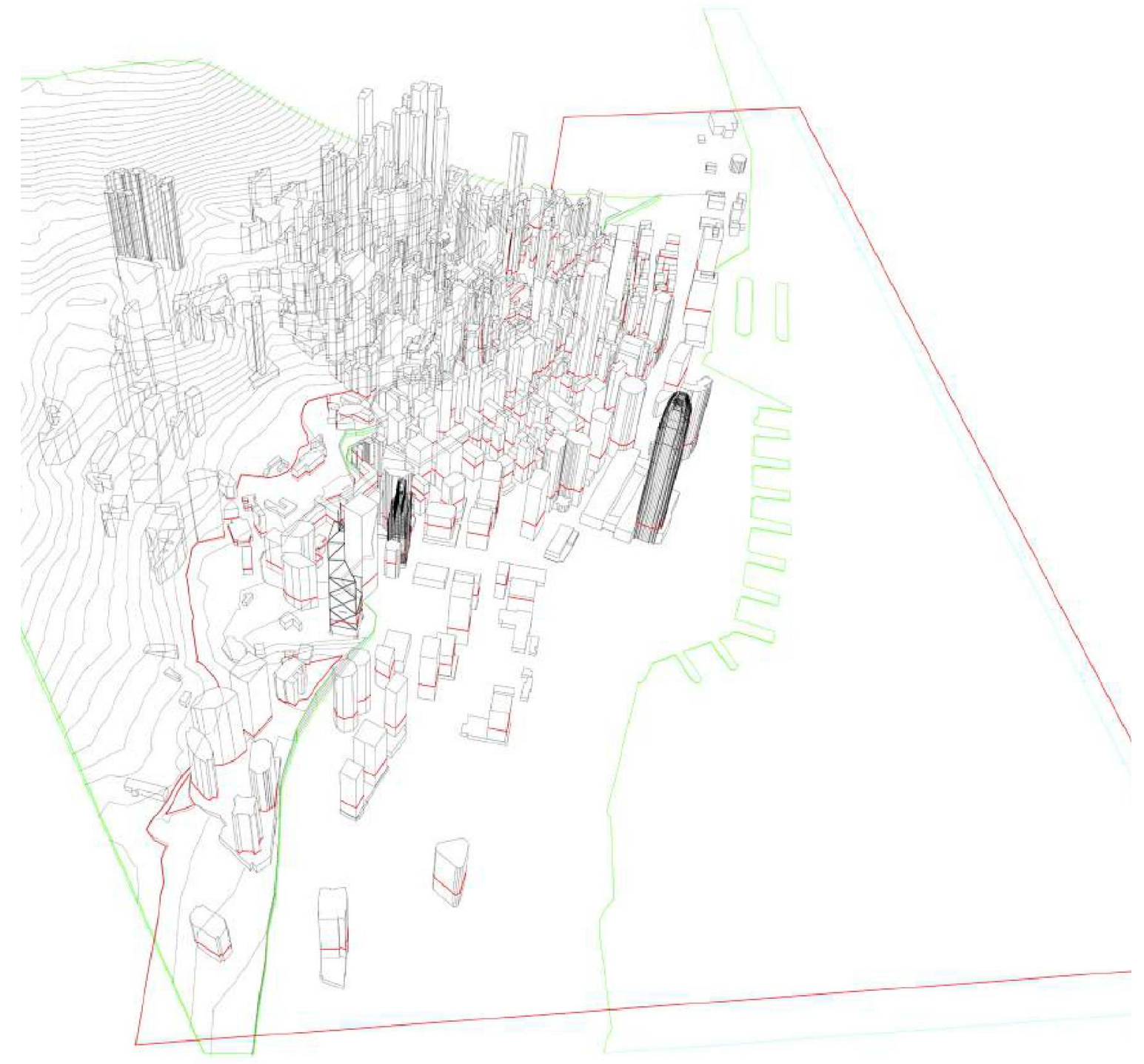




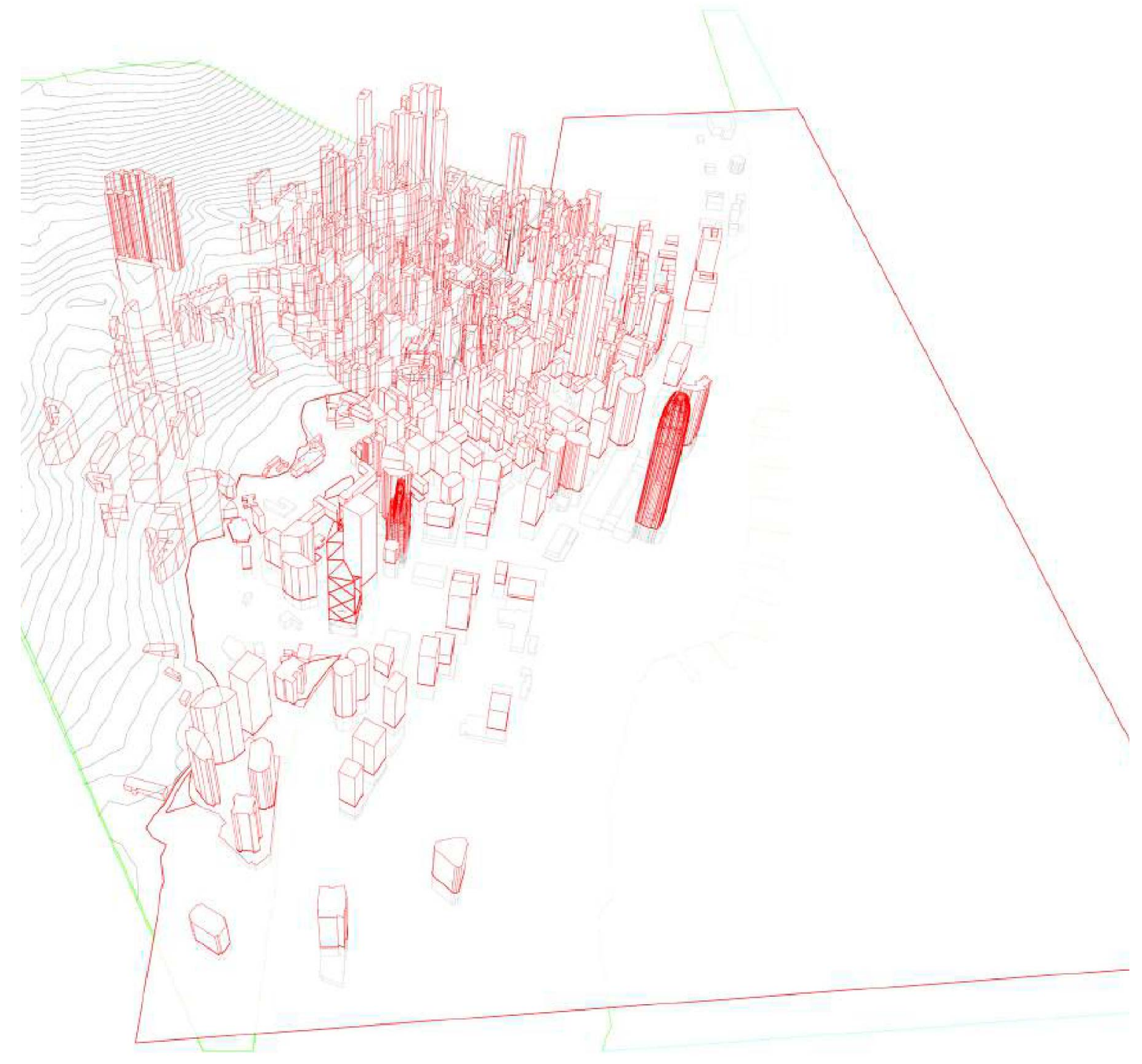




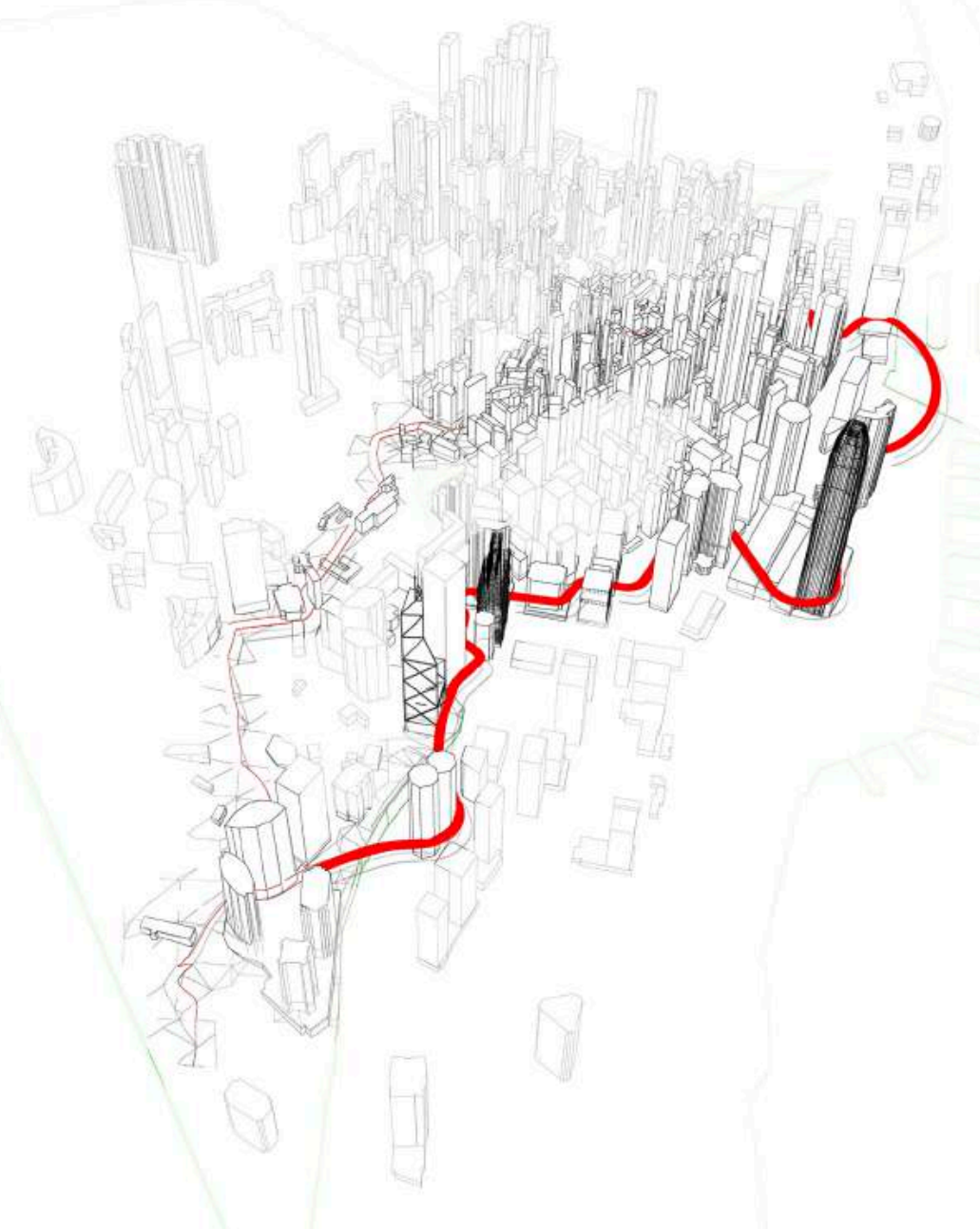




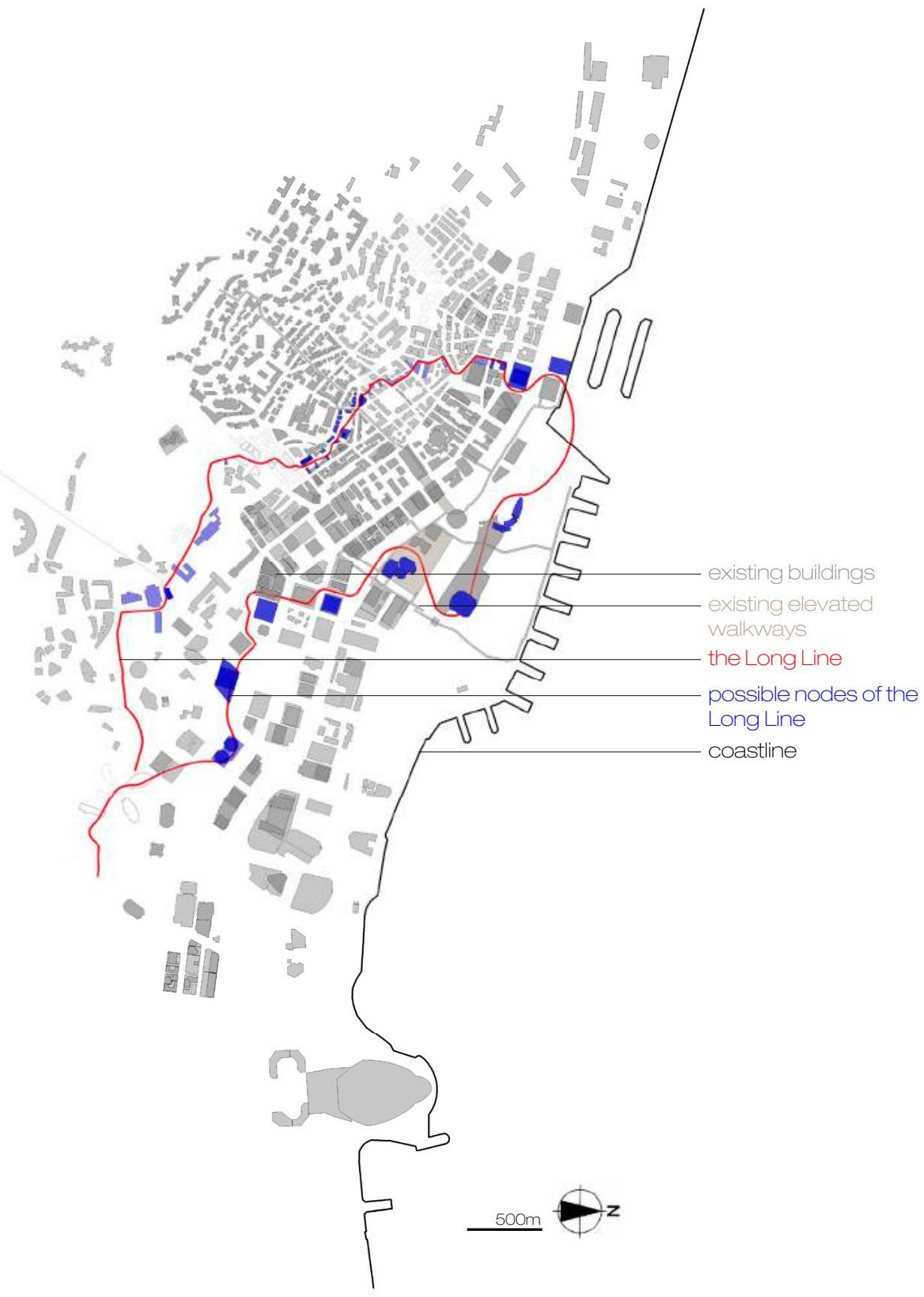




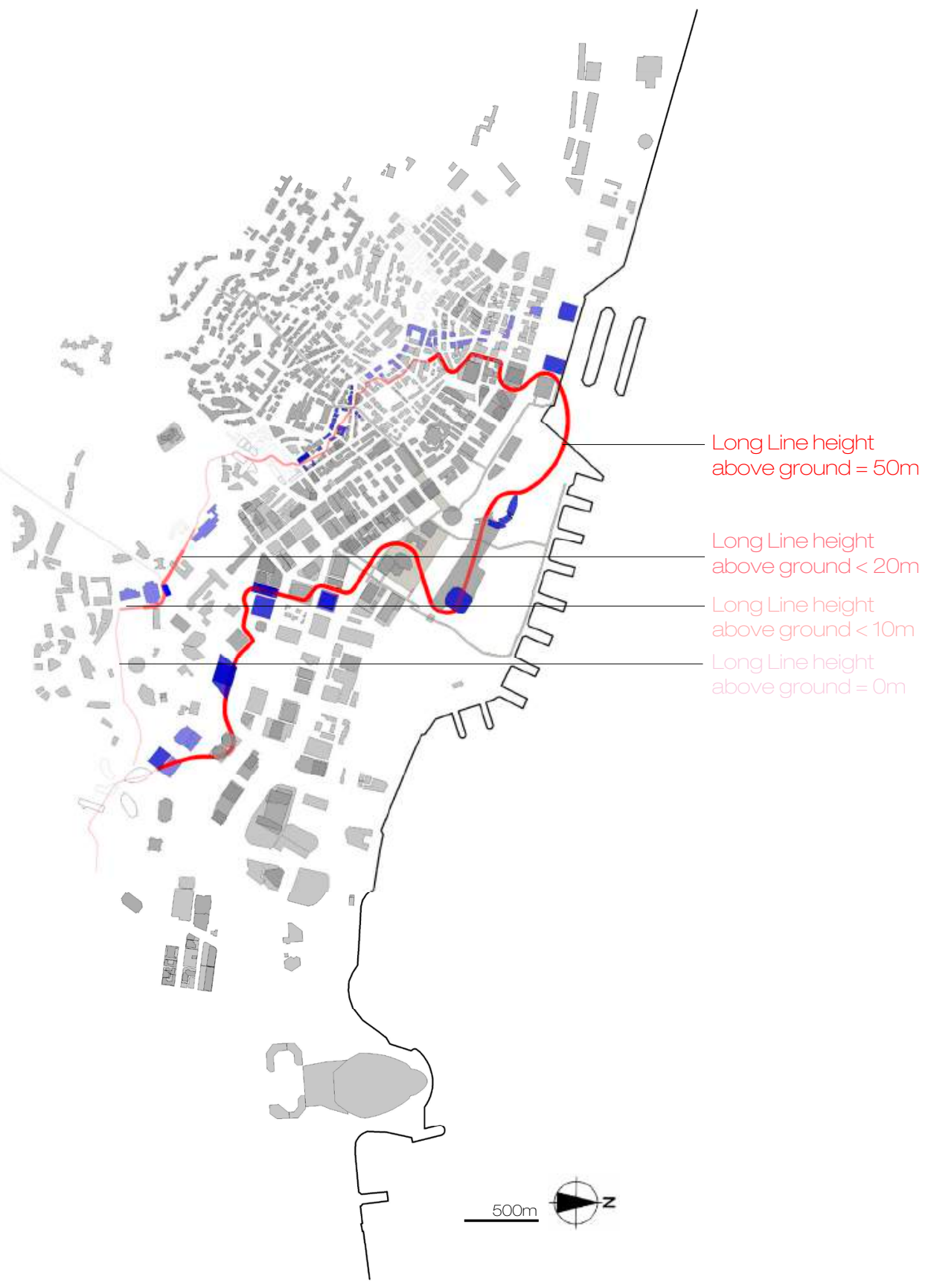


What is measurable/memorable is not the height of the bridge but the extent of void that varies from zero meters on the hill side, to twenty meters over the ladder streets and back lanes of Central, to the full fifty meters right over the seaside. The user moves horizontally on the Long Line, from node to node. However this separation between him/ her and the ground is vertical, therefore it is the city itself that shifts vertically. As a datum at a constant height, the Long Line will enable users to better read and appreciate the city's robust topography. 


\section{Merging Urban Scale with Human Scale: tower and man}

The existing elevated walkways connect towers, largely following the gridded patterns of the streets below. The use of elevated walkways allows hurried workers to avoid red lights, which are akin to «speed bumps» to their trajectories. In No Country for Slow Men, Jason Y. Ng beautifully depicts this aspect of the bustling city: one halts at one's own risk. That said, the network of elevated walkways is discontinuous and ad hoc. It has developed organically and irregularly over time. Walkways are clipped onto, rather than integrated with, the buildings they connect.

By contrast, as proposed, the Long Line infiltrates towers and redefines the way that pedestrians interact with buildings, more precisely, towers. It is important to stress that this project deals with high-rise buildings, varying in height from 80 meters to more than 300 meters, therefore the latter can afford such urban systems because they have that vertical margin, or rather that: they do not have any margin, any limit.

«the tower, vertical occurence, attempts to break free from its horizontal coverings. It pierces through these symbolic layers, breaking free from the existing ground to suggest a higher and better one. It plans an exile.») -Pascal Quintard-Hofstein'

The Long Line is an interpretation of a «higher and better» horizontal plane that Quintard-Hofstein suggests here.

«To live in a tower reminds us of the fact that beyond a certain height, the world's points of reference at grade change: the ground evades, the sky widens and the horizon lowers. Cardinal points get mixed up, or even disappear. The lack of reference erases perceptions, as if, beyond ground there was no dimension.»-Pascal Quintard-Hofstein'

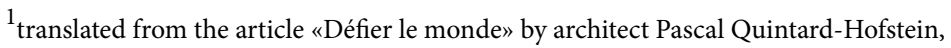
in magazine Le Visiteur number 21
} 

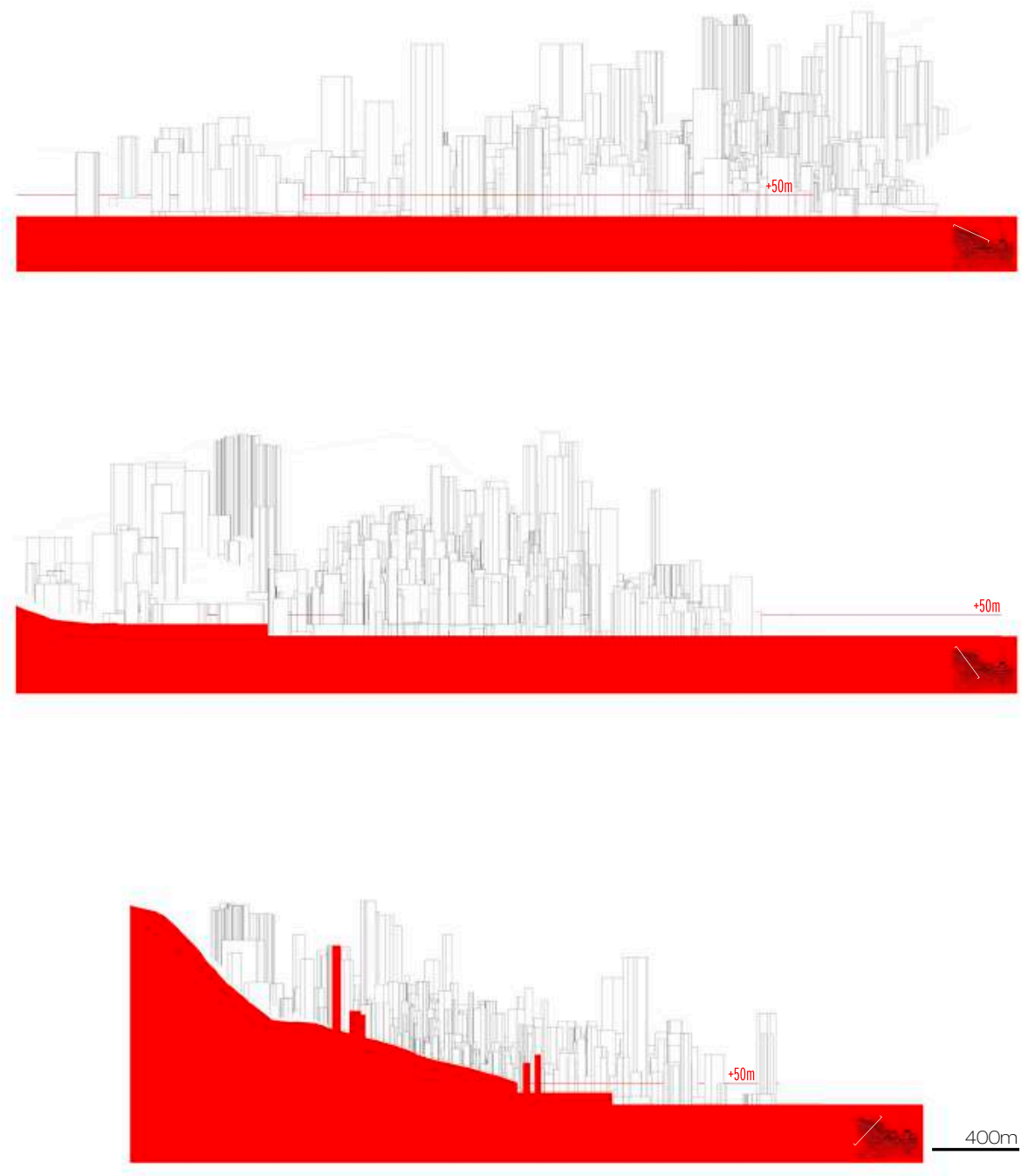
Node5: $L L+R E S$

As described previously, the hill side of the Long Line forces the path to find void in between buildings. Its main function on the south side of Central district is to gather and elevate the crowd from the back lanes which is why the design of the skyway is left to simply merge with the existing aarchitecture. The axonometric drawing is representive of such an instance. This point was chosen knowing the fact that it is also the closest the Long Line can get to the existing elevated walkways all the while creating a smooth transition by prolonging the existing stairs that bring you up to the Central-Mid-Levels escalators. The street at grade is for pedestrians only and is therefore able to receive such infrastructure that would have interfered with a main street. 


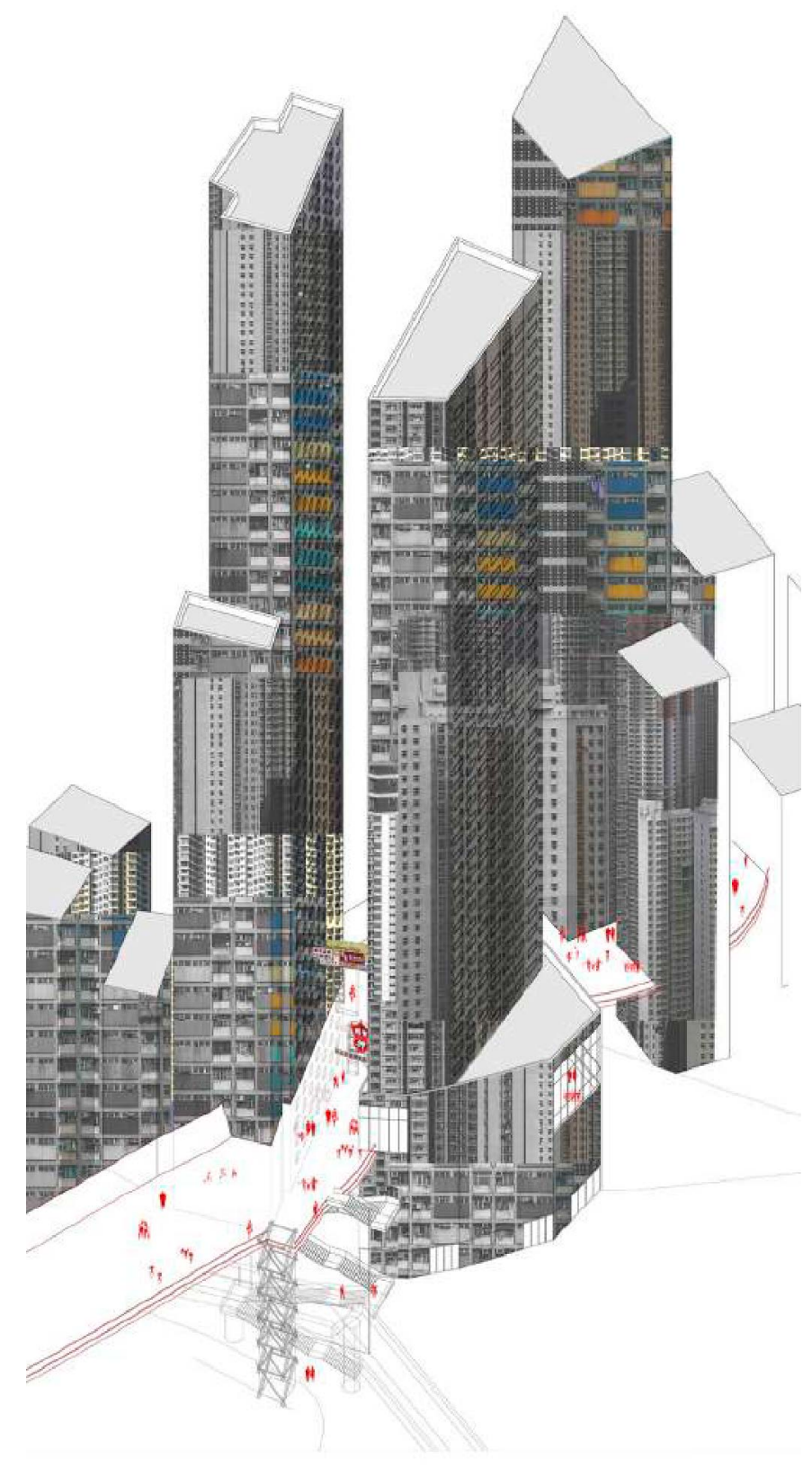




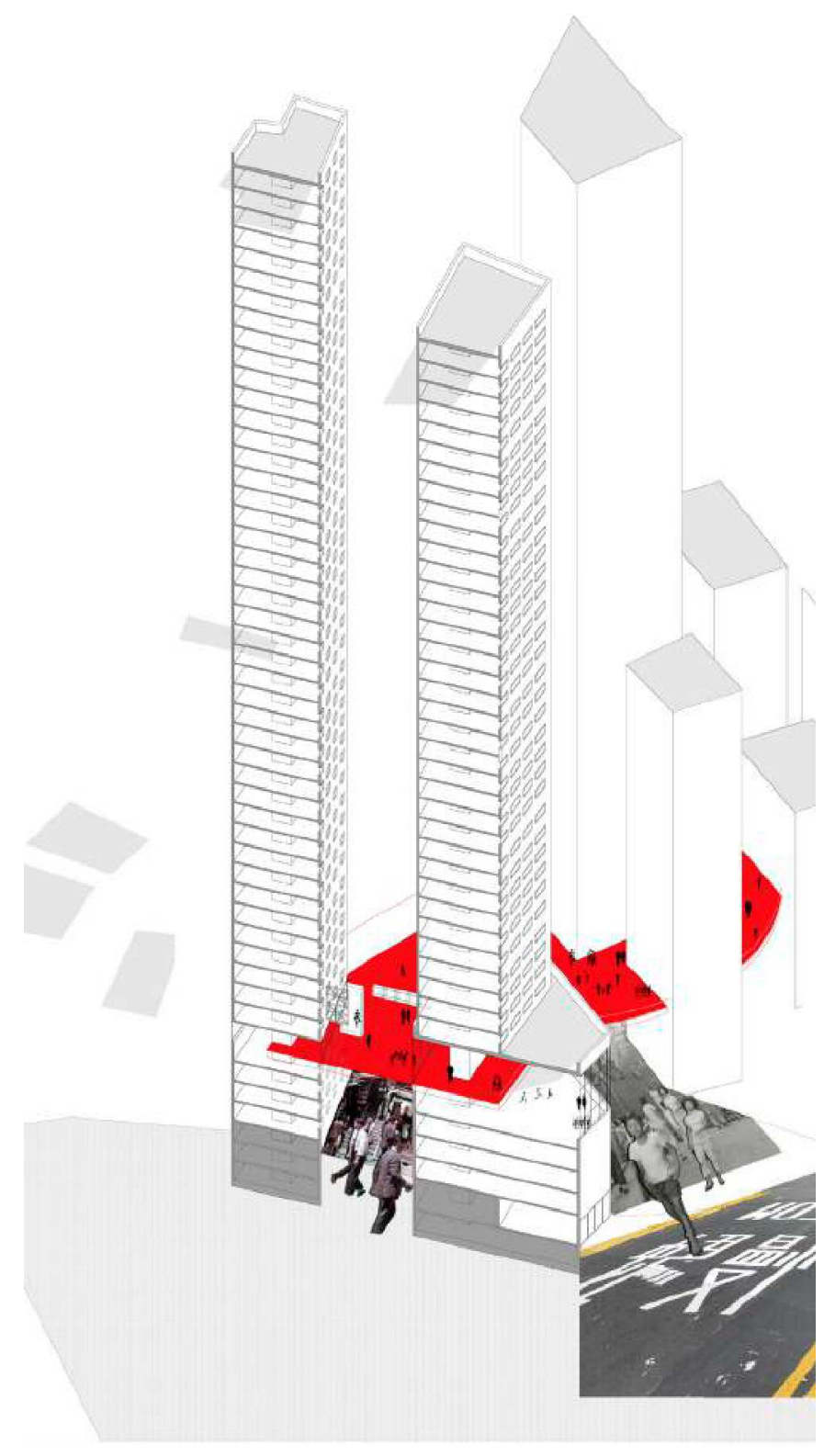




\section{Conclusion}

Hong Kong's urban layout must be analyzed three dimensionally.No grid exists to easily trace the main streets network of the city. The latter's development is partially controlled by the natural topography. However, once exploded into an axonometric view or a simple section, vertically speaking, the city is organized. We have distinguished three existing tiers for ciruclation purposes: the subway network underground, the streets network at grade and the third tier which are the elevated walkays; and one proposal for a fourth tier which is the Long Line.

The urban sprawl has grown towards both the hillside and seaside, there is a limit to the $\mathrm{x}$ and $\mathrm{y}$ directions. The only way is up. Because of its high-rise architecture, the city is now spreading vertically, and the Long Line is just beginning this process at an urban scale. The higher these horizontal infrastructures get the more freedom they obtain to skirt towers. And as these horizontal planes merge with the vertical façade they recreate the architecture internally. The breaks that the bridge and building design together trigger rearrangement at the human scale.

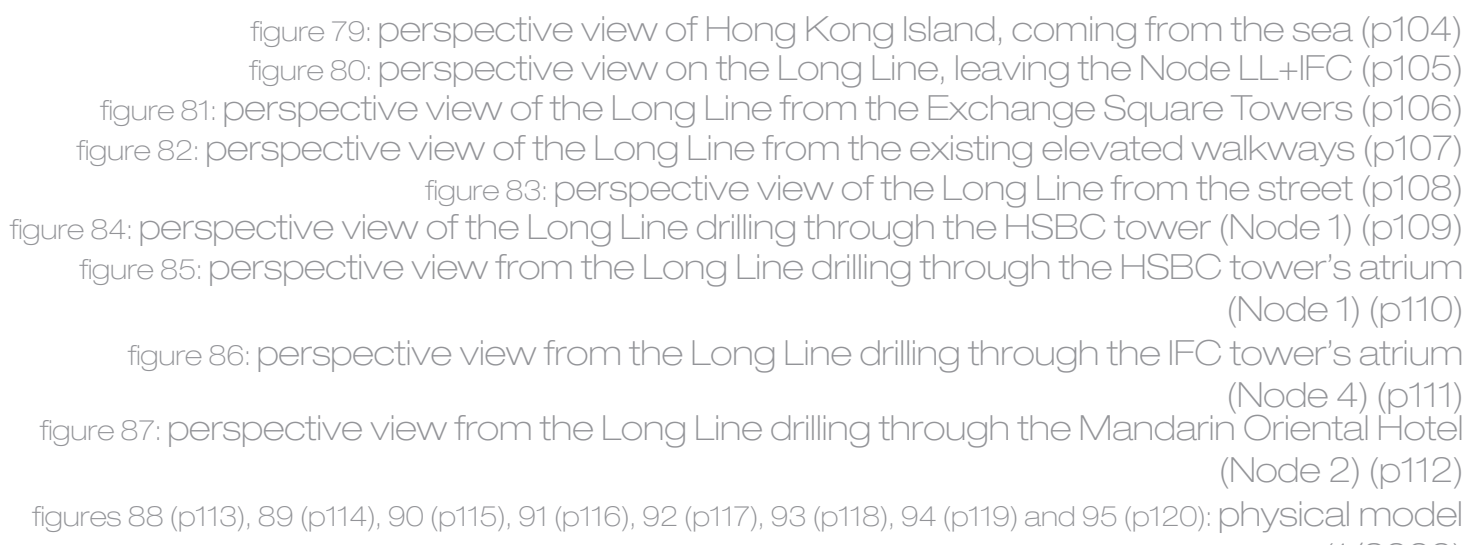




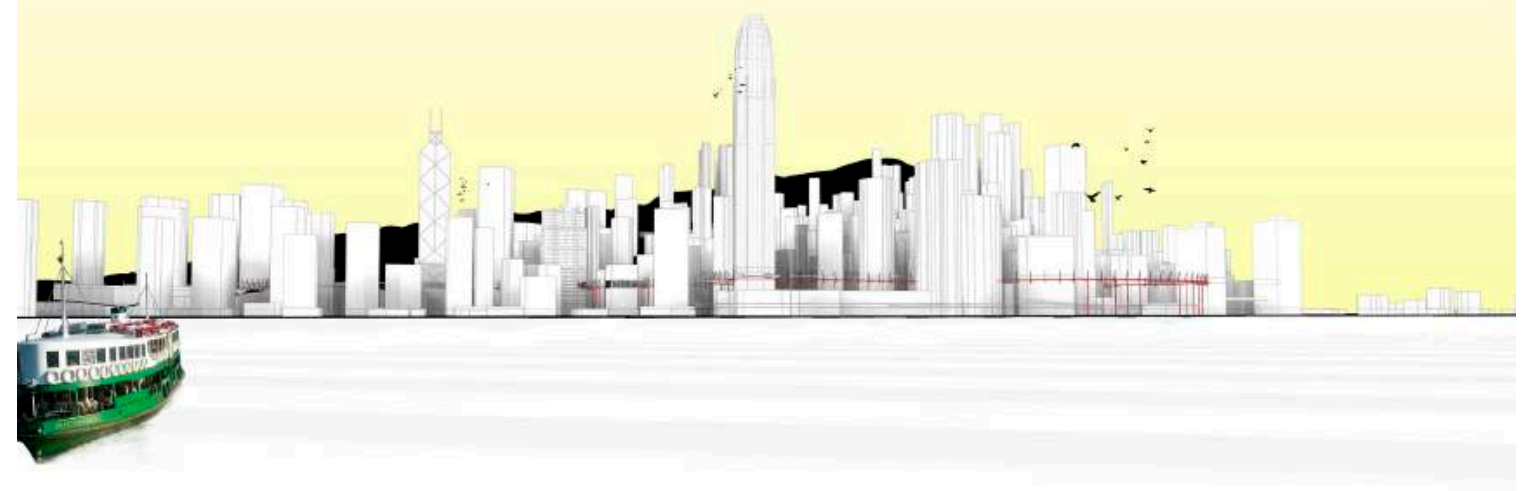




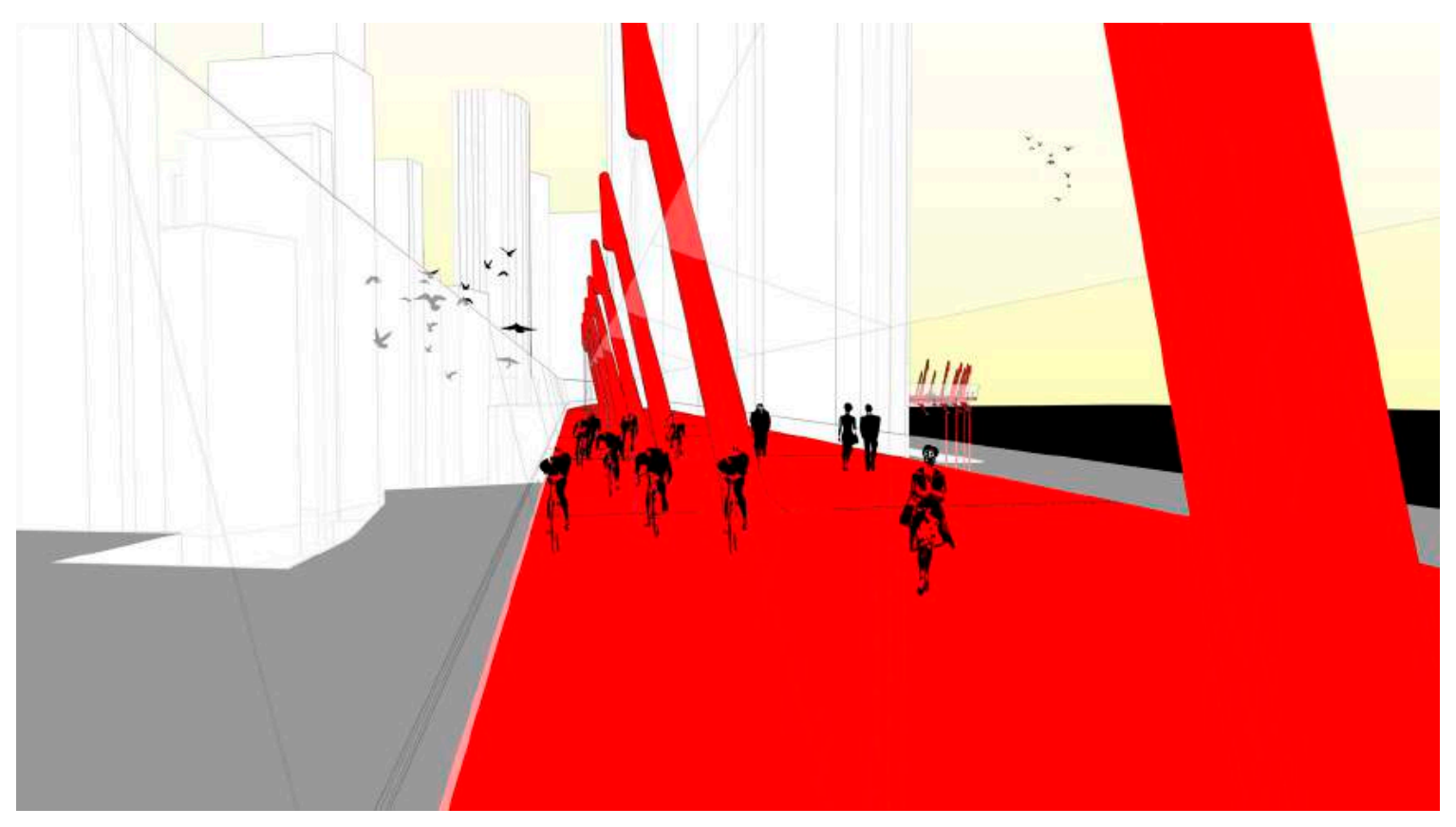




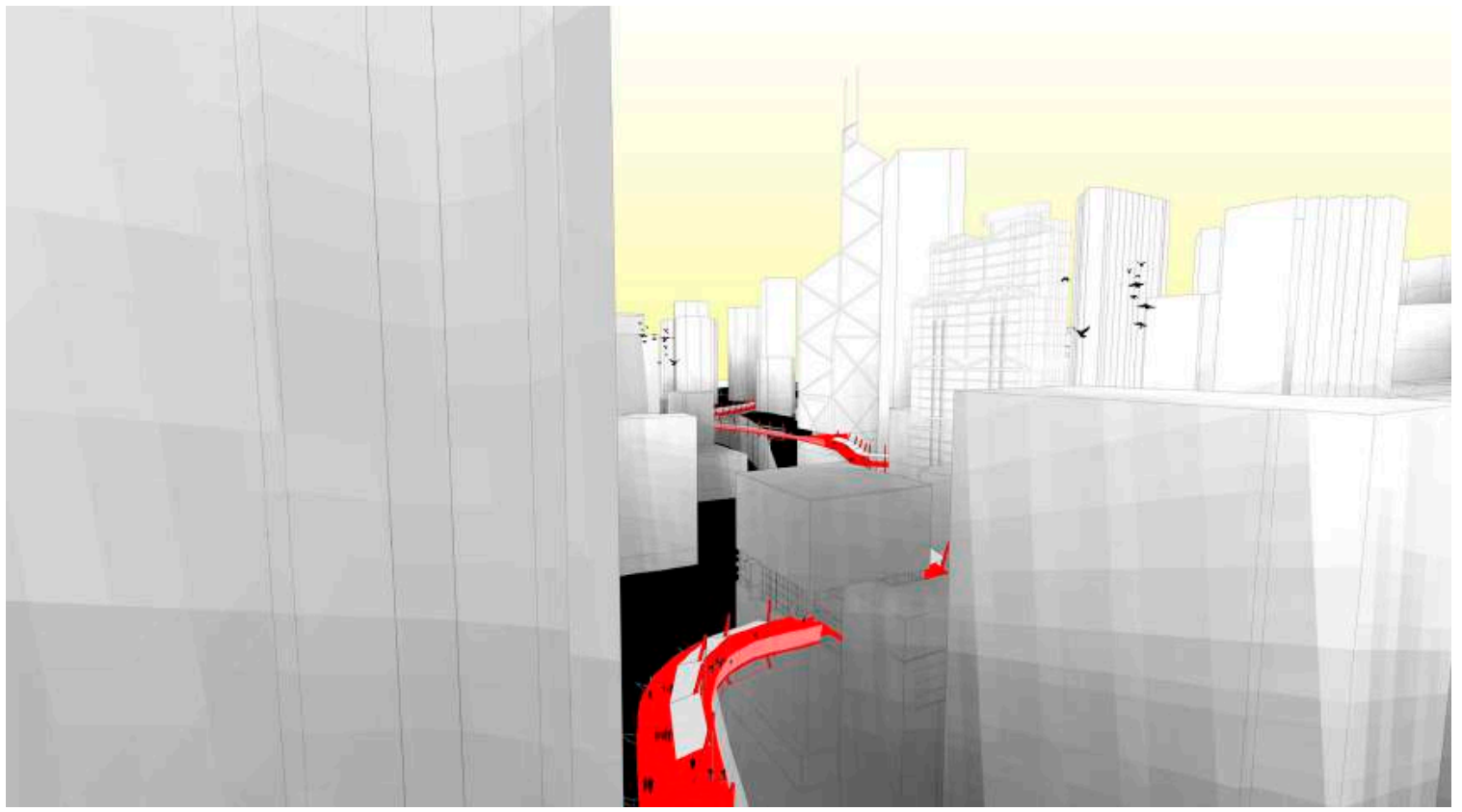




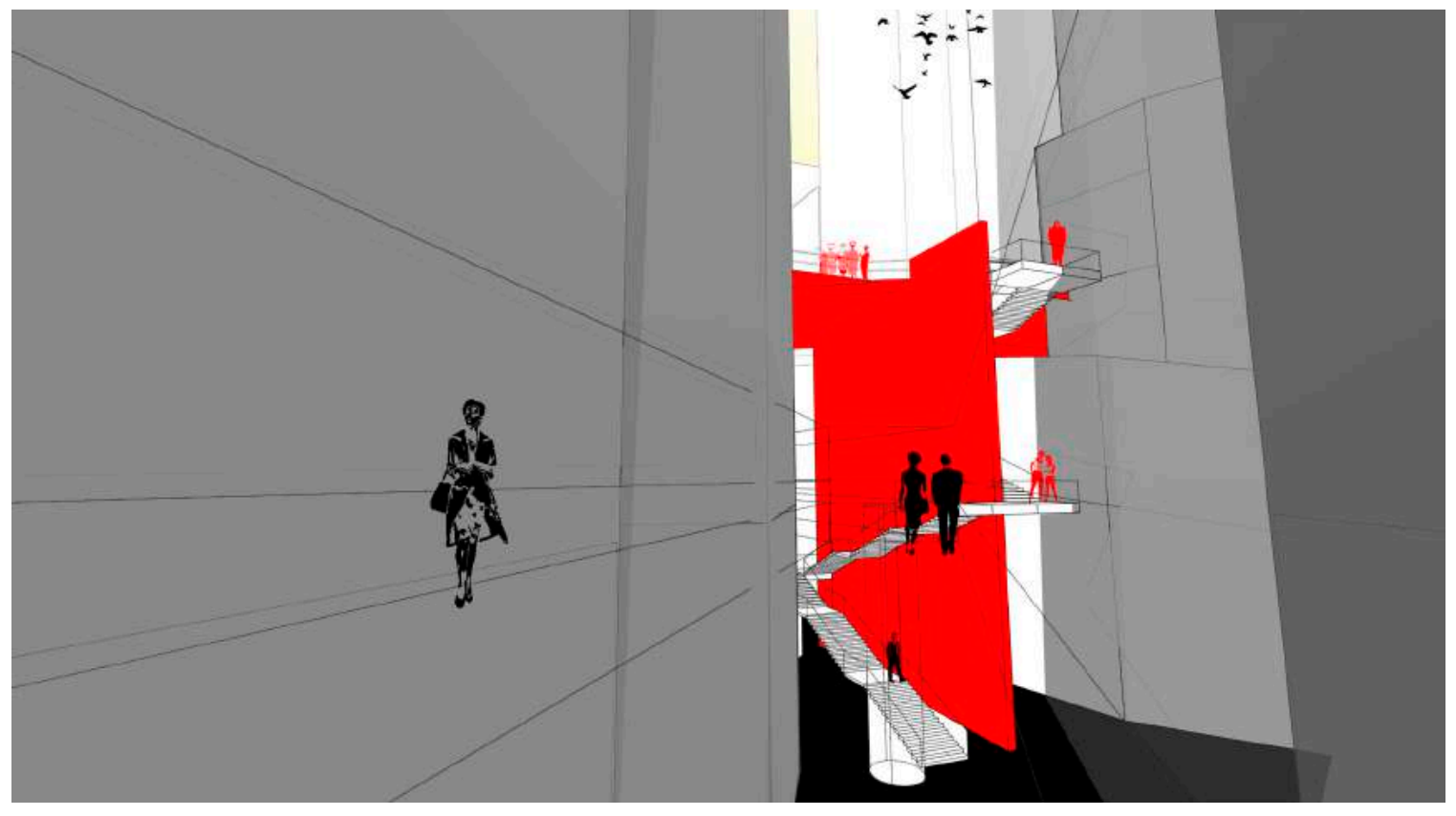




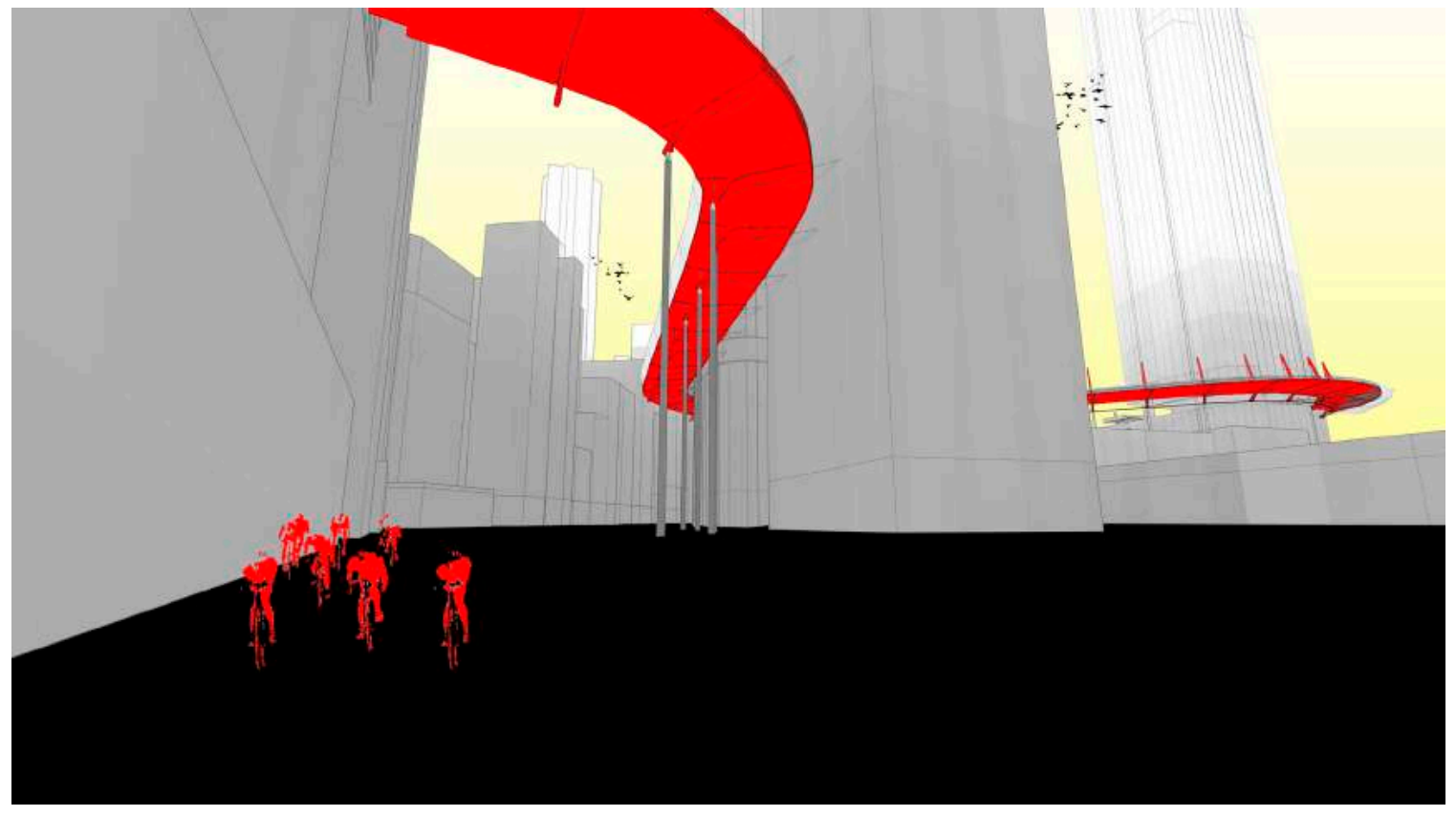




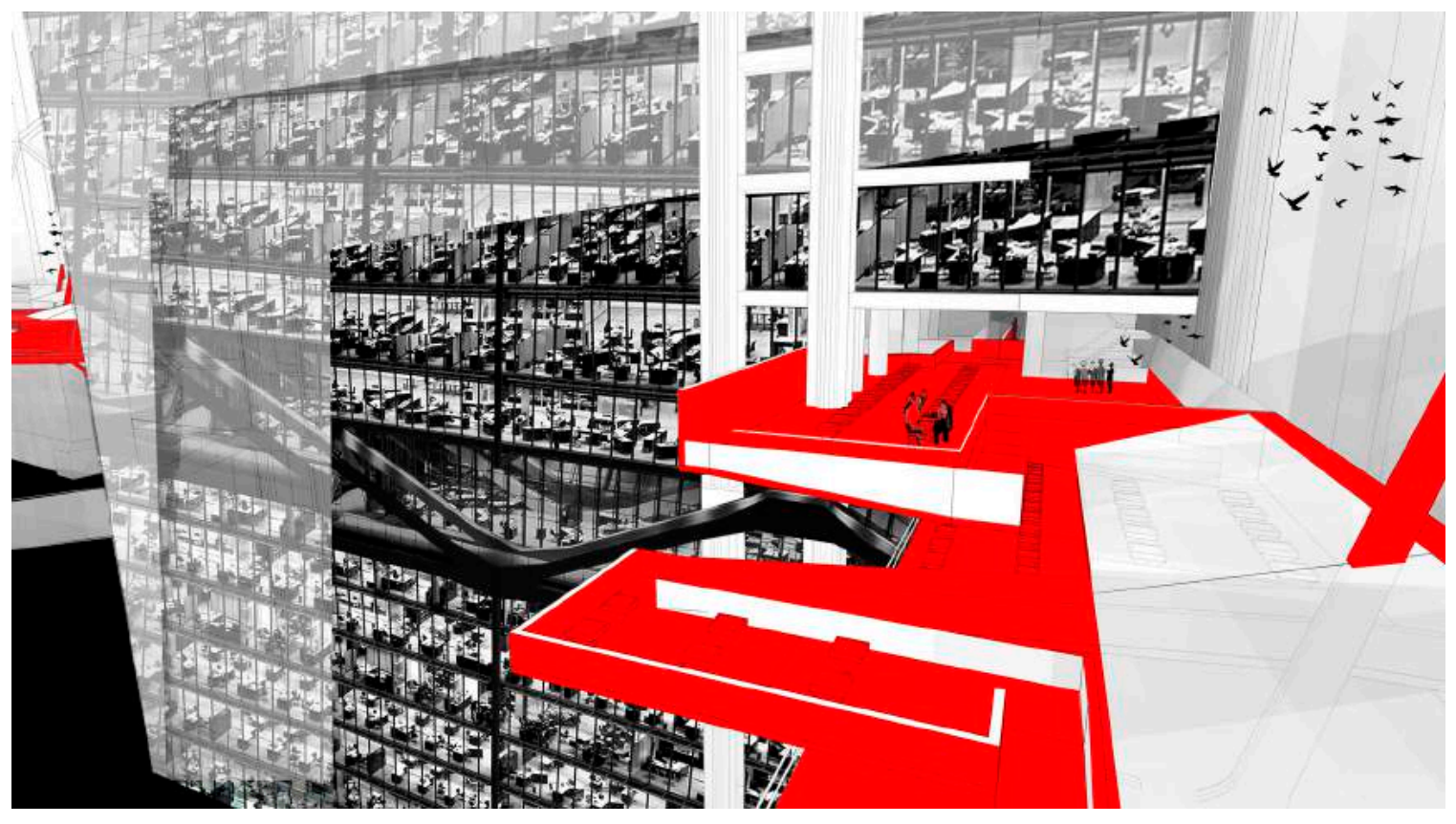




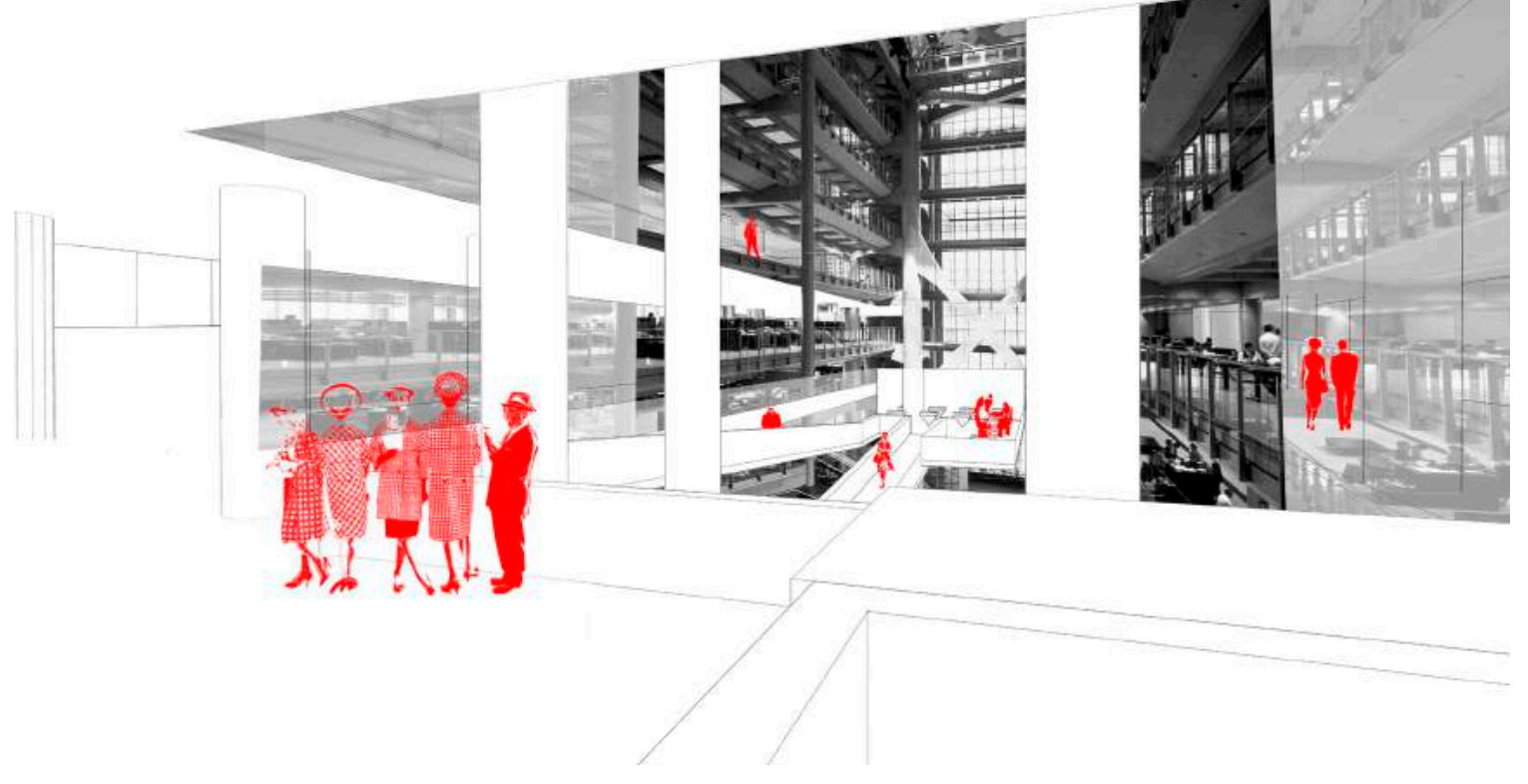




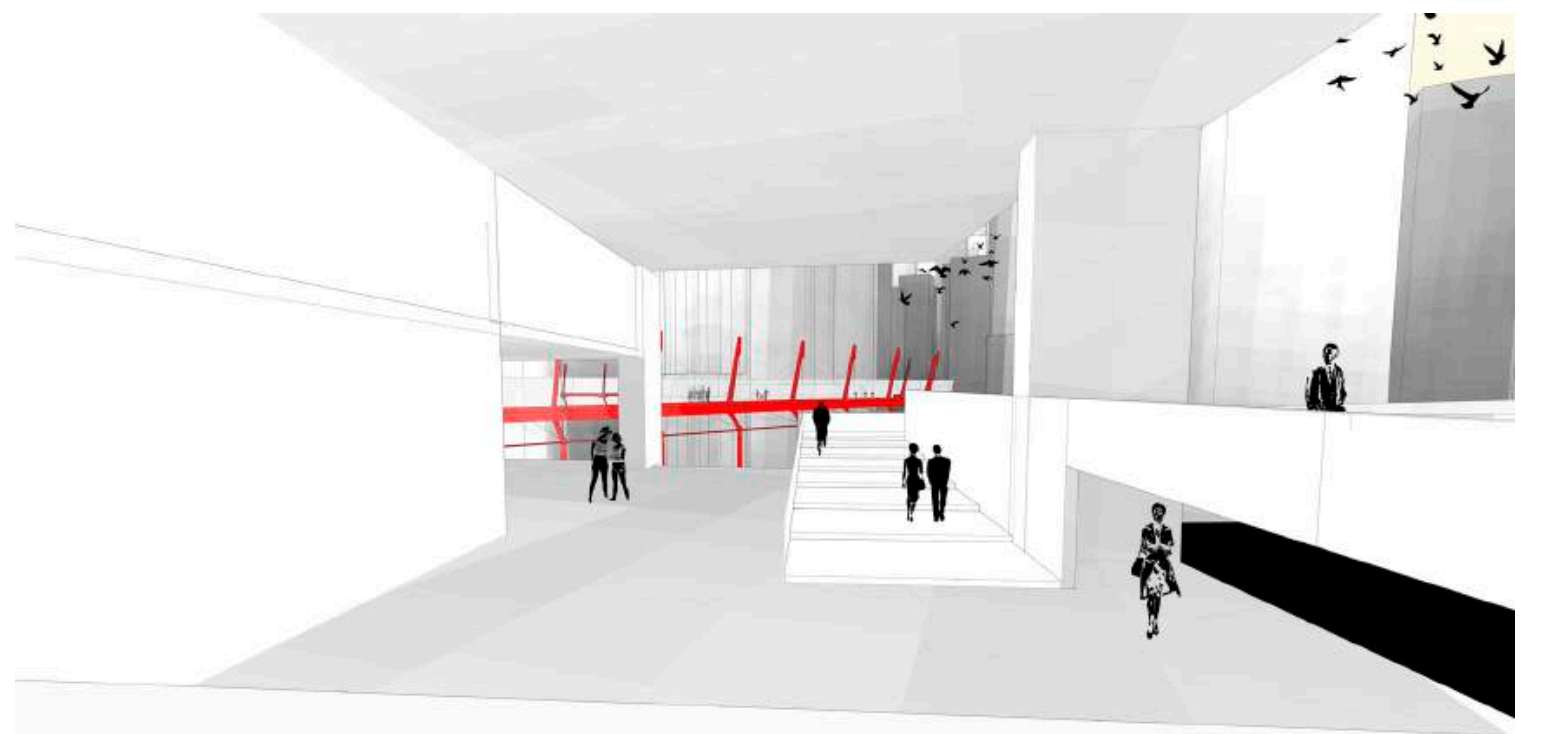




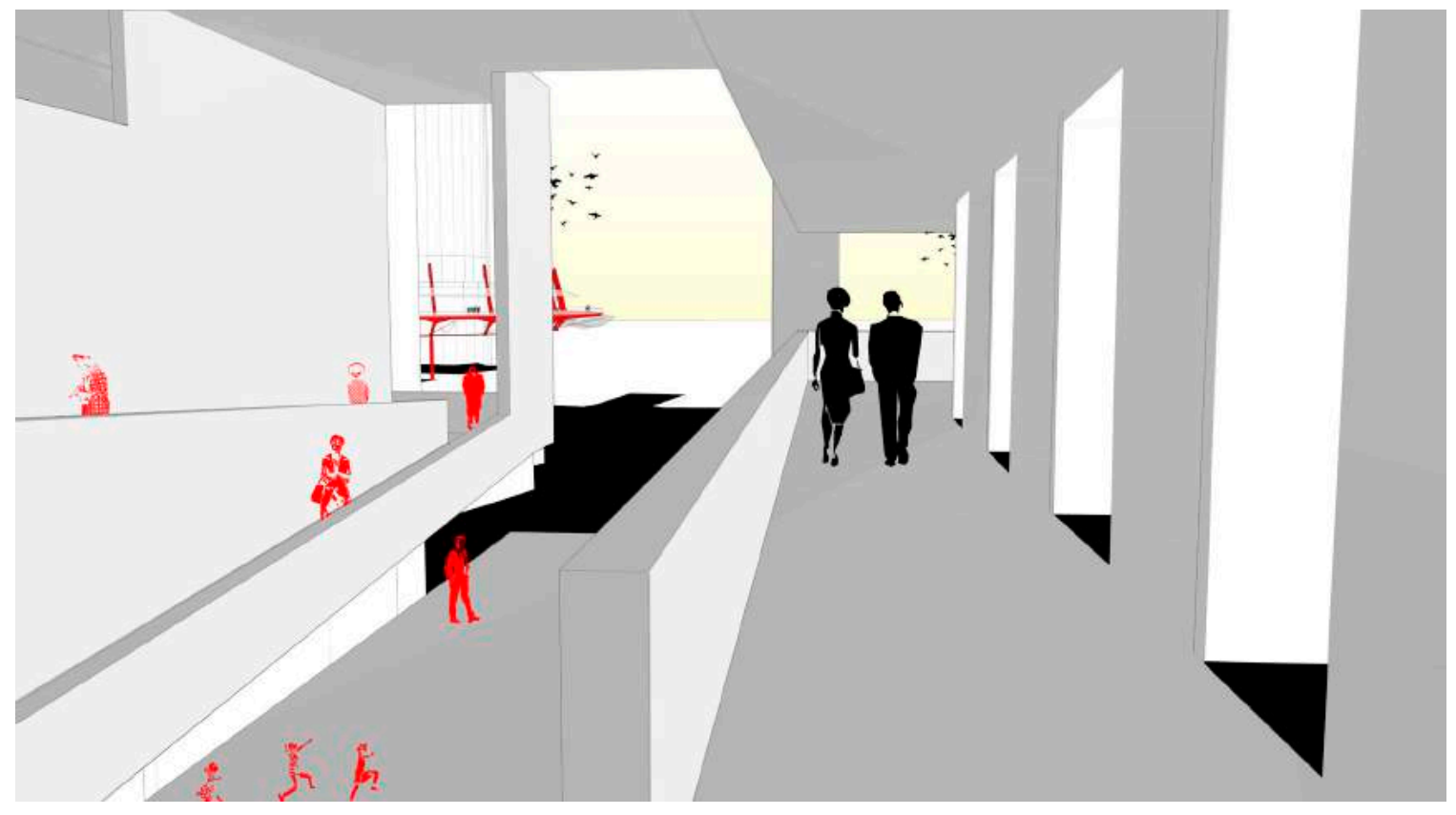




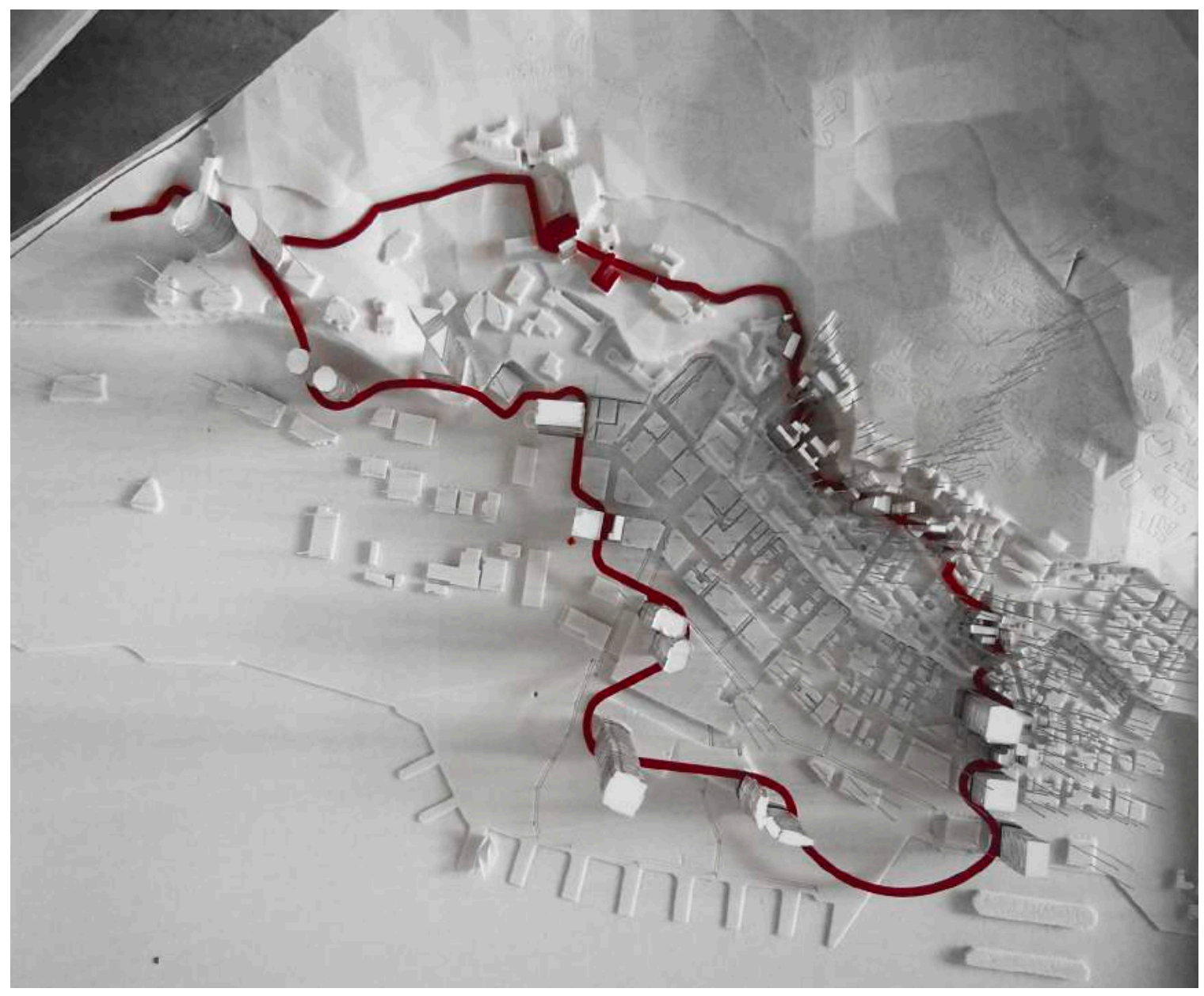




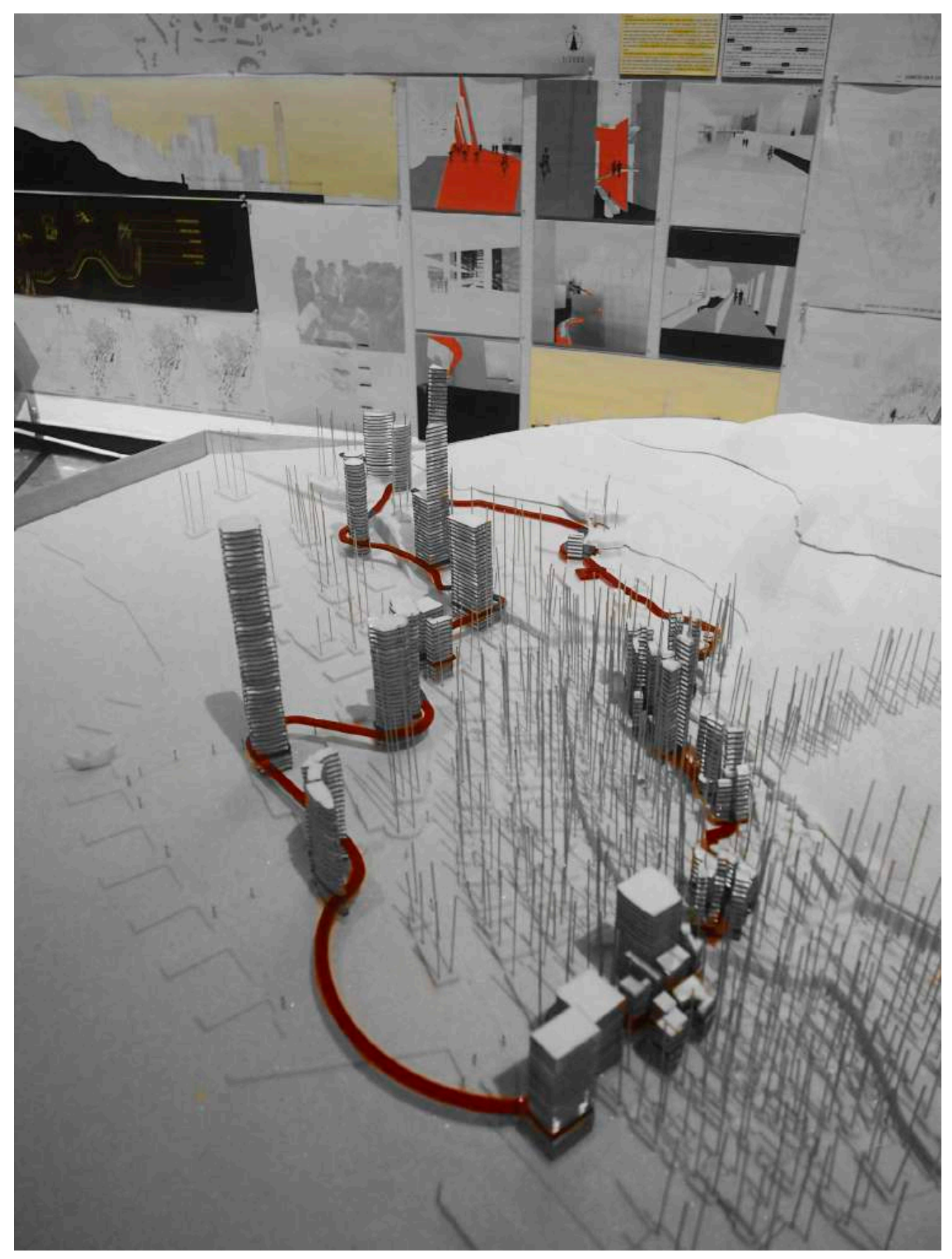




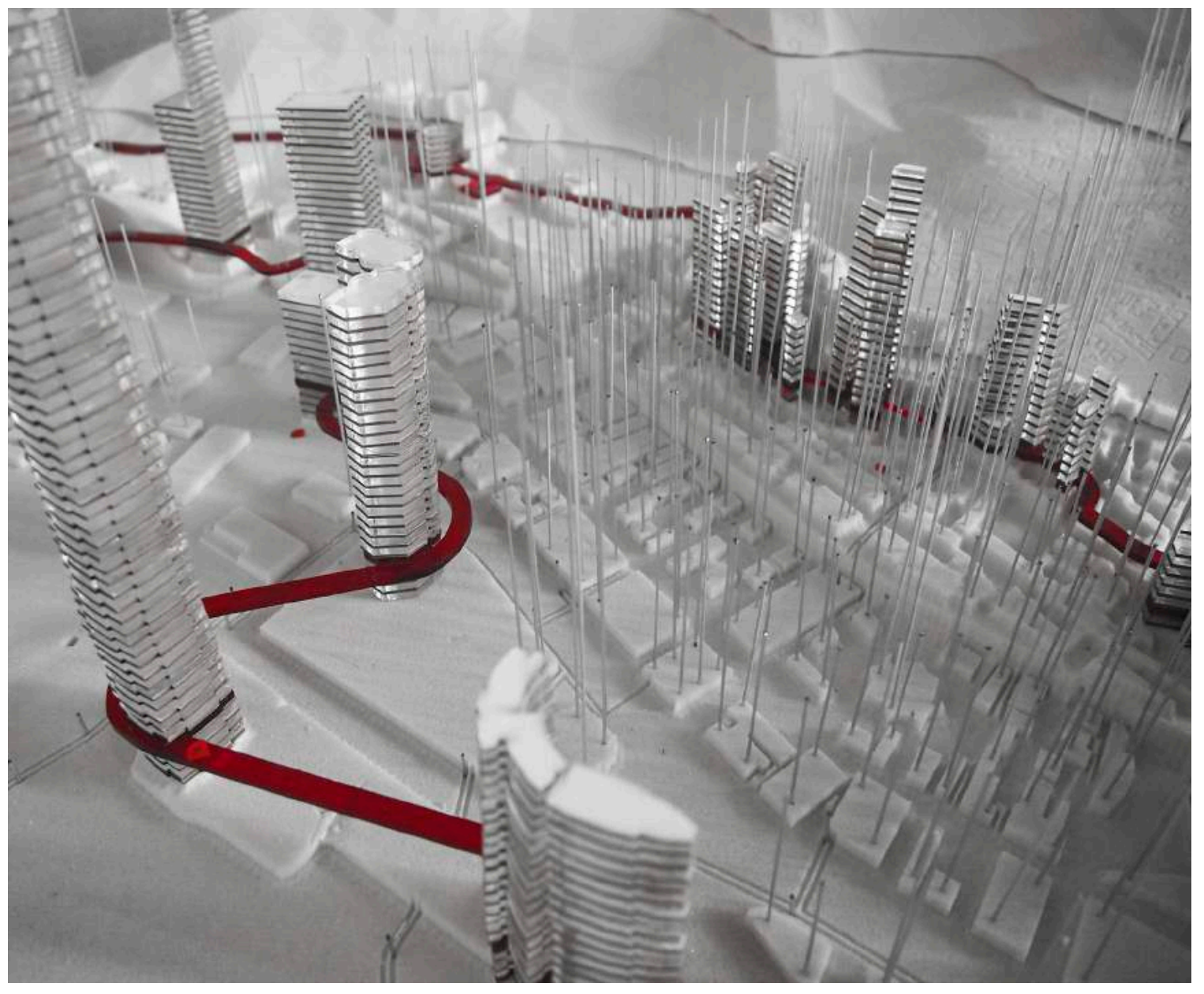




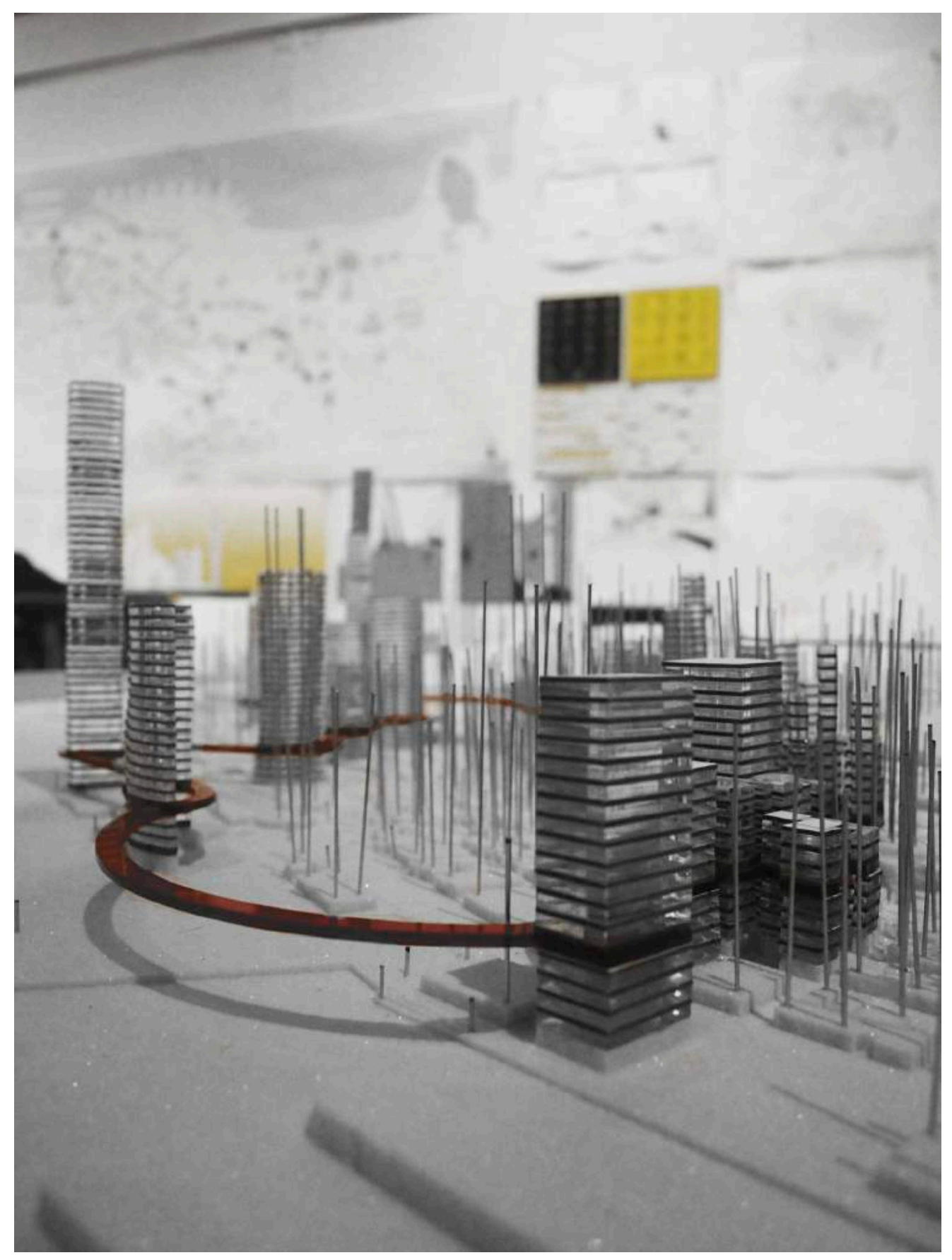




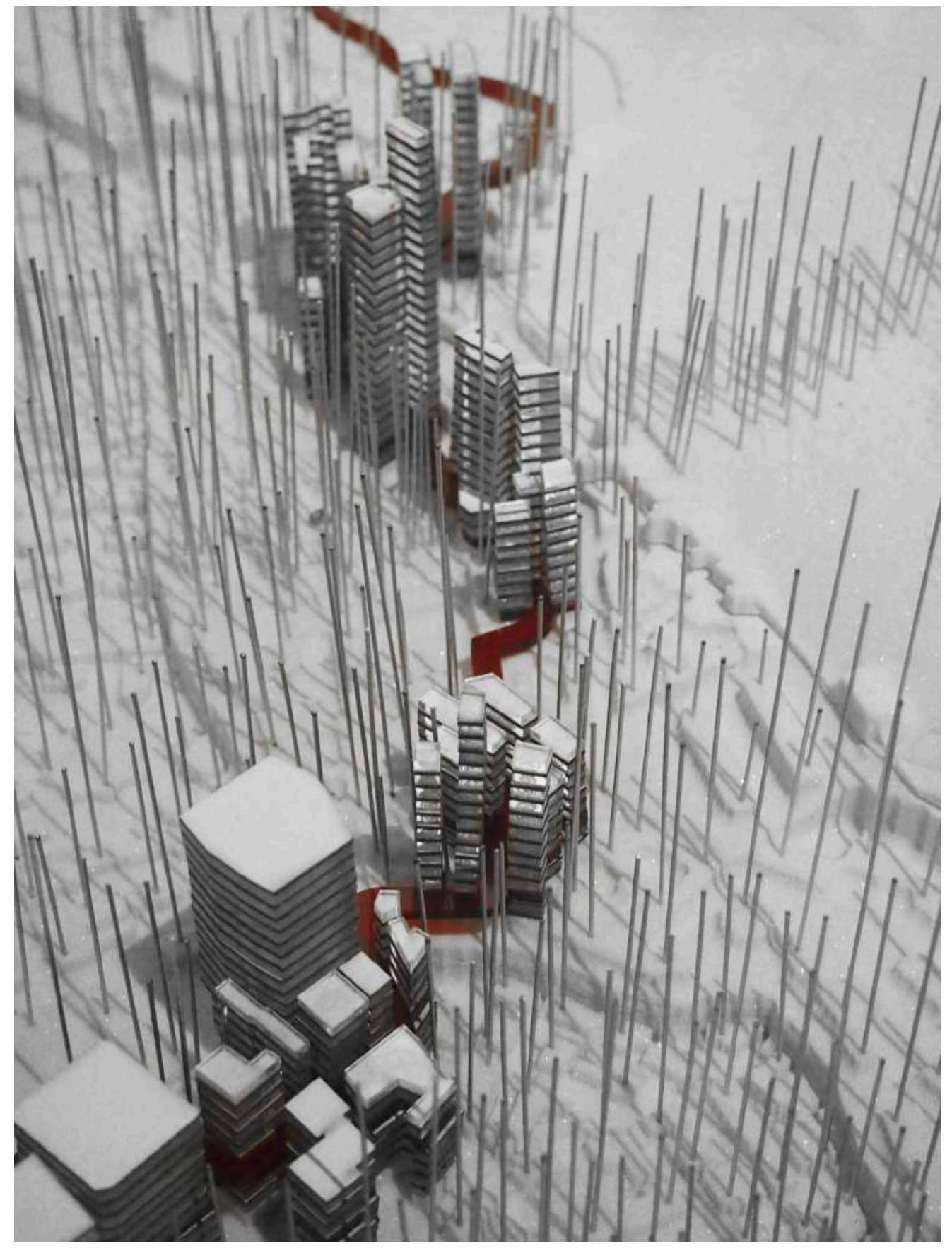




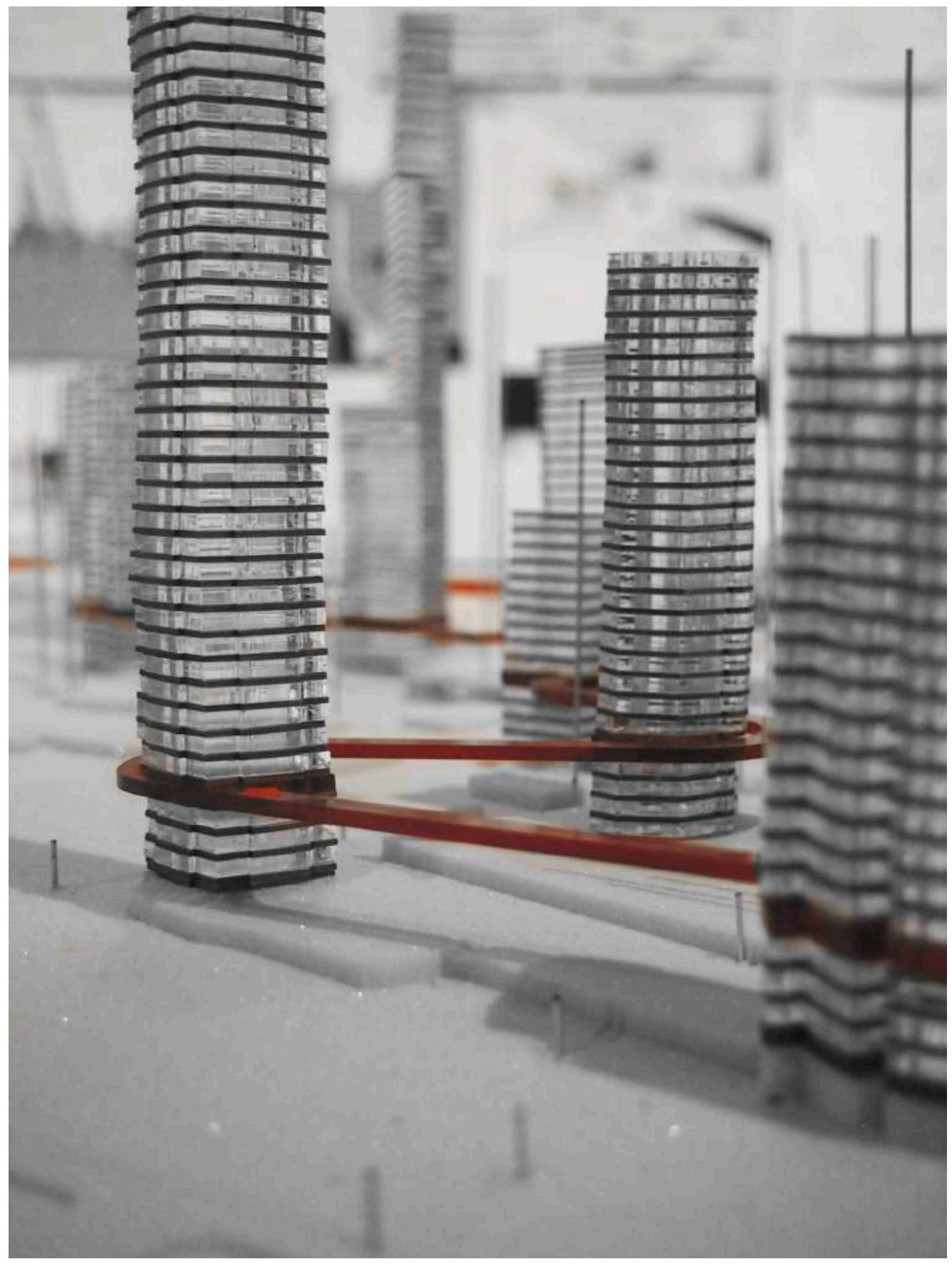




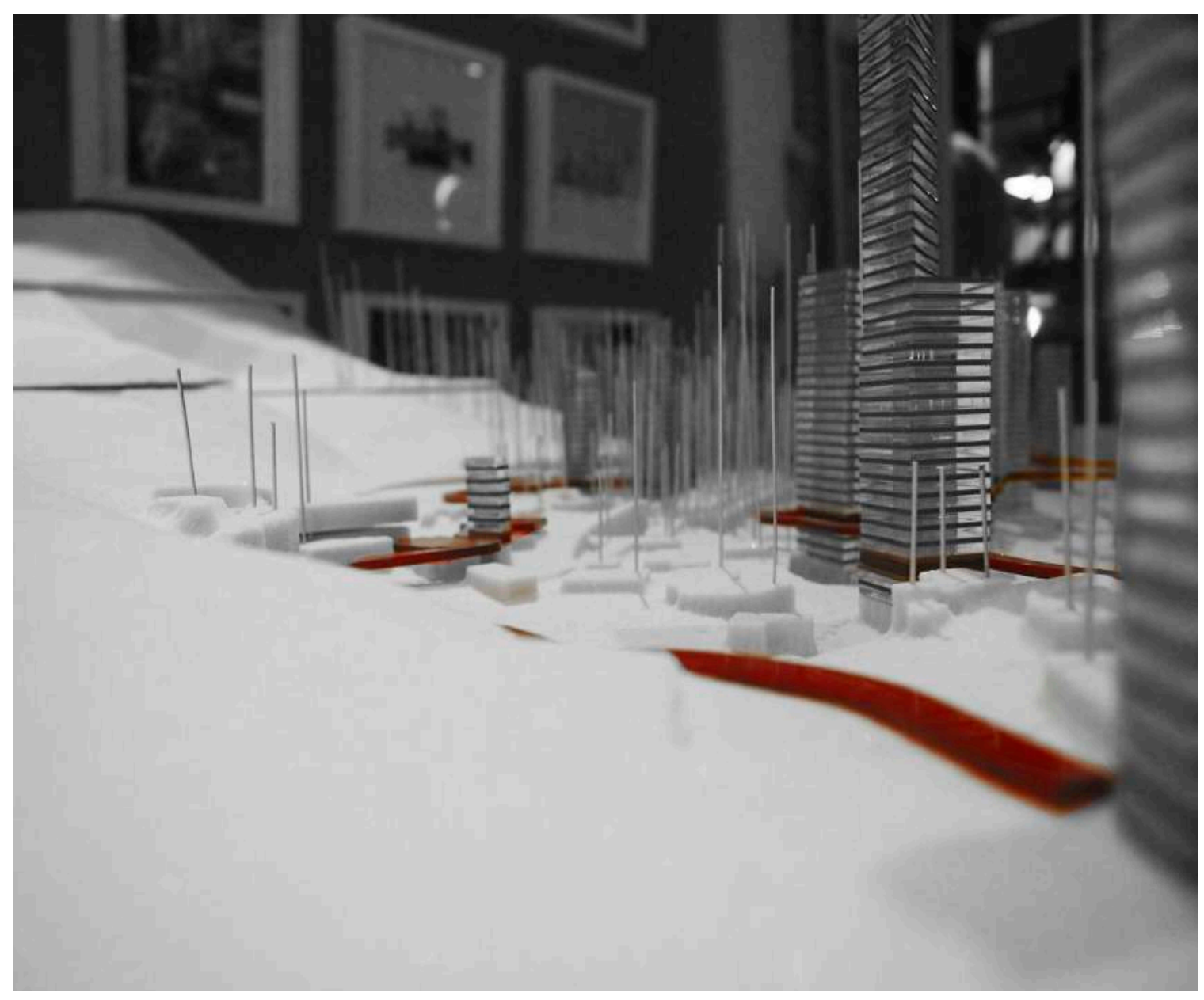




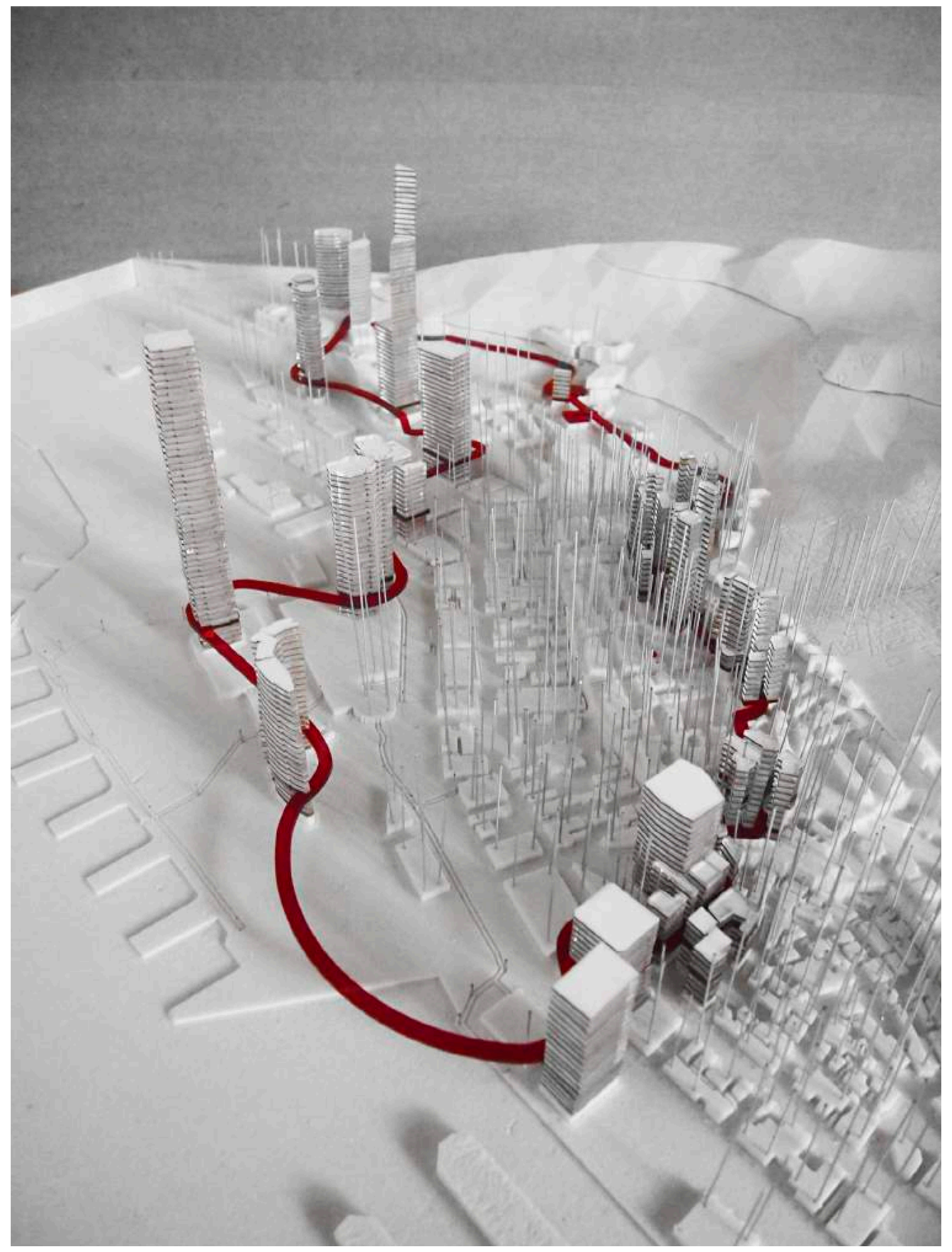




\section{Bibliography}

Le Corbusier. Urbanisme. Cahmps arts, 1925.

Hilberseimer, Ludwig, and Richard Anderson. Metropolisarchitecture and Selected Essays, 1927.

Arendt, Hannah. The Human Condition. Chicago: University of Chicago Press, 1958.

Rykwert, Joseph. The Idea of a Town: The Anthropology of Urban Form in Rome, Italy and the Ancient World. Princeton, N.J.: Princeton UP, 1976.

Gutierrez, Laurent, and Portefaix, Valérie. Mapping Hong Kong. Hong Kong: Map Book, 2000.

Huang, Tsung. Walking between Slums and Skyscrapers: Illusion of Open Space in Hong Kong, Tokyo and Shangai. Hong Kong: Hong Kong University Press, 2004.

Reader, John. Cities. New York: Atlantic Monthly Press, 2004.

Gutierrez, Laurent, Valérie Portefaix, and Laura Ruggeri. HK Lab 2: An Exploration of Hong Kong Interior Spaces. Sheung Wan: Map Book Publishers, 2005.

Smith, Peter Cookson. The Urban Design of Impermanence: Streets, Places and Spaces in Hong Kong (Jie Dao Yu Kong Jian : Bian Zou Zhong De Xianggang Cheng Shi She Ji. Hong Kong): MCCM Creations, 2006.

Maas, Winy. Hong Kong Fantasies: Challenging World-Class City Standards. Rotterdam: NAI Publishers, 2011.

Frampton, Adam, Wong, Clara, and Solomon, Jonathan D. Cities without Ground: A Hong Kong Guidebook. Oro Editions, 2012.

Jacobs, Jane. The Urban Wisdom of Jane Jacobs. London: Routledge, 2012.

Ng, Jason Y. No City for Slow Men: Hong Kong's Quirks and Quandaries Laid Bare. Hong Kong: Blacksmith Books, 2014.

Chian, Lee Kong and Provost, Lily Kong, Ching Chia-ho and Chou Tsu-Lung. Arts, Culture and the Making of Global Cities: Creating New Urban Landscapes in Asia. Edward Elgar Publishing, January 2015.

Borio, Géraldine, Caroline Wüthrich, and Ling Wong. Hong Kong In-between = Xianggang Zhijian. Hong Kong: Parallel Lab, 2015. 


\section{Exhibitions}

Uneven Growth: tactical urbanisms for expanding Megacities at the Museum of Modern Art, New York City (MAP Office, Hong Kong, and Network Architecture Lab, Columbia University, New York), USA, 2014.

Le Corbusier, mesures de l'homme, Centre Pompidou, Paris, France, april 29th - august 3rd, 2015.

1000 Singapores, Cité de l’architecture et du patrimoine, Paris, France, 2015.

\section{Films}

In the Mood for Love. Dir. Kar-Wai Wong. Perf. Maggie Cheung and Tony Leung Chiu-Wai. 2001. Film. 2046. Dir. Kar-Wai Wong. Perf. Zhang ZiYi and Tony Leung Chiu-Wai. 2005. Film. 